NISTIR 8245

\title{
Voices of First Responders - Examining Public Safety Communication Problems and Requested Functionality
} Findings from User-Centered Interviews Phase 1, Volume 2.1

Shaneé Dawkins

Yee-Yin Choong Mary F. Theofanos Kristen K. Greene

Susanne Furman Michelle Steves Sandra Spickard Prettyman 


\section{Voices of First Responders - Examining Public Safety Communication Problems and Requested Functionality Findings from User-Centered Interviews Phase 1, Volume 2.1}

Shaneé Dawkins Yee-Yin Choong Kristen K. Greene Susanne Furman Michelle Steves

Information Access Division Information Technology Laboratory

Mary F. Theofanos Office of Data and Informatics Material Measurement Laboratory

Sandra Spickard Prettyman Culture Catalyst, LLC

This publication is available free of charge from: https://doi.org/10.6028/NIST.IR.8245

May 2019

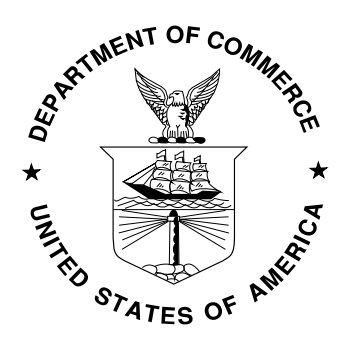

U.S. Department of Commerce Wilbur L. Ross, Jr., Secretary 
Certain commercial entities, equipment, or materials may be identified in this document in order to describe an experimental procedure or concept adequately. Such identification is not intended to imply recommendation or endorsement by the National Institute of Standards and Technology, nor is it intended to imply that the entities, materials, or equipment are necessarily the best available for the purpose.

National Institute of Standards and Technology Interagency or Internal Report 8245

Natl. Inst. Stand. Technol. Interag. Intern. Rep. 8245, 93 pages (May 2019)

This publication is available free of charge from:

https://doi.org/10.6028/NIST.IR.8245 


\section{Voices of First Responders Series}

This report is a part of a series of publications amplifying the voices of first responders (VoFR) in four public safety disciplines: Communication Center \& 9-1-1 Services (COMMS); Emergency Medical Services (EMS); Fire Service (FF); and Law Enforcement (LE). The VoFR series reports on the experiences of first responders with communication technology, including their needs for, and problems with, communication technology.

Publications in this series are primarily intended for designers, developers, vendors, and researchers of public safety communication technology, as well as for public safety administrators and decision-makers.

Published as a part of the VoFR series include NIST reports, conference papers, presentations, posters, articles and blog posts, a book chapter, and a web tool for disseminating the research results and data collected from the interviews with and survey of first responders. The reports from which all published materials are derived are listed below and can be accessed from the PSCR User Interface/ User Experience Publications webpage at: https://www.nist.gov/ctl/pscr/user-interface-user-experience-publications. The PSCR Usability Results Tool, providing access to results of the large-scale survey and in-depth interviews with first responders across the U.S. about their communication technology use, can be accessed via https://publicsafety.nist.gov/. The datasets from this research project are available via https://doi.org/10.18434/mds2-2820.

\section{Voices of First Responders}

* How to Facilitate Adoption and Usage of Communication Technology: An Integrated Analysis of Qualitative and Quantitative Findings (NISTIR 8443) https://doi.org/10.6028/NIST.IR.8443

* COMMS (NIST SP 1286pt1)

* EMS (NIST SP 1286pt2) https://doi.org/10.6028/NIST.SP.1286pt2

* FF (NIST SP 1286pt3) https://doi.org/10.6028/NIST.SP.1286pt3

* LE (NIST SP 1286pt4) https://doi.org/10.6028/NIST.SP.1286pt4

Phase 1: Findings from User-Centered Interviews

* Volume 1 - Identifying Public Safety Communication Problems (NISTIR 8216) https://doi.org/10.6028/NIST.IR.8216

* Volume 2 - Examining Public Safety Communication Problems and Requested Functionality (NISTIR 8245) https://doi.org/10.6028/NIST.IR.8245

* Volume 3 - Examining Public Safety Communication from the Rural Perspective (NISTIR 8277) https://doi.org/10.6028/NIST.IR.8277

* Volume 4 - Examining Public Safety Communication from the Perspective of 9-1-1 Call Takers and Dispatchers (NISTIR 8295) https://doi.org/10.6028/NIST.IR.8295

* Volume 5 - Applying Human Factors and Ergonomics Knowledge to Improve the Usability of Public Safety Communications Technology (NISTIR 8340) https://doi.org/10.6028/NIST.IR.8340

Phase 2: Nationwide Survey

* Volume 1 - Methodology: Development, Dissemination, and Demographics (NISTIR 8288) https://doi.org/10.6028/NIST.IR.8288

* Volume 2 - Mobile Devices, Applications, and Futuristic Technology (NISTIR 8314) https://doi.org/10.6028/NIST.IR.8314

* Volume 3 - Day-to-Day Technology (NISTIR 8400) https://doi.org/10.6028/NIST.IR.8400

* Volume 4 - Statistical Analysis Results (NISTIR 8444) https://doi.org/10.6028/NIST.IR.8444 


\section{Abstract}

The public safety community has a unique opportunity to improve communication technology for incident response with the creation of the national public safety broadband network (NPSBN). Understanding the problems currently being experienced by first responders with communication technology as well as first responders' communication technology requests provides the basis for addressing and developing solutions to improve public safety communication. The National Institute of Standards and Technology Public Safety Communications Research usability team has conducted in-depth interviews with approximately 200 first responders representing 13 states in eight Federal Emergency Management Agency (FEMA) regions. The population sample includes urban, suburban, and rural locations, and various levels in the chain of command within the fire, law enforcement, emergency medical services, and communications center disciplines.

This Volume 2 report is the second in a series of reports documenting the findings. A qualitative analysis of the transcribed interview data revealed thousands of problems currently being experienced by first responders and new functionality requests. Further analysis, with respect to current problems identified 25 distinct categories, with 1729 quotes categorized across the four domains. The new functionality request data analysis resulted in 1143 categorized quotes belonging to 18 categories. From the problems and requested functionality data, three major themes across the public safety landscape were identified in addition to discipline-specific topics that need to be addressed as future communication technology for first responders develops.

\section{Keywords}

First responders; Public safety communications research; Qualitative research; Usability; User-centered design; User needs and requirements.

\section{Audience}

This report is primarily intended for developers and researchers of public safety communication technology.

\section{Disclaimer}

Any mention of commercial products or reference to commercial organizations is for information only; it does not imply recommendation or endorsement by the National Institute of Standards and Technology, nor does it imply that the products mentioned are necessarily the best available for the purpose. 


\section{Executive summary}

With the emergence of the national public safety broadband network (NPSBN) and the transition from land mobile radios (LMRs), first responders have the opportunity to benefit from widespread, data-based communication technology. The usability team of the National Institute of Standards and Technology's (NIST) Public Safety Communications Research (PSCR) program focuses on identifying and mitigating the issues faced by users with emerging public safety communication technology. This report, the second in a series, provides an analysis of the currently experienced communication technology problems and the new functionality requested by first responders as input to researchers and developers of communication technology.

\section{Methods}

The PSCR usability program has implemented a multiple-methods research approach. The effort began with a series of methodologically rigorous in-depth interviews conducted across the United States. Approximately 200 first responders were interviewed, representing 13 states in eight Federal Emergency Management Agency (FEMA) regions including urban, suburban, and rural locations; and various levels in the chain of command within the fire, law enforcement, emergency medical services, and communications center disciplines. The initial qualitative data analysis of these interviews was documented in Phase 1, Volume 1, "Voices of First Responders - Identifying Public Safety Communication Problems: Findings from User-Centered Interviews." [1].

The Volume 1 report provides a detailed description of the research methodology and the interview protocol [1]. However, the results focused on how first responders' work influences their communication and technology requirements with only a brief overview of problems currently experienced by first responders and new functionality requests. In this volume, further qualitative analysis takes a deeper dive into the thousands of currently experienced problems and new functionality requests identified in the quotes of first responders from the in-depth interviews.

Results

Across the four public safety disciplines of fire, law enforcement, emergency medical services, and communications centers, the deeper analysis of the currently experienced problems data yielded 25 distinct categories, with 1729 quotes categorized. Additionally, the data analysis of the new functionality requested resulted in 1143 categorized quotes belonging to 18 categories. Summary cross disciplinary tables are provided that identify each of the categories. The high-level categories and their subcategories, with approximately 300 exemplar quotes from first responders related to each subcategory, are discussed. Graphics and quotes for each specific discipline are also provided.

Overwhelmingly, the requests for new functionality by first responders are primarily related to fixing or improving the problems they are experiencing with their current technology than any other need expressed. Not surprisingly, overlap exists in the majority of problems and requests expressed across disciplines. The top categories across disciplines for both current problems and requests are for:

- Reliability,

- Usability, and 
- Interoperability.

Thus, updates to the technology they currently use is at the forefront of how research and development can have a direct impact on the work of first responders. Beyond these essentials of increasing the effectiveness of first responders' tasks, certain technological advancements are needed. The greatest need for cutting edge technology, across disciplines, is for devices that provide information to the first responders in real-time. First responders want timely, accurate information during incident response. The real-time technology these responders need ranges from GPS traffic navigation to distance estimation to language translation. In addition, nearly $50 \%$ of real-time technology needs in our interview data is related to live video and images of the scene.

While there were various cross-cutting themes in the data, the unique environments and tasks within each discipline revealed distinct communication technology problems and requested functionality. Firefighters have major issues with audio clarity on the fire ground. They would also benefit from technology more seamlessly integrated into their gear. Those in emergency medical services, specifically, need a method of reliably transmitting patient records to hospitals. Uniquely, body camera improvements would be most useful to first responders in law enforcement, as well as usable security, and technology integrated into their vehicles. Exclusively for personnel in communications centers, their greatest concerns are the ability to accurately track the location of 911 callers, preparations for continuity of operations, and preparing for text-to-911 and images and videos.

\section{Contributions}

This report is primarily intended to be a resource for developers and researchers in the public safety communication technology domain. It provides PSCR-relevant information and significant details about the views of first responders' problems and new functionality for communication technology. Tables and graphics are provided for easy comprehension of the large dataset. Understanding the issues with current systems and first responders' communication technology requests provides the basis for addressing and developing solutions towards improving public safety incident response. 
Table of Contents

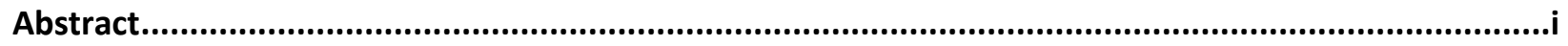

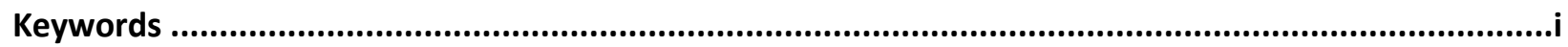

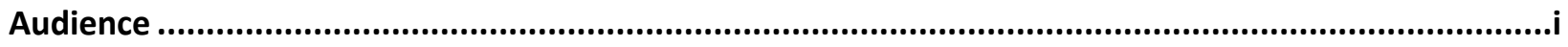

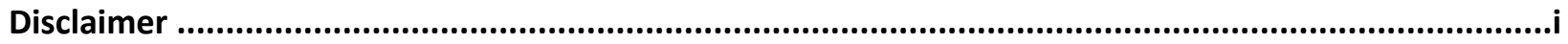

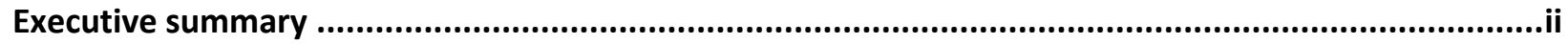

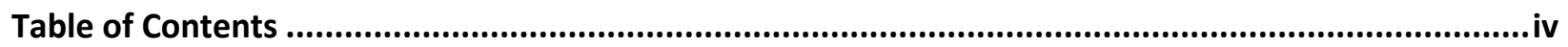

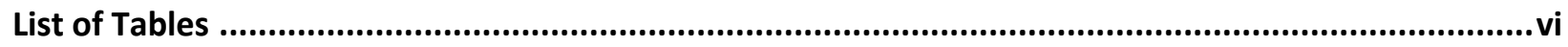

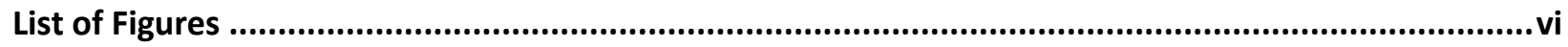

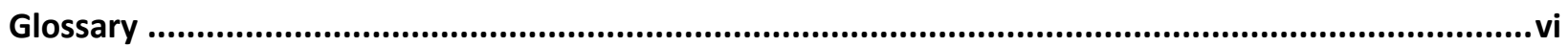

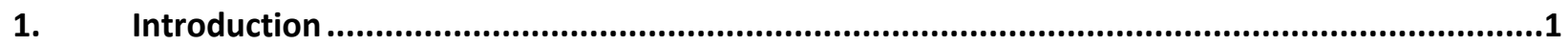

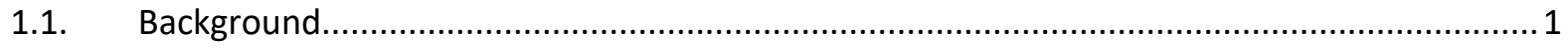

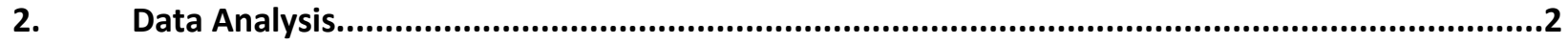

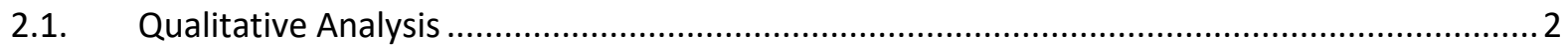

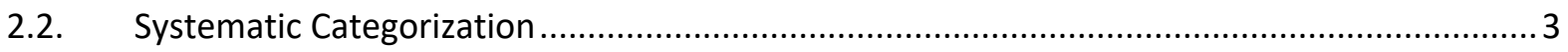

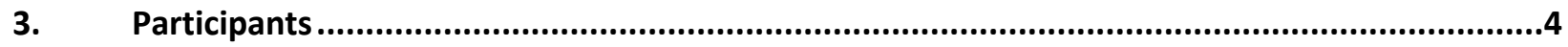

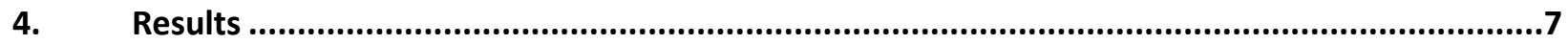

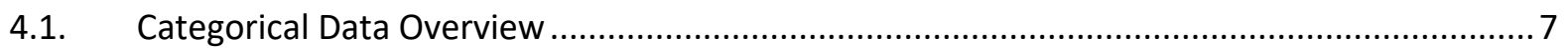

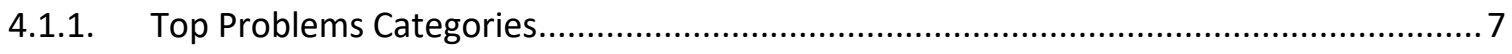

4.1.2. Top Requested Functionality Categories ...................................................................... 8

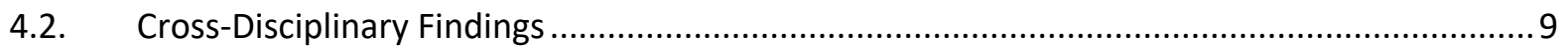

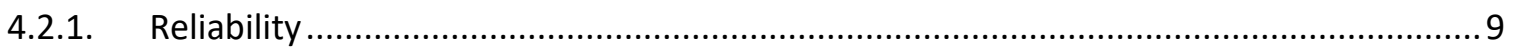

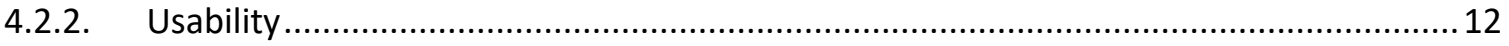

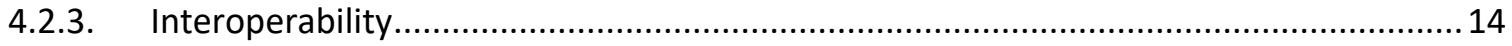

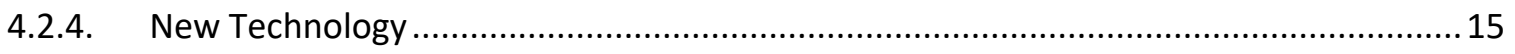

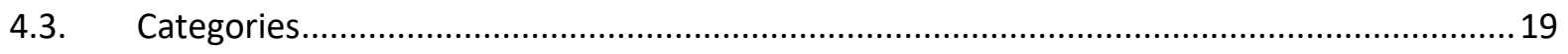

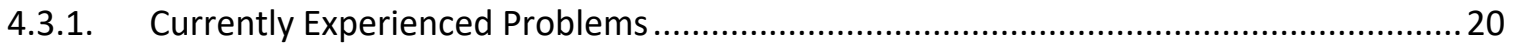

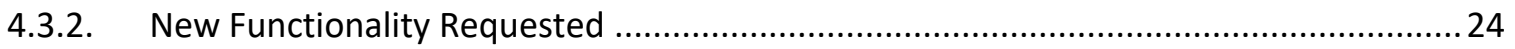

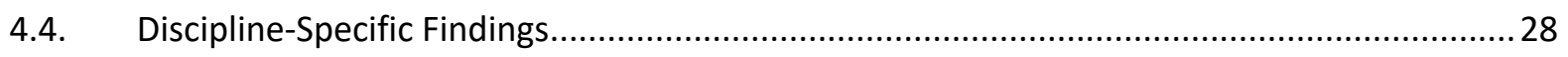

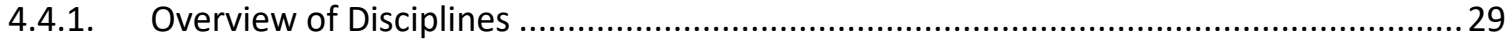


4.4.2. Problems and Requested Functionality Data

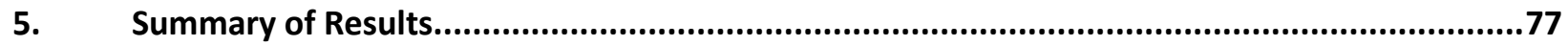

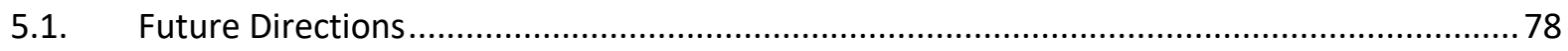

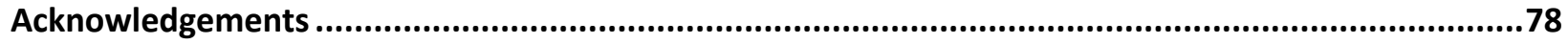

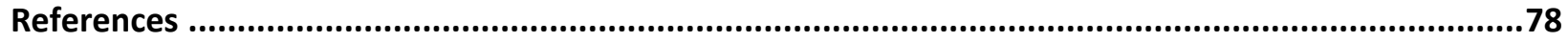

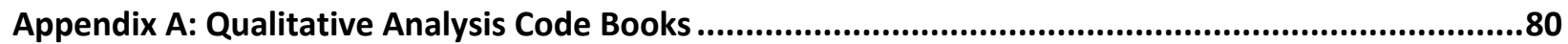

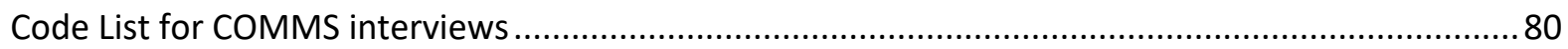

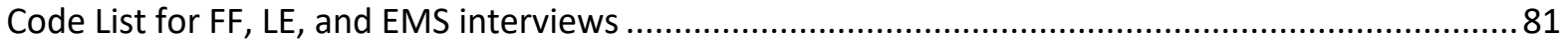

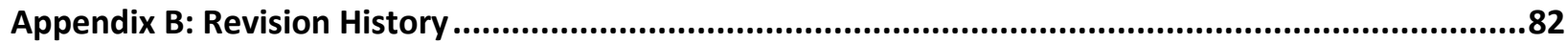




\section{List of Tables}

Table 1. Total number of participants interviewed by discipline ........................................................ 5

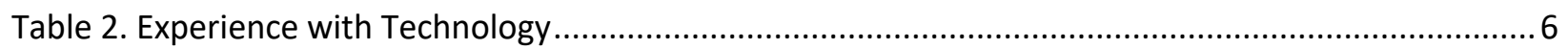

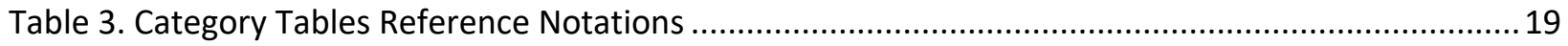

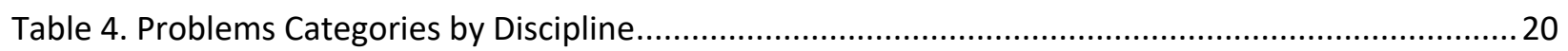

Table 5. Requested Functionality Categories by Discipline ..................................................................2 24

Table 6. Most Unique Discipline-Specific Problems and Requested Functionality ..................................29

\section{List of Figures}

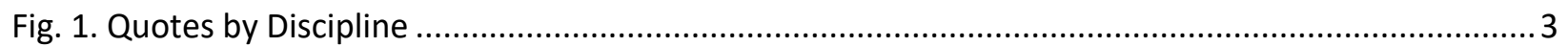

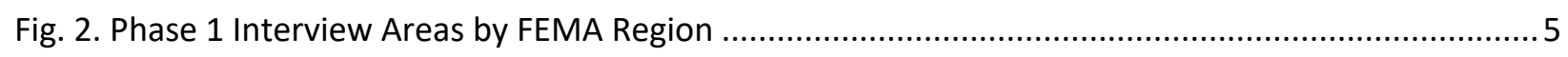

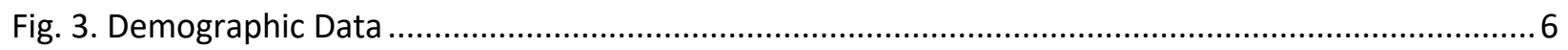

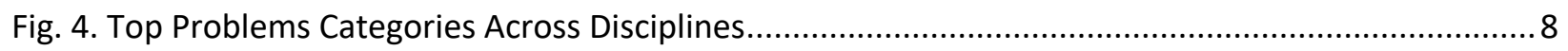

Fig. 5. Top Requested Functionality Categories Across Disciplines ...................................................... 8

Fig. 6. FF Technology Problems Categories and Subcategories .......................................................... 31

Fig. 7. FF Requested Functionality Categories and Subcategories ..................................................... 37

Fig. 8. EMS Technology Problems Categories and Subcategories ............................................................. 45

Fig. 9. EMS Requested Functionality Categories and Subcategories..................................................... 49

Fig. 10. LE Technology Problems Categories and Subcategories..........................................................5

Fig. 11. LE Requested Functionality Categories and Subcategories ...................................................59

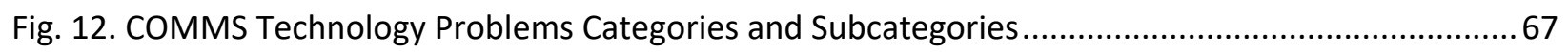

Fig. 13. COMMS Requested Functionality Categories and Subcategories ............................................. 72

\section{Glossary}

\begin{tabular}{|c|c|}
\hline Al .... & ...Artificial Intelligence \\
\hline AR ... & ...Augmented Reality \\
\hline CAD. & ....Computer-Aided Dispatch \\
\hline $\mathrm{CO} \ldots$ & ....Carbon Monoxide \\
\hline COM & ....Communications Centers \\
\hline COOF & ....Continuity of Operations \\
\hline DUI . & ....Driving Under the Influence \\
\hline DWI & ....Driving While Intoxicated \\
\hline ECC. & ....Emergency Communications Center \\
\hline EKG. & ....Electrocardiogram \\
\hline EMS & ....Emergency Medical Services \\
\hline ePCR & ....Electronic Patient Care Report \\
\hline FBI .. & ....Federal Bureau of Investigation \\
\hline FEM & ..Federal Emergency Management Agency \\
\hline FF..... & ....Fire Service \\
\hline
\end{tabular}


FY2017.............Federal Government 2017 Fiscal Year: October 1, 2016 through September 30, 2017

FY2018..............Federal Government 2018 Fiscal Year: October 1, 2017 through September 30, 2018

GIS ..................Geographic Information System

GPS ..................Global Positioning System

HIPAA .............. Health Insurance Portability and Accountability Act of 1996

HUD ...................Heads-Up Display

HW ................... Hardware

IC .......................ncident Commander

IP ........................ Internet Protocol

IT ......................Information Technology

KVM...................Keyboard, Video, and Mouse

LE.....................Law Enforcement

LETS ..................Law Enforcement Telecommunication System

LMR ...................Land Mobile Radio

LPR....................License Plate Reader

LTE ....................Long-Term Evolution

MDC .................Mobile Data Computer

MDT..................Mobile Data Terminal

MRU .................Medical Response Unit

NASA ................National Aeronautics and Space Administration

NCIC................... National Crime Information Center

NCIS ..................Naval Criminal Investigative Service

NG 911 ..............Next Generation 911

NPSBN ..............National Public Safety Broadband Network

PBX ..................Private Branch Exchange

PCAD................Police Computer-Aided Dispatch

PCR ..................Patient Care Report

PPE ..................Personal Protective Equipment

PS....................Public Safety

PSAP ................Public Safety Answering Point

PSCR ................NIST's Public Safety Communications Research Program

R\&D .................Research and Development

RMS ................. Records Management System

SCBA .................Self-Contained Breathing Apparatus

SIM ..................Subscriber Identification Module

SSO ...................Single-Sign On

SW ....................Software

TAC ...................Tactical Channel

TIC ...................Thermal Imaging Camera

UI ......................User Interface

USB ...................Universal Serial Bus

VHF ..................Very High Frequency (radio frequency) 
VIN...................Vehicle Identification Number 


\section{Introduction}

The public safety domain is embarking on a major technological shift. The community is transitioning from the use of present-day LMR towards a LTE network. The network, currently under development, is a dedicated LTE network for public safety known as the nationwide public safety broadband network (NPSBN). The goal of the NPSBN is to improve communication for first responders by providing an independent, interoperable communication platform during incident response and by providing the capabilities of network priority and preemption. With the emergence of the NPSBN, the public safety community is beginning to transition to more widespread, data-based communication technology. NIST's PSCR program is dedicated to supporting the R\&D of this technology. Research within the PSCR program focuses on identifying and recommending ways to mitigate the issues faced in emerging public safety communication technology.

The PSCR usability project focuses on the human factors issues surrounding the use of communication technology [6]. The research within this project centers on the technology users - the first responders. This project seeks to better understand first responders' environments, tasks, and communications needs. In doing so, part of the project is to directly engage with first responders to examine their perceptions about their use of communication technology during incident response. The ultimate goal is to capture the requirements for the effectiveness, efficiency, and user satisfaction of first responders' use of communication technology, and to share their concerns with the wider public safety community. Three initial research questions guided this work:

1. How do public safety personnel describe the context of their work, including their roles and responsibilities as well as process and flow?

2. How do public safety personnel describe their communication and technology needs related to work?

3. What do public safety personnel believe is working or not working in their current operational environment related to communication and technology?

\subsection{Background}

The PSCR usability program is using a multiple-methods research approach to gain an understanding of first responders and their communication needs. The first phase of the project- the qualitative component - was designed to get a deeper look at the user population without making assumptions about the first responders or their technology use. A series of methodologically rigorous in-depth interviews were conducted throughout the United States. The first responder population sampled for the interviews accounted for geographic and cultural diversity; urban, suburban, and rural locations; and various levels in the chain of command within the fire, law enforcement, emergency medical services, and communications center disciplines. The first round of interviews was conducted in FY2017. The second round of data collection in FY2018 was geared towards expanding the rural area representation and communications center representation in the data. Through both rounds of data collection, nearly 200 first responders were interviewed, representing 13 states in eight FEMA regions. The first round of interviews of Phase 1 was documented in, "Voices of First Responders - Identifying Public Safety 
Communication Problems: Findings from User-Centered Interviews, Phase 1, Volume 1" [1]. This report, Phase 1, Volume 2, includes data from both rounds of interviews.

The second phase - the quantitative component - further investigates first responder communication technology needs with a broader representation of the population. The quantitative component consists of a large-scale nationwide survey of first responders designed to verify and expand on communication technology use findings from Phase 1 . The mixed-method approach will provide a more holistic view of first responders' technology needs.

Phase 1, Volume 1 reported on the overall qualitative analysis methodology and the research results from the first round of data collection (FY2017) [1]. Given that most of the interview questions focused on understanding first responders' characteristics, their tasks and contexts of use, the Phase 1, Volume 1 report focused on those areas. However, the interview questions also elicited a set of currently experienced problems. In addition, one interview question specifically asked first responders to think outside the box and describe their technology wish list: "pie in the sky here-if technology could do whatever you wanted it to, what would you want?" Thus Volume 1 also included brief descriptions of problems and new functionality requests expressed by first responders (see Phase 1, Volume 1, Appendix D: User-Identified Technology Opportunities and Needs) [1].

A key finding of Volume 1 is that first responders do not want technology for technology's sake [1]. What first responders want is improved technology to address their problems and requested functionality. Given the large quantity and variety of first responder-identified technology problems and functionality requests expressed in the interview data, a comprehensive analysis further characterizing those data was required. The qualitative analysis and refinement of the thousands of functionality requests, requirements, and problems with communication technology explicitly voiced by first responders throughout the course of the in-depth interviews is reported here, as a follow-up to Phase 1, Volume 1 [1]. This Volume 2 report includes data from the entire in-depth interview dataset (both FY2017 and FY2018). The report presents a more exhaustive analysis of the technological problems and the new functionality requests of the first responder disciplines, citing exemplars of the technological problems and requests across public safety disciplines (fire, law enforcement, emergency medical services, and communications centers). It provides a summary of the categorical data for the technological problems and requested functionality, and presents a more exhaustive analysis of those realities within each discipline.

\section{Data Analysis}

\subsection{Qualitative Analysis}

The rigorous data analysis process used in this qualitative research is detailed extensively in Phase 1, Volume 1 (Sec. 4: Qualitative Data Analysis) [1]. To summarize:

1. In-depth interviews were audio recorded and transcribed. The first round of qualitative data collection included interviews with personnel primarily in fire service (FF), law enforcement (LE), and emergency medical services (EMS) disciplines. The second round of qualitative data collection focused more on personnel from public safety answering points (COMMS). 
2. A code list was generated in order to label, or tag, participant statements. The codes are a set of labels based on the research questions, relevant literature, and an understanding of the communication and technology space in the first responder community. Two code lists were generated; one for EMS, FF and LE and one for COMMS given the unique environment and primary tasks within that discipline. Both code lists can be found in Appendix A.

3. The transcripts were coded. Qualitative coding is a process of using the code list to label sections or chunks of transcribed data capturing the essence of the statements to group, compare, and/or manipulate chunks.

4. The data was extracted. Data extraction refers to exporting the data associated with a code from each transcript into a separate document.

5. Themes were identified. Qualitative analysis is the process of exploring the relationships of the data and the codes to identify themes. The iterative process of going back and forth between data and codes, between the full data set and extracted files facilitates the identification of themes, trends, and outliers, and provides an overall impression and understanding of the data.

\subsection{Systematic Categorization}

For this effort, the participant statements coded as "problems: technology" or "wish list" were extracted from the interview transcripts. This resulted in separate extraction files, by discipline, related to each code. In this report the participant statements extracted are referred to as quotes. There were over 1100 "wish list" quotes extracted; "problems: technology" consisted of over 1700 quotes. The total percentages of quotes for both codes, by discipline, is depicted in Fig. 1.

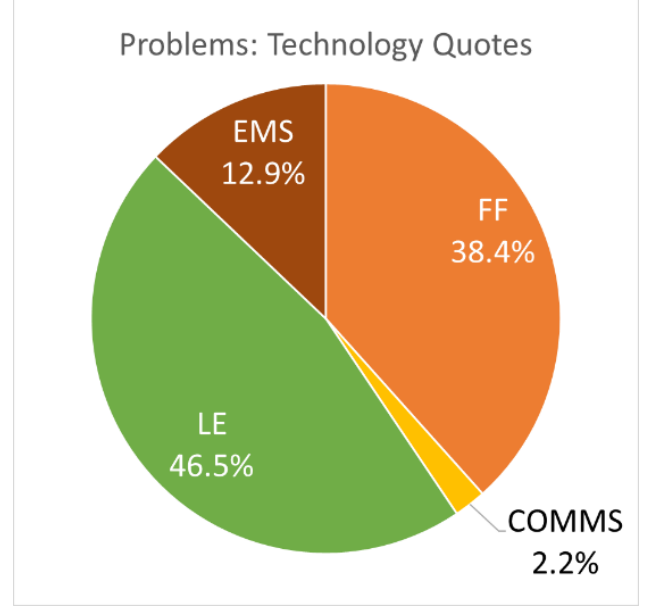

(a) Quotes Coded “Problems: Technology" ( $n=1767)$

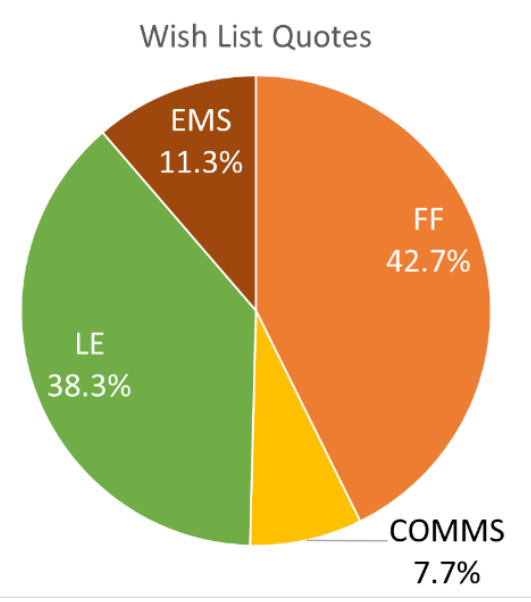

(b) Quotes Coded "Wish List" ( $\mathrm{n}=1$ 113)

Fig. 1. Quotes by Discipline

The currently experienced problems in this report refer to participant quotes coded as "problems: technology"; the new functionality requested refers to participant quotes originally coded as "wish list". Participants were not restricted to discussing technology when asked about their wish list. While "wish list" data included information, equipment, policies, procedures, and funding, the requested functionality reported here are only those that are related to technology. 
In order to have a better understanding of the technology problems and requested functionality discussed by first responders, additional analysis of the data was required. Qualitative research is fundamentally iterative in nature. The research process consistently returns to the research questions to inform future elements of the process. The data analysis of Volume 1 and the extractions provided the initial data set for this iteration of qualitative analysis [1]. Focusing on the codes of problems and requests, the qualitative analysis steps were repeated from the development of new code lists (step 2) through the identification of new themes (step 5).

The quotes of problems were analyzed independently from those quotes of requests for new functionality by separate members of the research team. Each member independently identified new codes and subcodes for either problems or requests. The team members met to review and discuss the codes. The codes were revised and operationalized based on ongoing discussions, ensuring that multiple points of view were captured. In this report the new codes and sub-codes are called categories and subcategories, respectively (see Sec. $\mathbf{4} 3$ for the full list of categories).

The problems and requested functionality quotes yielded two separate sets of categories and subcategories. Each of the problem quotes were coded using the new categories and subcategories for problems; the quotes related to requested functionality were coded using the new categories and subcategories for requested functionality. However, due to the nature of the interview process and how participants described the execution of their operational tasks, some overlap between the category sets does exist. For example, a participant who has a problem with technology frequently crashing may also articulate a request for more reliable devices. In addition, on several occasions first responders gave voice to multiple subcategories in a single quote; these were also included in the final quote list for the respective subcategories. The newly coded data were extracted-meaning each of the quotes associated with a particular code was filtered in preparation for analysis of themes.

Finally, themes were identified. Relationships were examined among the codes, among and across the four disciplines, and between the problems and requests quotes and their respective codes to identify themes. This iterative process of going back and forth between quotes and codes, and between the quotes and transcripts, facilitated the identification of themes, trends, and outliers and provided an overall impression and understanding of the data documented in the results section.

\section{Participants}

Through the two rounds of interviews, a total of 193 first responders participated, resulting in 158 interview transcripts. Some interviews included multiple participants; five participants opted to not be recorded (see Phase 1, Volume 1, Sec. 3: Methods, for interview protocol and procedure) [1]. Table 1 below shows a breakdown of interview participants by area type and discipline. Fig. 2 shows the geographic areas where interviews were conducted, by FEMA region [3]. 
Table 1. Total number of participants interviewed by discipline

\begin{tabular}{l|lllll} 
& FF & LE & EMS & COMMS & TOTAL \\
\hline URBAN & 28 & 32 & 13 & 4 & 77 \\
SUBURBAN & 24 & 20 & 6 & 3 & 53 \\
RURAL & 19 & 20 & 6 & 18 & 63 \\
TOTAL & 71 & 72 & 25 & 25 & 193
\end{tabular}

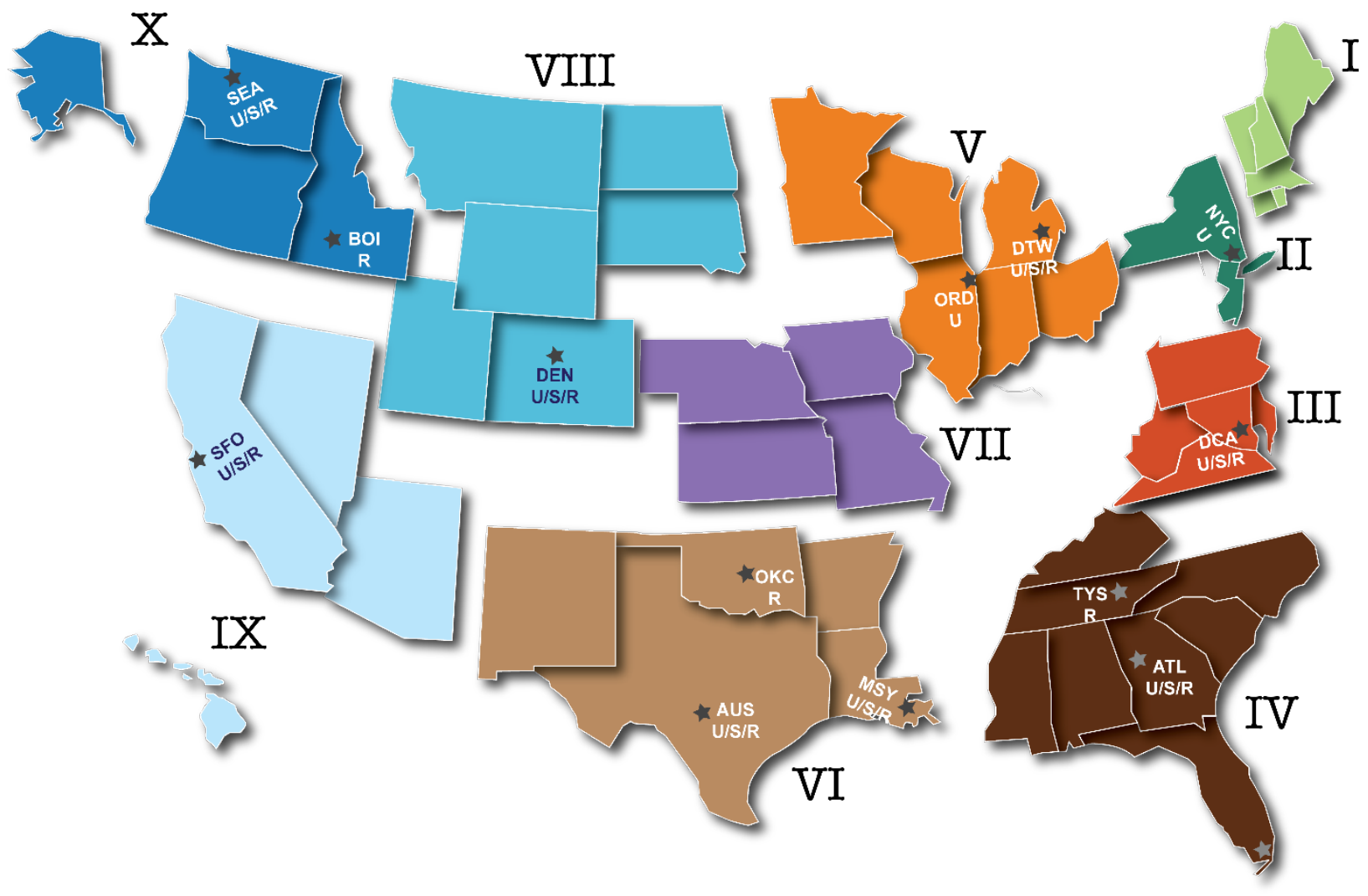

Fig. 2. Phase 1 Interview Areas by FEMA Region

At the start of each interview, participants were asked to complete a demographic questionnaire (see Phase 1, Volume 1, Appendix B: Demographic Questionnaire) [1]. The resulting data are shown in Fig. 3. Corresponding to the first responder population, $86 \%$ of the interviews were conducted with male participants. In the U.S., approximately $87 \%$ of LE [7] and over $95 \%$ of FF [5] are males. The majority of participants were nearly evenly distributed between 26 and 55 years of age; with $25 \%$ from 26-35, $28 \%$ from 36-45, and $35 \%$ from 46-55. The interview sample included participants with diverse levels of experience, divided into five-year intervals, representing the novice to the most experienced. 

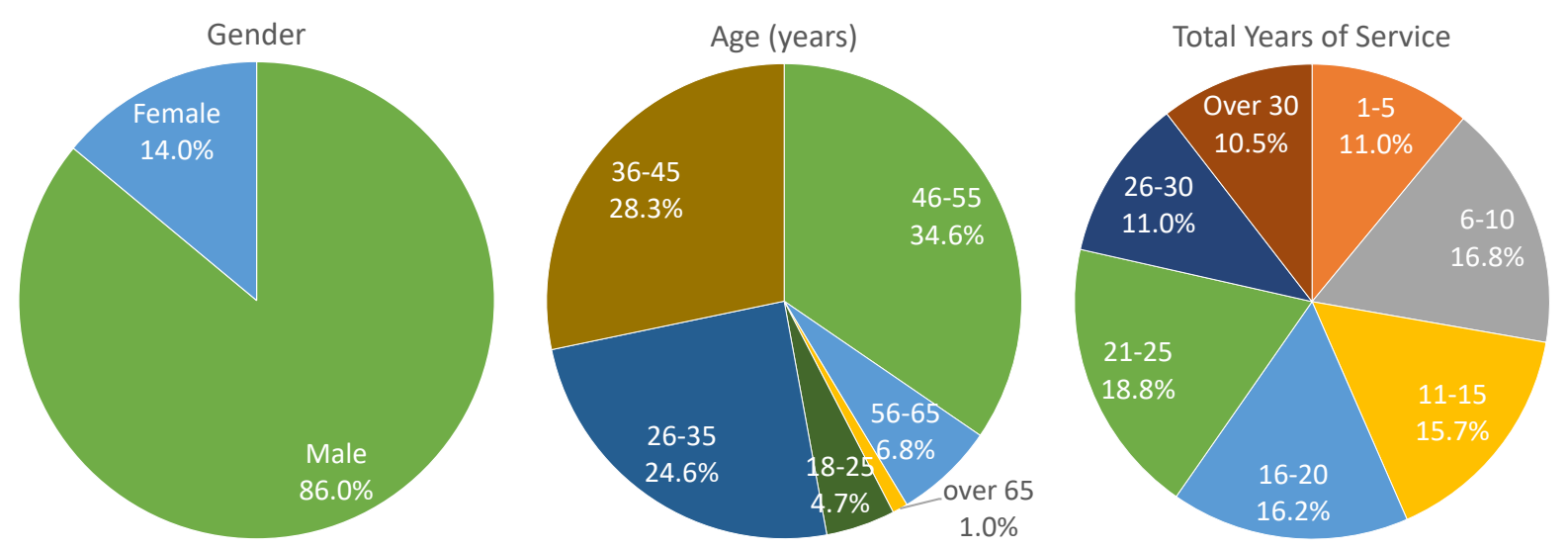

Fig. 3. Demographic Data

The demographic questionnaire also included two questions about participants' experience with technology. The first questions addressed knowledge of technology while the second question focused on user characteristics of technology adoption. The results are listed below in Table 2 .

Table 2. Experience with Technology

\begin{tabular}{|c|c|}
\hline $\begin{array}{l}\text { Q1. Experience with different kinds of technology: (including desktop or } \\
\text { laptop computers, tablets, smartphones, and the internet). }\end{array}$ & Percentage* \\
\hline $\begin{array}{l}\square \text { I have limited experience using technology and I don't know much } \\
\text { about how technology works. }\end{array}$ & $1.05 \%$ \\
\hline $\begin{array}{l}\square \text { I have some knowledge about how technology works, but often } \\
\text { need to ask for help to perform more advanced activities - such as } \\
\text { to configure the privacy settings on my cell phone. }\end{array}$ & $10.99 \%$ \\
\hline $\begin{array}{l}\square \quad \text { I can do most things that I want to do with technology and only } \\
\text { need help occasionally. }\end{array}$ & $71.20 \%$ \\
\hline $\begin{array}{l}\square \quad \text { I can do all things that I want to do with technology without help } \\
\text { from others. }\end{array}$ & $18.85 \%$ \\
\hline Q2. In general, when do you adopt new technologies? & Percentage* \\
\hline$\square$ I try the latest technologies as soon as they come out. & $19.90 \%$ \\
\hline$\square$ I follow technology trends. & $38.22 \%$ \\
\hline$\square$ I let others work out the kinks first. & $39.27 \%$ \\
\hline$\square \quad$ I wait until my old technology dies. & $8.38 \%$ \\
\hline$\square$ I only adopt new technologies when it's required. & $5.24 \%$ \\
\hline
\end{tabular}

* The percentages do not add up to $100 \%$ since participants could select more than one option 


\section{Results}

The results of the in-depth analysis of the problems currently experienced by first responders and their requested functionality are presented in this section ${ }^{1}$. Since the categorized data from this more in-depth analysis is best presented by reporting the quotes directly from the first responders, the high-level categories, their subcategories, and the quotes related to each subcategory are discussed. All quotes in this report are verbatim presented in blue, indented text. Each quote is followed by a notation representing the source transcript. The notations are comprised of three parts: discipline (FF; EMS; LE; COMMS); city type (Urban=U; Suburban=S; Rural=R); and interview number. Thus, (LE-U-006) refers to an LE interview, from an urban location, who is law enforcement interviewee number 006. This convention provides assurances to the reader of the data's provenance and that the data can quickly and easily be located within the larger dataset when necessary. The quotes in this report are exemplars from the coded transcripts. Each exemplar quote was chosen as an illustration representing a category or subcategory.

Sections 4.1 and 4.2 present a view of the data across each of the four disciplines. The former provides a brief overview of the technology problems and functionality requests categories; the latter, a summary of the top categories in both the problems faced by first responders and their requests for improved technology. In the final two results sections, 4.3 and 4.4, each of the categories and subcategories are described in detail and a thorough view of the data provides unique perspectives from each discipline.

\subsection{Categorical Data Overview}

The analysis of the 2872 problems and requested functionality quotes resulted in 43 categories of data. As described in Sec. 2.2, the problems and requested functionality category sets were developed separately but contain some overlap due to the nature of the participant responses. While some of the top categories presented here are similarly related, the data categories overall represent a breadth of topics. Examining the categorical data across disciplines reveals where first responders in the public safety community stand, both in the problems faced and the functionality requested.

\subsubsection{Top Problems Categories}

Analysis of the problems data yielded 25 distinct categories, with 1729 quotes categorized. The most pressing problems categories across disciplines are shown in Fig. 4, proportional to the quotes in the dataset.

\footnotetext{
${ }^{1}$ The terminology used throughout the results sections is a reflection of the voices of first responders. Terms and phrases used were directly from the interview data.
} 


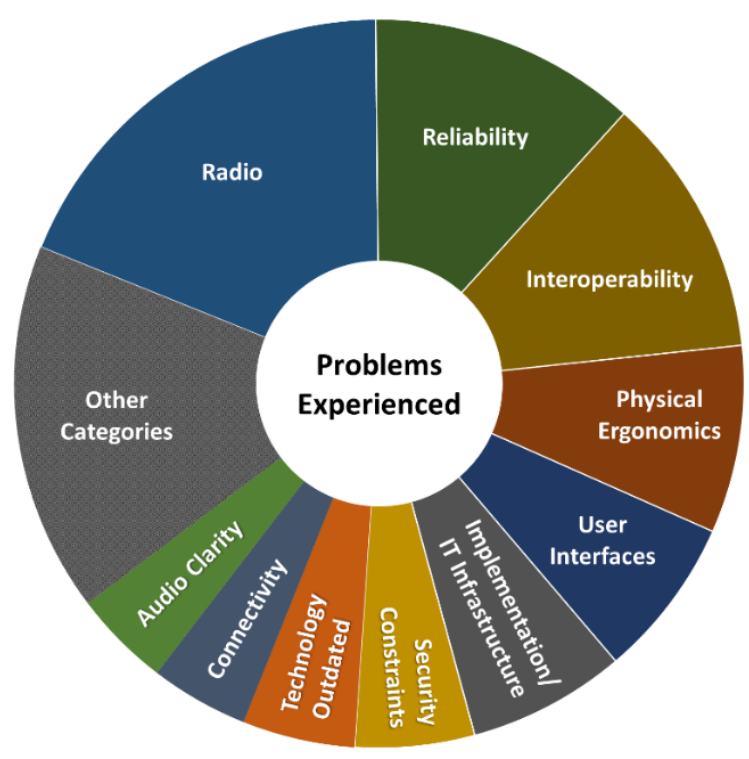

Fig. 4. Top Problems Categories Across Disciplines

By far, problems with radios are the most pressing concerns for first responders, who across disciplines experience a variety of issues (see Sec. 4.3.1 for detailed problems faced). Other categories include problems with microphones and earpieces, body cameras, MDCs, 911 calls, and video media.

\subsubsection{Top Requested Functionality Categories}

Requested functionality data analysis resulted in 1143 categorized quotes belonging to 18 categories. Categories include a wide variety of topics, from technology needs and improvements (e.g., usable security, wireless microphones) to futuristic technology aspirations (e.g., self-driving cars, facial recognition). Fig. 5 shows the most important categories from the data across disciplines, proportional to the quotes in the dataset.

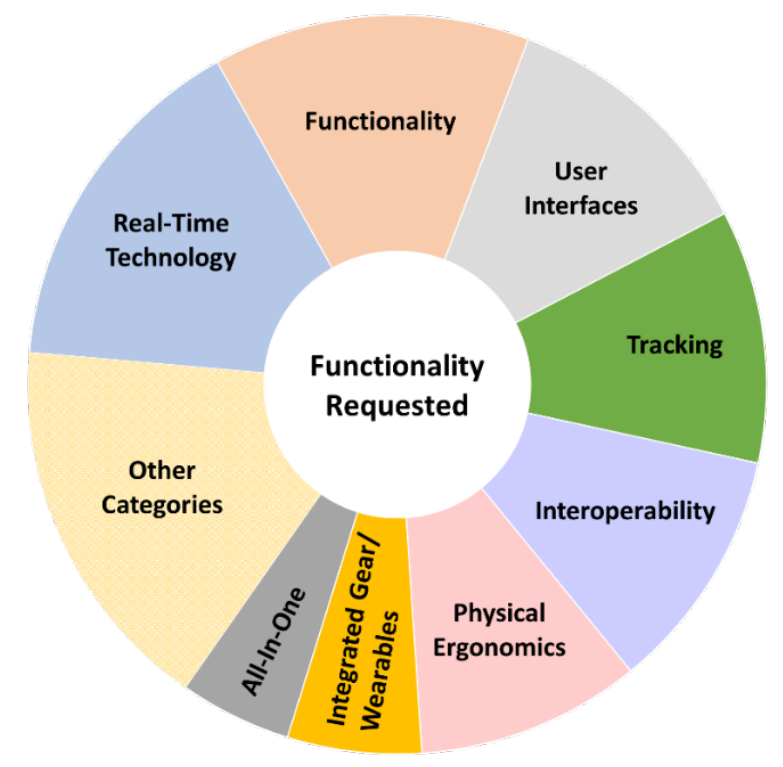

Fig. 5. Top Requested Functionality Categories Across Disciplines 
While many categories are important to first responders, having technology that is able to deliver realtime information during an incident is the most pressing functionality request. Other categories in the requested functionality data include futuristic technology, microphones and earpieces, radios, mobile apps, enhancement to responder vehicles, and usable security.

\subsection{Cross-Disciplinary Findings}

The focus of this section is on those technology problems and requested functionality of greatest importance to first responders. First responders' use of communication technology hinges on their perception of its usefulness and trustworthiness. For their current devices and for those on the horizon, first responders want technology to work without being a detriment to their primary tasks. If technology doesn't work properly, doesn't work as advertised, or doesn't work as expected, first responders expressed that they wanted it fixed or replaced with new technology, or when possible, they would revert back to older methods to accomplish their tasks.

By a large margin, the functionality requests of first responders are more related to fixing or improving the problems with their current technology than any other functionality requested. This intersection between problems and requested functionality across disciplines revealed three standout categories:

- Reliability,

- Usability, and

- Interoperability.

For these categories, this section presents, via quotes directly from the first responders, the technological problems first responders want fixed, how they want them to be fixed, and how they think their current technology can be improved upon. Also discussed is one of the greatest individual functionality requests posed by every discipline - the use for technology with the ability to provide real-time visual information during an incident. To better gauge the specific requests of a single discipline, see Sec. 4.4. See Sec. 5.1 for information regarding access to the full dataset.

\subsubsection{Reliability}

First responders, across all disciplines, experienced technology failures \& disappointments, leading to expressions of a lack of trust using technology due to its unreliable nature. Responders expect technology to fail, so they feel the need to constantly be prepared with backup plans, causing more work for responders. Often, backup plans involve other technologies, which in turn have their own set of issues. In addition to the extra preparedness due to anticipated technology failures, responders are provided with technology that becomes useless when there are data network or radio coverage interruptions. When network connectivity breaks down, devices that use that broken infrastructure are then unreliable. Responders need their technology to work when they need it and how they expect it to work.

"The biggest thing is a device that works $100 \%$ of the time, not $90 \%$ of the time." (FF-U-004)

"Everything we use, I mean, we don't have time to mess with it, or tweak it, or play with it. It has to work the first time, every time, or people will just to stop using it. They will just refuse to use it and go back to the old way." (EMS-U-003) 
"The radio is extremely important. It is our lifeline. When we need it, it doesn't always work." (LE-R-018)

"I want it to work. I don't care what name is on it... We run 24/7, internet is important to me, phone system working is important to me, radio system working; those are my top three priorities." (COMMS-R-020)

The inability to rely on technology in high stress situations causes responders to constantly be prepared for that technology to fail. Even when the responders have extra precautions in place, those backups often have their own set of issues.

"Technology is great when it works. When it doesn't, you got to fall back to pen and paper." (LE-S-037)

"You start that [tanker truck] out it might go or it may not go because it has got all its computer stuff on it, if they don't go you got to cut everything on and off and start all over." (FF-R-054)

"Using the computer to follow directions to get to a location, and you hit a bump and the computer shuts down. So then you go back to a mapping system, which is just a hard-- Paper, hard copies. So we always have redundancy in everything that we do." (EMS-S-015)

"Well, apparently one of the main fiber optic lines, a squirrel chewed through it and the whole system shut down. There were supposed to be backups to the backups to the backups, and we just laughed because we don't understand the details, but apparently this squirrel hit something and chewed through something that bypassed the backup to the backups to the-- I don't know that much about it." (COMMS-S-003)

"In any type of critical incident, that is one of the first things that goes is the communications on cell phones... we try to have the redundant systems in place, probably more so in public safety than any other profession; we try to have those redundant systems but it still doesn't mean that, you know, some of them haven't been utilized in years and we are not sure that they are going to continue to work if we need them to do so." (LE-R-059)

One of the major causes of unreliable devices is the interruption of the supporting communications network. First responders face issues such as dead zones, geographical interference (e.g., valleys, canyons), and structural interference (e.g., high rises, basements, tunnels and subways). When radio coverage or data connections fail, first responders deem the devices themselves unreliable.

"The big issues with our communications are the dead zones and kind of holes in our communications." (EMS-S-016)

"...the reliability, the radios dropping out mid-conversation... the signals dropping out when you really need them sometimes." (LE-R-054) 
"Sometimes when you call [law enforcement officers], it'll go straight to voicemail. So the tower for the radio tends to reflect the same or similar to your cell phone service. So like if I'm not getting him on the radio, chances are I'm not going to get him on the phone. But sometimes I do, but for the most part they're about the same. Like if you walk into a hospital, neither your radio nor your cell phone is going to work." (COMMS-R-012)

"The downside is when a firefighter goes down in a basement, and his radio doesn't see a repeater, he can't call for help, so the radio is useless. So the fix to that is to go to a direct channel. The downside of being on a direct channel is only people within a mile can hear the radio, so other people across the city or incoming to the fire don't get to hear what's going on before they get there until they get into range of the direct channel. So that's a conundrum. I guess there are some fixes. You can put a repeater on every chief's buggy that will also take that direct channel and put it into a repeater system that way everybody to hear it that way. That requires infrastructure, investment, and installation, and so forth, and money, so." (FF-U-016)

"We see enough cell phone failure, especially at the large events. We don't trust them yet to be reliable enough. We think that especially when we really, really need them is when they're going to do down." (EMS-S-003)

The coverage and connectivity issues first responders face during incident response led to further expressions of a need for new technology to fill the gap.

"You go into a low spot then you lose [radio coverage]. If we go south and we go east, we've got a straight shot, no hills, no bumps, or anything, you could go miles and miles and miles and still listen to the radio. You go two blocks in our city north, and you hit on the other side of the hill, and you lose transmissions. So the more towers we can get, the better. The more signal that we can get out, the better." (LE-S-021)

"The people that are involved in the actual manufacturing of radios have to work a little closer with the building people, maybe, and just from the onset of a building being put together, maybe have repeaters throughout the-- you know what I mean? Be proactive a little bit and just because of the state of the world. That wasn't a thought 25 years ago, but today we have to think that way." (FF-U029)

"We have a lot of software with connectivity between the patient care records we have on our laptops to our monitors, which are the 12-leads and defibrillators and all that. So I think a lot of times there could be ways to improve the connectivity between that because it's so integrated. And you can't finish reports if the connectivity is not there, and you can't upload your monitor to your computer. So WiFi is plan A, and then there's also USBs that we can use if the 
WiFi's not working. But it just seems like that's a hang up in our system often and increasing the time of the reporting. And getting back into service until the report's done. So once again, technology issues there." (EMS-S-006)

The stability of wireless network connections must be considered when improving the reliability of communication technology, for both for day-to-day operations and the big events.

\subsubsection{Usability}

Universally, first responders expressed frustration in using their communication technology. Issues ranged from the size and weight of their devices to the overly complex nature of their user interface designs. Overall, first responders want a limited number of light-weight devices that don't interfere with their dayto-day tasks while being easy to use.

First responders experience a level of discomfort due to the physical attributes of their technology. For fire and law enforcement especially, weight and bulkiness are significant factors in the safety and productivity of the responders.

"In my opinion, technology should make life easier not harder. Right? And if the radio doesn't do anything other than just add more weight to your belt-- with these new radios, I'm not accessing any new channels that I didn't have privy to before. They're mainly for if for whatever reason you're doing law enforcement stuff out of state or whatever, then I guess you can add some new channels with that. But majority of the officers are never going to do that." (LE-U-003)

"As they're adding technology [to the SCBA cylinders] they're adding weight. And I would say that one of the number one complaints... the Scott pack that we used to have with no bells and whistles, just air, that was it. It was 18 pounds. The thing we have now is like 27 pounds. Now, it has technology built in. It lets you know when your bottle is low. It has all these things. And if you go down, it has a computer chip and someone can use a homing device to find you. And that's all amazing, except it's $50 \%$ more on your back. And the minute you put that on, you're not thinking about the fact that the microchip might help somebody find you, you're thinking about the fact that, 'I'm slamming this thing against my back 12 times a day. I'd really rather not slam 27 pounds. If I had to slam something against my back, I wish it was 18,' right?" (FF-U-012)

"Anything that you could make lighter that we have to carry is always going to be good because we carry a lot of stuff." (LE-S-037)

Responders are required to use a number of different devices and equipment, often having to wear or carry them. As this responder said, making technology lighter will improve their satisfaction within their work environments. The more clunky the hardware they are required to use, the more their physical load increases. As such, first responders were unified in wanting to carry less technology.

"We have a lot of things that we carry. So there's so much on our belts... Just a little bit of weight off your belt is huge. So I have a hard time trying to fit 
everything on my belt as required in policy. Especially if you're some of the smaller officers, male or female just depending on your waist size, it's like you don't have enough real estate to fit all this stuff that's required. So a lot of people have dropped tasers or that kind of stuff. Now they're adding the body camera's right here. And you have a radio right here. You have the mic. This is just here. And then you're like-- and then you've got your notepad. You've got your pens and then everything around your waist and your gloves. So I would hope that sometime the technology could help us remove some of all this hardware that we're carrying around all the time. That would be a big deal. I mean health wise for officers too." (LE-U-007)

"I mean, right now, on an incident, I'm carrying usually two 800 radios, a VHF, and two cellphones when I'm running an incident. And that's ridiculous... So, I mean, I'm usually sitting in a vehicle. It's also too much information... When someone's talking, I can't process all that information. So to fix that problem, we're not carrying so many different-- just to be able to talk to different people through cell phones, consolidate it down, but then, somehow, have it manageable." (FF-R-019)

For COMMS, the burden of too much technology still exists; however, this is not a result of being physically weighed down. In COMMS, the issue is how much technology they have to manage.

"...with all the things that everybody wants to integrate. They want you to have apps, they want you to be able to bring in apps, they want you to be able to bring in photos and videos and texting and this and that. The more stuff we add-- the more computer screens, the more keyboards, the more mice. It just keeps adding, and it's the more burden." (COMMS-U-007)

"So, you've got 10 new radio channels but you've got one dispatcher. Are you expecting that one person to handle 10 channels? So, what is the limit? I mean, what is the cut-off in that -- right? Because there is no specific... and there is no defined number, you should be responsible for your primary channel and two side channels or three side channels." (COMMS-R-019)

When discussing interactions with their devices, across the board, first responders faced problems with the complexity of the user interface design. In voicing their frustrations, responders mentioned the need for simple, easy-to-use interfaces. They want devices that are easy to use, hard to make mistakes, and easy to recover if mistakes are made.

"Ease of use and usability is a big deal, and we're doing the same things over and over and over again, so we want those to be as efficient as they can be. Sometimes the software needs to be tweaked, sometimes I hit this button and it's supposed to do $X$, and when it doesn't that creates more work for me and I've got to do-- and it's gets frustrating." (EMS-U-001) 
"I would say, first thing [I want] would be a more user-friendly phone system. That'd be number one... I think the one we have now just-- it requires a lot of steps. If I wanted to call a fire station, for example, it's one, two, three, four, four steps. Whereas before, I would just click on the fire station tab and find fire station one, double click... And I'm done. Now I have to go click phone book, I have to type in fire, hit enter, and then all of my choices pop up. Then I have to scroll over... sideways to find what station I'm looking for, and then click it. That's just one example." (COMMS-S-004)

"When we need the technology, we need it to be simple. We don't need it to be complex because we don't have the time to work through complexities in anything technology because our decisions are instant... And so technology is great, but if it's complex, it kind of is counterproductive." (FF-U-025)

"In the police world, if you want somebody to use something, it has to be simple. The more complicated it is, it's very seldom getting used." (LE-R-001)

In addition to concerns about the complexities associated with using their technology, responders' issues with user interfaces often stemmed from how information was displayed.

"There's a level of art and science to how information is displayed. And I don't think that those who are creating the applications for us now either understand that or have the capacity to invest in the infrastructure necessary to display it cleanly in a way that works." (FF-S-032)

"The push is important, how [information] gets to the officer. Flying, bing, and you just see a big picture, 'This is the car we're looking for.' That's awesome... It needs to be boom, 'Wanted vehicle for this,' boom, and just the picture of it. Simple, bold writing. That's the key... Give it to me so I can digest it." (LE-U-023)

First responders require technology solutions that are simple to use, simple to learn, and simple to integrate into their environments; they need usable technology.

\subsubsection{Interoperability}

First responders want their technology to work when they need it to work and how they need it to work, without overwhelming complexity. Beyond the usability and reliability issues widespread throughout the data, the functionality of first responders' devices was often presented as a hindrance to their operations. Responders want improved functionality in their technology, which in many cases involved the interoperability of their devices. There are many issues surrounding interoperability; a predominant theme being the inability to effectively communicate with responders in other disciplines, jurisdictions, and agencies.

"It takes longer to get things done just because there's a lag time, obviously. If I'm telling my dispatcher to tell the fire department dispatcher to tell the firefighter or paramedic to do something." (LE-S-034) 
"Being able to share that public safety data from one agency to another... CAD interoperability. Being able to share that data. [City redacted] right next door to us, they have a domestic violence case going on. The suspect may live here. It's going to take a 10-minute conversation between the dispatcher over there and the dispatcher here to catch up on all of the information on that suspect when all they could do is send us a file card over in our CAD system and, boom, we have everything that they had as far as all of the comments. We can't do that now." (COMMS-R-016)

"I don't care what field you're in, communication is the key to either success or failure and you're only as good as your communication components and your knowledge of communication. So we're always lacking, in my opinion, when it comes to radio communication. There's always problems, there's always problems getting on the right channel or being able to communicate with a different entity or different agency. You see that in, unfortunately, but you've got mass shootings and there's always a problem with cops being able to talk to firefighters. There are paramedics... And I don't know what the answer is, but I mean, there's hundreds of millions of dollars of grants that have been thrown towards it and we get better but I don't know if-- I don't know what the answer is to that streamless [sic] communication. Practice. But I mean, there's always technology that's going to give you problems." (FF-U-021)

"We have very little to no communication with our police agency. We are able to scan their channel, but I don't think they want us on their channel, and they don't come onto our channel. And that's been identified as a huge problem in some of these large-scale incidents around the country of, for instance, the [city redacted] shooting. There was no communication between the police and the fire on one scene. So I think that needs to get bridged. I think that's done through policy and procedure. I think the technology is there. I just don't think we utilize it efficiently." (EMS-S-006)

"I guess the biggest thing, I think, that would help first responders is an easier, more efficient way to communicate with each other when we have to. Like us and the fire department. I mean it's not something we need to do every night, but when we need it, it's important. So the more time we can cut down on that, the better." (LE-S-037)

\subsubsection{New Technology}

First responders have a great deal of improvements that need to be made to their existing communication technology, the most pressing of them reported in the previous section. By and large, updates to the technology they currently use is at the forefront of how research and development can have a direct impact on the work of first responders. Beyond these essentials of increasing the effectiveness of first responders' tasks, certain technological advancements are warranted. 
"I think there's room for [new technology] as long as it's durable and it's user-

friendly. That's huge." (FF-U-025)

The greatest request for cutting edge technology, across disciplines, is for devices that provide information to the first responders in real-time. First responders want timely, accurate information during incident response. The real-time functionality these responders requested ranges from GPS traffic navigation to distance estimation to language translation. In addition, a large majority of real-time technology requests in our interview data is related to live video and images of the scene.

For COMMS, real-time video and images are most critical when an emergency call is received at the communications center. During that time, visuals of the caller's environment would help provide clarity and context to call takers and dispatchers, who would then be more effective when contacting fire, EMS, or law enforcement.

"[It] would be nice if [the communications center] could see [video] but like we have that option to turn it on or turn it off. And like, maybe if they want to do that, we can turn on, like the phone companies would give up or like Apple or Galaxy or whoever it is, Note 8 or whatever, whoever makes that -- like, we have access to -- like if a caller, $90 \%$ of our calls are wireless. So, if they are calling in - then maybe we would have access to their camera. Like, by them calling 911 would grant us access to let's say their camera... And that way like that would help us if we are having trouble locating -- I don't know where I am at. Okay, well- let me see where you are at." (COMMS-R-019)

However, technologists must consider the unintended consequences of COMMS technological advancements, and the potential for negative impacts on call-takers.

"I have speculation, but I really don't know how [receiving video is] going to impact and if that's going to take too much time. I don't know if it's going to slow things down or quicken it, I don't know. I know it's a technology that the millennials love and it's easy for them, but it may not be necessarily easy for us. I don't understand how a video would be better than a text or a call... If there's something going on and it's a video of a house fire and they turn around and we can see that there's flames shooting out the windows, advantage... But an ambulance call? Maybe, maybe not. If they're bleeding and we can see it's an artery or a vein, maybe it's an advantage. I don't -- I mean video feeds of the scenes to help get the right resources a lot quicker I'm all for; videos to make a 911 call, not too keen on that." (COMMS-R-020)

"I think that there are some technologies that are coming that are going to be good. But then there's some technologies that are out there that I don't want to have anything to do with... Mostly accepting pictures and video from the public directly into the 911 center. I don't want to have anything to do with that. Number one, I think it's going to be a huge liability. And then it's going to expose people to things that they didn't sign up to see a baby who may have died in their 
crib. They may not have signed up for being an investigator on a kidnapping that somebody took a video of and they missed something in that video that was critical and then some attorney down the road 6 months, 2 years down the road gets them on a witness stand and says why didn't you see this, [whatever]. He's had 2 years to review that video and go, you know, you should have seen this piece of evidence in the video. I just don't want to have anything to do with it." (COMMS-R-016)

For fire, law enforcement, and EMS, real-time information is needed most en route to, and on scene at an incident. Live videos and images in these disciplines would be beneficial from a diverse set of perspectives, including aerial, interior, and perimeter views of the incident.

"If you could text message a picture to 911, and they could send it to us, that would help as far as we could look and say, 'This car accident here and the people can't get out of their vehicle.' A lot of times, the engine is dispatched by themselves. We could see that picture and say, 'Hey, let's add on a truck,' and achieve to that so we can extricate. Let's get that ball rolling sooner. Images would be pretty fantastic, but actual words and perception is just so different. My pain scale might be very different from yours, so." (EMS-S-005)

"Some kind of FaceTime application or something that as I'm walking down the hall, the chief sees us and is seeing what I'm seeing exactly and the command post on a screen... that might cut down on a ton of radio traffic because command doesn't need to know if there's smoke in a stairwell because he can see it." (FF$\mathrm{U}-005)$

"I would dispatch, and [the dispatcher would] be like, 'Listen, dude. Until the day that we can see everything that's happening there, we can't tell you what we can't know. We can't tell you.' So if there's some way to see that..." (EMS-R-007)

"I guess, if I had the ability, if you could have a real-time satellite picture, that would be nice. So if you can get an overhead, how you can get an overhead of a satellite picture of an area. If you could get a real-time to see if it was a burglary and you heard that the liquor store was being broken into and you could pull up a picture of the liquor store, a video showing real-time and see the person running." (LE-S-034)

"So if you could get into the truck and have information there readily available, like a picture of the building, and a residential buildings. Now, a lot of our commercial buildings we'll get pictures, but they're historical pictures or pre-plan pictures. If I could get accurate on-scene information in front of me before I leave, can change my entire way of thinking." (FF-S-023)

Responders have broad, but consistent views on what technology can provide real-time information. The most consistent ideas about new technology are the use of drones for incident response. Responders 
think both aerial and ground drones would be useful for various purposes, especially when combined with high definition cameras, infrared, or night vision.

"For a river rescue, that would be awesome. Send a drone up in the air, search it out ahead of time, so then that drone can pinpoint according to our GPS, coordinates right to the person. We can have video, audio, tell the people, 'We're here, we're overhead, help is on the way.' Immediately, we can tell the people to pinpoint instead of us searching miles of stuff. Then if we have visual on them, we can see them, we can tell what the clothing they're wearing, male and female, what their injuries are. We can ask them questions and we can-- all of that stuff can already be ahead of, before someone even goes face to face. So Al in that regard is awesome, to be able to do something like that." (COMMS-S-003)

"I mean, a drone's not going to put a fire out. A drone is not going to solve a car accident. But what a drone can do is give you information... So if we're responding to a house fire and it takes us five minutes to get there, but the drone can be there in 2 minutes and have a live feed 360 view of what we're going to, that would be invaluable." (FF-S-033)

"So some type of a drone with a camera. And before we go into this area, what do we have there? Is there something that can be relayed back to us and say, 'Okay, you have three cars in this type of an accident. Here's a picture of where you can come in, it's easier for you to come in.'" (EMS-U-010)

"Even ground drones. I was thinking about the BB-8 character from Star Wars. So there's a guy with a gun in the building, and I get that little ball with the camera and just send him in there... Reconnaissance. We don't need the tact robot with the arms. We just need that little ball with the camera." (LE-U-013)

"We had an 80-car pile up here on the [highway] here... it took them over an hour to really get a handle on the number of victims... And it was on an elevated part of the expressway, so you really couldn't get a lot of foot traffic up there... [a drone] could have just flew up and down, up and down, and it could have got a really good handle on what they needed as far as resources go. And resources for an incident like that are critical for life-saving. Do we need five ambulances or 50 ? And if they don't know, now the people that need them the most are going to have to wait the longest. So that's not good." (FF-U-029)

Responders were also cautious of how drones would be used, as well as how their use was perceived by the public. However, they thought in certain situations drones would be a worthwhile technology, stating the advantages of their use.

"I wouldn't be a big fan of [drones] for routine patrolling and that kind of stuff. It is a little too big brotherish for me. But for a barricade, being able to put a drone up to get a view of the house the person barricades in, or looking for lost people in [the park] or something, I think they'd be phenomenal." (LE-U-029) 


\begin{abstract}
"There's a lot of concerns with [a drone] program, and I completely understand that. But for that fire, that gave it an overhead perspective. It was a large building fire, huge, of which, the operation section chief could look down, and he's like, 'Good, we've got everything in place.' But for us to get a helicopter up and do the same shot, it's not only thousands of dollars more per hour, we just don't have those resources. I mean, they're busy. They're doing other things. My buddy's a helicopter pilot for [state highway patrol], and they get to fly just a few hours a day because of the cost these days. It's just expensive. So, yeah, drone technology is pretty amazing." (PS-S-0012)
\end{abstract}

\title{
4.3. Categories
}

In this section, the list of the categories, subcategories, and their descriptions are provided for both currently experienced problems and new functionality requested. While the categorical data are not reported in their entirety, the categories and subcategories relevant to the PSCR community are reported. Results of the qualitative analysis of the categorical data are presented in tabular format, for both problems (Sec. 4.3.1, Table 4) and requested functionality (Sec. 4.3.2, Table 5). Noted in these tables are the categories and subcategories expressed by the corresponding discipline. The icons used for the notations are defined in Table 3 below.

Table 3. Category Tables Reference Notations

\begin{tabular}{ll}
\hline $\begin{array}{l}\text { Problems } \\
\text { Icon }\end{array}$ & $\begin{array}{l}\text { Requested Functionality } \\
\text { Icon }\end{array}$ \\
\hline
\end{tabular}

\begin{tabular}{lll}
\hline- & $\begin{array}{l}\text { The shaded dot represents a frequently discussed problem } \\
\text { or functionality request of first responders }\end{array}$ \\
\hline$\circ$ & $\begin{array}{l}\text { The hollow dot represents a problem or functionality } \\
\text { request expressed by first responders }\end{array}$ \\
\hline
\end{tabular}

While these notations are intended to provide useful insight into the interview data, the icons do not indicate that a subcategory is exclusive to a discipline. Likewise, the absence of an icon does not categorically indicate a lack of problems encountered, nor a lack of requests for functionality, merely that first responders didn't mention it in the interviews. It should be noted that, as this is a qualitative analysis, first responders' problems and functionality requests are not binary in nature; context of use should be considered as each subcategory description is not a blanket statement for a discipline.

All categories and subcategories presented in this section are arranged from most discussed problems and most requested functionalities requested to the least, in proportion to the first responders' quotes in the dataset. The problems categories (Sec. 4.3.1, Table 4) and requested functionality categories (Sec. 4.3.2, Table 5) may contain some overlap due to the nature of the participant responses (see Sec. 2.2). The categories between the two lists should not be considered redundant, even though some category

\footnotetext{
2 The PS notation refers to "Public Safety" interviews, where the first responder was cross-trained in FF, LE, and EMS disciplines.
} 
names may appear as the same. Highlights from each discipline and exemplar quotes for each subcategory here can be found in Sec. 4.4. For access to the full dataset, see Sec. 5.1.

\subsubsection{Currently Experienced Problems}

Table 4. Problems Categories by Discipline

CURRENTLy EXPERIENCED Problems

Radio

Dead zones

Areas where radio coverage is poor or nonexistent

Traffic

Problems with jammed radio channels due to reasons such as only one person can talk at a time; people communicating too much

Channel switching

Problems finding and/or switching to the appropriate radio channel, or radio channels becoming out of sync

Usability

Problems with physical aspects of the radio, e.g., accidental button activation

\section{Reliability}

Unreliable technology

Problems with unreliable technology

Redundancy

Backup plans needed due to unreliable technology

Unreliable transmissions

Uncertainty about whether messages have been properly sent/received

\section{Interoperability}

External interoperability

Interoperability issues communicating with other disciplines, jurisdictions and agencies

Internal interoperability Issues with technology and data not being integrated, not communicating with each other, and often times from different vendors

\section{Physical Ergonomics}

\section{Robustness}

Problems with technology not being durable enough

\section{Battery problems}

Problems with battery - e.g., doesn't last long enough, compatibility, charging issues

\section{FF EMS LE COMMS}

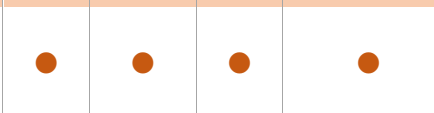

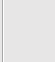

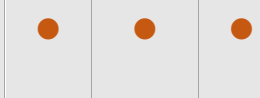

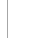
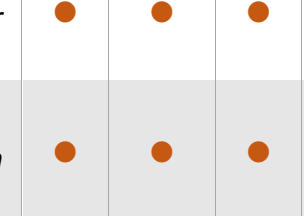

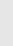

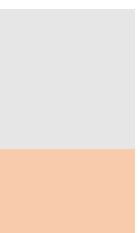

$+$

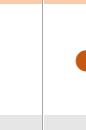


Bulky and heavy

Problems with device's big size and/or heavy weight

Too many devices

Problems with carrying too many devices

Physical discomfort

Technology causes physical stress on body

Display size

Problems with legibility if screen is too small

Safety concerns

Technology putting officers at risk

\section{User Interfaces}

Ineffective and inefficient

User interface not designed to be intuitive, user-friendly, or consistent; not supporting users' needs

\section{Alerting}

Problems with user interface that provides warnings or alerts to users

Modality

Inappropriate modality (e.g., visual vs. auditory)

\section{Implementation/IT Infrastructure}

Implementation/Installation issues

Problems with implementation and/or installation of technology

\section{Cost a prohibitor}

Expensive technology preventing adoption

IT management

Problems with having adequate IT management

No user requirements collected/considered

Technology implemented without users' input

Public safety network reservations

Concerns with the implementation and/or operation of a large-scale public safety communication network (e.g., service provider, coverage, quality, bandwidth)

\section{Security Constraints}

Authentication

Problems with the authentication process, multiple system logins, or passwords during incident response

Access control

Responders not able to use all technology/functions 


\section{Technology Outdated}

\section{Outdated}

Problems with aging, outdated technology

Incomparable to personal technology

Problems with technology being incomparable with personal technology available commercially

\section{Connectivity}

\section{Reception}

Dead-spots within cellular reception or connection not always stable

Bandwidth issue

Bandwidth issues with wireless connection

\section{Audio Clarity}

Hard to hear

Difficult to hear due to technology, background noise, sensitivity of worn microphone/radio position, or SCBA mask

Audio feedback

Audio feedback causing static or noise on channel

\section{Microphone/Earpiece}

\section{Cord}

Microphone/earpiece cord susceptibility to melting, entanglement, becoming disconnected, or problems integrating into uniform

\section{Earpiece}

Problems with earpieces or earbuds (e.g., hearing loss concerns, fit)

Wireless microphones

Problems with pairing wireless microphones

\section{Overwhelmed}

\section{Sensory overload}

Problems with handling a lot of things concurrently while actively performing primary task

\section{Situational awareness}

Technology can be distracting, requiring responders' attention

\section{Body Camera}

\section{Functional issues}

Problems with video quality, data transfer, accuracy of scene capture, additional operational tasks, etc.

Physical issues

Problems with placement (e.g., video occlusion) and placement mechanism 


\section{Technology Overrated}

Problems with new technology

New technology functionality doesn't meet expectations (e.g., disappointing, time consuming)

Doesn't solve communication problems

Technology can enable communication, but is not necessarily the answer to communication problems

\section{Mobile Data Computer (MDC)}

Navigation/ Mapping

Navigation/Mapping inaccurate and/or not available

Functionality

Lack of functionality or functionality seldomly used

\section{Calls}

\section{NG 911}

Concerns about excessive contextual information via visual input to 911, lack of contextual information via text to 911, or information transfer interference with callers' 911 apps

Caller location

Problems with identifying caller location especially with cell phones

Nuisance calls

Accidental non-emergency calls, e.g., pocket dials with cell phones, smart watches and medic alert buttons

\section{Disruption of Operations}

\section{Continuity of Operations (COOP)}

Problems with separate communications centers, lack of redundancies (e.g., trunk lines, cell towers), etc.

Mobile operations Problems with functionality available (e.g., mobile truck unit, VPN)

\section{Video}

\section{Data issues}

Problems with storage, quality, or interoperability among systems

Surveillance videos

Problems with using surveillance videos 


\subsubsection{New Functionality Requested}

Table 5. Requested Functionality Categories by Discipline

NEW FUnCTIONALITY REQUESTED

Real-Time Technology

Live video \& images - capture/live feed technology

Technology to record and disseminate videos and images live to responders and incident commanders (IC) en route and on scene

Traffic \& Navigation

The need for real-time traffic information and/or GPS navigation en route to an incident

Drones

Technology to assist first responders during incident response, en route or on scene

Language translation

Technology used to communicate effectively with the public without going through a third party

Identification device

Technology used to efficiently and effectively identify a victim or person of interest on scene (e.g., mobile fingerprint reader, iris scanner)

\section{Functionality}

\section{Reliability}

The need for technology to work when necessary and how expected

\section{Better coverage}

The need for improved connections to radio or cell towers from any location

\section{Clearer communications}

The ability to hear and be heard more clearly via technology

Improved functionality

Instead of new technology, improve functionality of current technology to be more effective in assisting first responders in completing their tasks

Longer battery life

The need for device batteries to last the duration of an incident

Faster devices

The need for faster technology

\section{User Interfaces}

\section{User friendly}

The need for technology that assists responders in completing their tasks by designing device operations to be efficiently and effectively completed in one simple step, not a series of complex steps

\section{FF EMS LE COMMS}

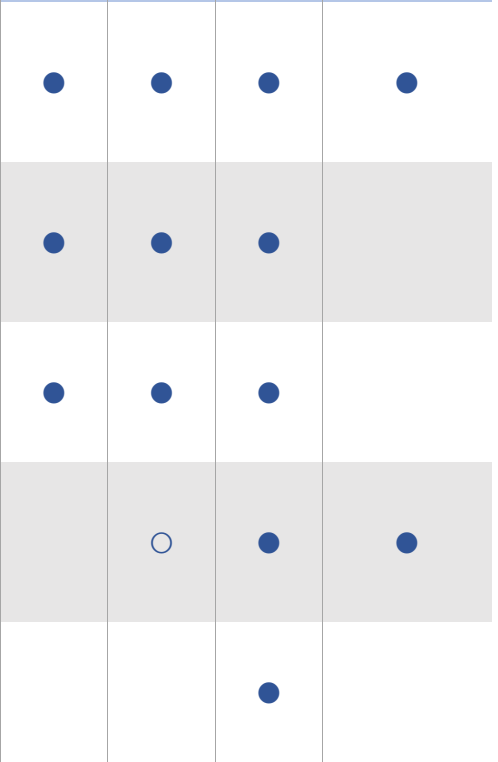


Hands free

Technology that can be operated without the use of first responders' hands

Non- verbal communication

The transmission of information using methods alternative to voice communication

\section{Tracking}

\section{Responder location}

Technology that provides the accurate location of responders and responding resources both inside and outside of structures (e.g., number, discipline, location, direction)

Caller location

Technology that allows responders to pinpoint from where a 9-1-1 call originated

Search technology

Technology that assists responders in search and rescue for victims (e.g., sonar, drones) or finding persons of interest (e.g., cell phone pinging)

\section{Interoperability}

Software/Hardware compatibility

The need to operate a variety of hardware devices and software systems seamlessly (e.g., RMS and CAD)

Interagency communication system

Technology that makes it possible for responders to communicate between public safety disciplines, jurisdictions, and agencies, either locally or statewide

\section{Patient care reporting (PCR)}

Technology that has the ability to send patient information to the hospital and other entities that provide emergency medical services during incident response

Body camera integration

The need for body camera technology to be integrated with other technology used for incident response, e.g., facial recognition systems and other camera systems

Interjurisdictional criminal data

Technology that allows information sharing about criminals between jurisdictions

\section{Physical Ergonomics}

Smaller and lighter

The need for technology to be smaller and lighter, enabling easier portability

Fewer devices

Minimizing the need to have too many devices 


\section{Robustness}

The need for technology to be more durable

Larger devices

The need for certain devices to be larger (e.g., buttons, keyboards, screens)

\section{Integrated Gear/Wearables}

HUD

The need for a heads-up display built into the SCBA mask, and for it to display specific information, e.g., air tank levels, CO levels, thermal imaging, responder location

In-mask microphone/earpiece

The need for a microphone inside the turnout gear instead of having to speak into the radio via mask amplifier

\section{Responder vitals}

Sensors and other technology built into the turnout gear that monitors health and safety status of responders

PPE technology

The need for various types of technology built into responders' gear

\section{All-In-One}

Cell phones and/or radios

The need for hardware and software applications to be built into smartphones, or for multi-functional radios (e.g., phone-radio combination device)

Tablets

The need for tablet computers to be used as all-purpose devices, incorporating various software applications

Software \& Apps

The need for various software applications or mobile apps to be combined into one for improved efficiency and to reduce duplication of effort

General multifunctional devices

The need for devices to serve a variety of purposes, combining multiple software applications into one device

\section{Cameras}

The need for hardware and software applications to be built into photo and video cameras

\section{Futuristic}

\section{Media/Science-fiction influenced}

Advanced technology that replicates or repurposes what is used in mainstream media, e.g., Minority Report movie, Iron Man movie 
Smart buildings

Buildings with sensors and other technology built-in to provide more information to responders during an incident

Face and object recognition software

Technology that has the ability to identify people and specific vehicles based on their appearance

Self-driving vehicles

Automated vehicles that do not require a driver

Augmented reality (AR)

Technology that can be used to enhance responders' environmental information during incident response

Emergency traffic light system

Traffic lights that adapt to emergency vehicles, changing traffic signals to allow vehicles responding emergent to pass through intersections

\section{Microphones/Earpieces}

\section{Wireless}

The need for cordless microphones and/or earpieces

Specialized earpieces

Custom earpieces that permit non-radio sound to be heard while the earpiece is in use

\section{Radios}

\section{Channel switching}

Non-manual radio channel switching capabilities, either automatically by location or remotely by dispatch

Multiple talk groups

The need for a variety of different avenues for communicating on the radio

Prevent accidental transmissions

The need for devices to guard against unintentional radio use

\section{Mobile Apps}

\section{Information references}

Mobile apps that provide access to the internet for databases of searchable, downloadable, or printable information

\section{Discipline-specific apps}

The need for specific apps (e.g., e-ticketer or license scanner for $L E$, asset tracking for FF) 


\section{Vehicles}

Windshield HUD

Technology built into the windshield of police vehicles that displays relevant incident information

Built-in camera

The need for a camera to be mounted on the dashboard or in rear of vehicle

Automatic license plate reader

The need for technology that automatically scans and flags license plates from the vehicle without officer actions

\section{Dashboard computer}

The need for CAD technology to be built into the vehicle's dashboard

\section{Usable Security}

SSO

The need for single-sign on capabilities to simplify authentication across apps

\section{Communications Center Technology}

Improved dispatch interface

The need for dispatch-specific interfaces to be more useful and intuitive

Multimedia data packages

The need for call takers to be able to receive information in other

methods, e.g., video

Access to caller cell camera

Technology that would allow COMMS to activate and view the caller's camera to see the caller's environment

Large multi-view display

The need for multiple computer monitors setup in the control room

\subsection{Discipline-Specific Findings}

While there are a number of commonalities across disciplines, each discipline faced its own set of challenges based on its unique environments and tasks [2]. This section reports a more complete view of the categorized problems and requested functionality data, centered around each individual discipline. It opens by highlighting the most pressing and most unique problems and requested functionality of each discipline. Following these highlights are visual representations of the categories by discipline (Fig. 6 - Fig. 13) and exemplar quotes for each subcategory. The categories and subcategories presented are arranged from the most discussed problems and most requested functionalities to the least. 


\subsubsection{Overview of Disciplines}

All disciplines are well known to have issues with radios and radio use. Next to radio problems, the most pressing problems categories for each discipline are listed below. While these categories reflect major issues within each discipline, they are not isolated to the discipline noted.

- FF: Reliability

- EMS: Reliability

- LE: Interoperability

- COMMS: 911 Calls

Likewise, the most important functionality requests for each discipline are listed below. However, as in the problems data, these functionality requests are not isolated to the corresponding disciplines.

- FF: Real-Time Technology

- EMS: Functionality

- LE: Interoperability

- COMMS: Tracking

The remainder of this section presents the most unique discipline-specific problems and requested functionalities. Unlike the most pressing problems and requested functionality categories listed above, these are those categories that stand out from the other disciplines due to unique environments and tasks. These unique categories are summarized in Table 6.

Table 6. Most Unique Discipline-Specific Problems and Requested Functionality

\begin{tabular}{|c|c|c|}
\hline Discipline & Top unique problems & Top unique requests \\
\hline $\mathbf{F F}$ & Audio clarity & Technology integrated into PPE \\
\hline EMS & Transmitting patient information & $\begin{array}{l}\text { Interoperability of ePCR and EKG } \\
\text { with external systems }\end{array}$ \\
\hline LE & Body camera safety and usability & SSO; vehicle windshield HUDs \\
\hline COM & $\begin{array}{l}911 \text { call technology; continuity of } \\
\text { operations preparation; } \\
\text { implementation and infrastructure }\end{array}$ & $\begin{array}{l}911 \text { caller tracking; improved } \\
\text { dispatch and camera interfaces }\end{array}$ \\
\hline
\end{tabular}

FF

Firefighters reported experiencing many technological problems - one unique challenge during firefighting being audio clarity. On a noisy fire ground - with deafening sirens, chainsaws running, fire burning/crackling - it is hard to talk or hear, especially since firefighters often have to talk through a mask that muffles their voices. In addition to wanting clearer communications on the fire ground, firefighters also uniquely requested technology to be seamlessly integrated into their PPE and SCBA. Firefighters feel that technology such as HUDs and in-mask microphones and earpieces would have a major impact on firefighters' approach to incident response. 


\section{EMS}

Unique to EMS personnel are problems with transmitting patient information to hospitals and other medical providers (e.g., Red Cross). They feel the interoperability of their electronic PCR and EKG systems with external systems will reduce their workloads, and minimize their effort and stress, and improve patient care and outcomes.

\section{$L E$}

A unique technology challenge for police officers is a byproduct of the increasing use of body cameras. While police officers recognize the benefits of body cameras, they expressed concerns with the burdens of their use. For example, having to remember turning it on and off; the difficulty with having it attached to their uniforms, especially while performing strenuous physical activities; and issues with uploading videos. There are also concerns about officer safety, for example, the flashing light on the body camera could reveal their location; the distraction caused when turning on the body camera while facing a suspect. While body camera improvements are clearly needed, more prominent in the requested functionality data for law enforcement officers is for usable security on their devices (e.g., SSO), as well as integrated vehicle systems (e.g., HUDs integrated with their windshields).

\section{COMMS}

Communications center personnel identified problems in three unique areas: 911 incoming calls; preparations for continuity of operations (COOP); and implementation and infrastructure problems. Interestingly, many of the problems expressed with incoming 911 calls result from callers' use of newer technology. Such problems include loss of contextual information from text messages to 911, nuisance calls (pocket dials) from cell phones, smart watches and medical alert buttons, and an abundance of incident calls from well-meaning on-lookers with cell phones. Similarly, the most pressing functionality requested for communications center personnel is to be able to track the precise location of 911 callers, which is particularly an issue for accurately locating callers using cell phones, because many callers do not know where they are or have trouble articulating information about their precise location. When COMMS personnel have an accurate caller location, they can more effectively communicate incident information to the units responding to the scene.

Unsurprisingly, the second concern is for appropriate preparations for continuity of operations in the event the communications center is incapacitated. While all disciplines expressed problems with implementation of technology and infrastructure, communications personnel are in a unique position in that many are required to be interoperable with all responding disciplines. Finally, within the COMMS environment, personnel expressed the unique request for improved dispatch and camera interfaces. Whether it is a display with multiple views, a wall of monitors for street cameras, or something more futuristic like the visual and gesture-based interfaces seen on modern crime television series, COMMS personnel want improvements made to the way they interact with their technology. 
4.4.2. Problems and Requested Functionality Data

\section{FF Technology Problems}

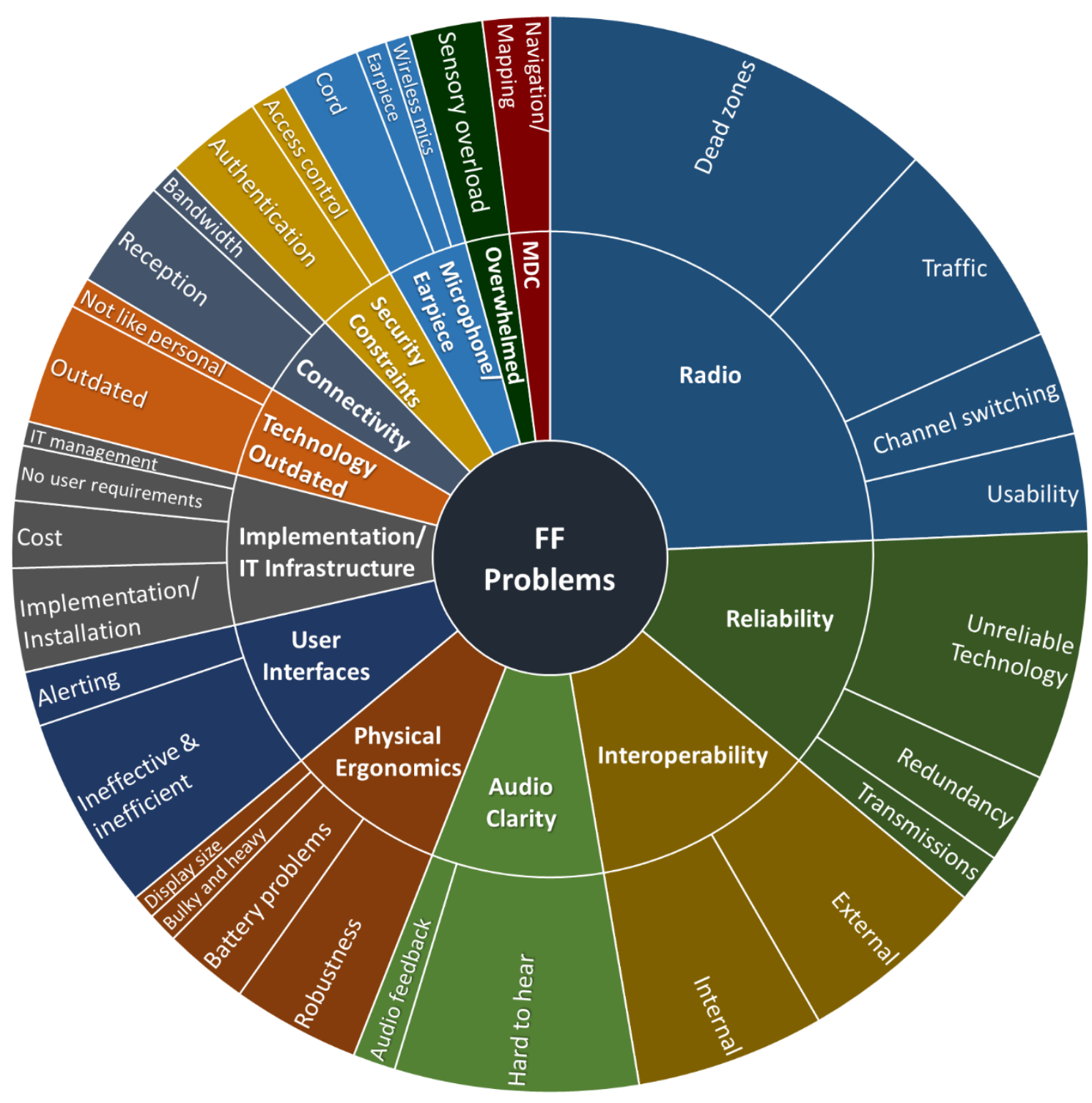

Fig. 6. FF Technology Problems Categories and Subcategories 


\section{Radio: Dead zones}

"So we have an older legacy building that we've never had problems with, they put up a new high rise next to it, oh, all of sudden we've got a problem there. So that's become more and more of a problem, that even though the new buildings we generally have good coverage because of the code requirement, we're overall seeing a degradation in our coverage level in those urbanizing areas of the county because of the interaction of the buildings with the existing coverage, the new buildings with the existing coverage." (FF-S-040)

\section{Radio: Traffic}

"Everybody has something to say about what they see or what they're doing. And everybody thinks it's the most important thing out there, right? But if you all try to say at one time then nobody's getting through and you get bogged. Only one person is going to get through at a time in one type of a channel. So if you have 30 people there in certain portions of that building or under whatever they're going through, someone's going to be waiting a while to get on the air. And it's hard." (FF-S-035)

\section{Radio: Channel switching}

"But we do have the capability to talk to them if everybody moves to these certain channels. But they're so rarely used that a lot of our guys, they have to search for them. They're literally going bank to bank in the radio to try to find it." (FF-R-024)

\section{Radio: Usability}

"Emergency activations are a huge problem on fire grounds because you've so many people moving around with the radios positioned in different spots... And then you're trying to, in a smoky building where you can't see anything, there's zero visibility, one, figure out if you're the one who did it, with everything else going on, and then you're trying to reset it with a gloved finger in a lot of cases. So it's just that's a huge thing... God forbid you hit the emergency button and you have the ruthless [preemption] or whatever the hell it's called. Then you literally have priority on the channel and there's no way anybody would ever be able to talk over you. That's a huge issue." (FF-U-042)

\section{Reliability: Unreliable technology}

"The tablets [MDC], they're not reliable... We were going to the tablet shop almost every day because the way that the bracket and the way it was mounted in there, the tablet would shake so much that essentially it'd just shake the thing to death and it would just crash. In the docking port, it would not get a charge because anytime you were moving, it wouldn't be able to keep the connection so it would just die all the time. That's across the board." (FF-U-042)

\section{Reliability: Redundancy}

"Being a very active community we do a lot of back country rescue and communications again is one of our biggest issues so we kind of look at different ways that we can improve communications and have backup communications for those responders that are going out into the field because especially during winter with avalanches there's so many additional hazards that the responders face out there added on top of it." (FF-R-054)

\section{Reliability: Unreliable transmissions}

"And in order for it to be officially termed a communicative process, there has to be feedback, right? Without feedback, how do you know if the message was actually perceived on the other end by whoever transmitted it in a proper way, or was that information disseminated properly from one place to another." (FF-U-029) 


\section{Interoperability: External interoperability}

"We have four different dispatch units that we have potentially to interact with, and they're all operating on different CAD systems... So we have a lot of interoperability challenges." (FF-S-035)

\section{Interoperability: Internal interoperability}

"The vendors, the 50 , or 100 , or whatever, they've really focused on one area. And they try to do the other two or three things, but they never do them well. And so we've created work-around after workaround to try to get everything to work, but it doesn't work well. It creates a ton of work on our side to be able to make all of this work." (FF-S-022)

\section{Audio clarity: Hard to hear}

"And depending on what's going on inside with other noises and things, that can sometimes challenge it. But every once in a while you get a garbled communication coming from somebody wearing a mask just because of placement of the radio and where they're talking." (FF-S-038)

\section{Audio clarity: Audio feedback}

"If I have my radio up too loud and my officer's next to me, we get feedback. So you got to be careful of that. And it may not even be my officer, it may be the next firefighter next to me. So then if your radio is down too low, then [you can't hear]." (FF-S-022)

\section{Physical Ergonomics: Robustness}

"There could be a problem with the portable radio if left outside of your protective equipment due to thermal insult or a thermal exposure to it. Yeah. You'll melt the thing and it becomes useless, then you've got to rely on yelling, or if you're lucky enough, escape a pre-flashover. So if worn right, worn correctly, and following the procedures or guidelines of the fire department, it won't fail you. Most of those things that occur in the fire service, a lot of it is then human error and miscommunication. Communication is a big factor." (FF-U-028)

\section{Physical Ergonomics: Battery problems}

"Everything has to be powered. How are we powering it? And power is your limitation. And it could be a cord or battery or fuel, but that is your limitation. And how do you extend that and get more efficiency and more power? Got to get that too because it's got to be more effective." (FF-U-012)

\section{Physical Ergonomics: Bulky and heavy}

"We explored a TIC that was integrated into a helmet. It was about $\$ 1$ million a piece when we were looking at, and it proved to be a very cumbersome piece of technology. It was 10 years ago, so the screen was really thick. The camera was really heavy. It added another 10 pounds to somebody's head... And if you'd look like an orange sitting on top of a toothpick, that's basically what it was. So it just proved that it just wasn't a good technology." (FF-S-022)

\section{Physical Ergonomics: Display size}

"I can't read so much information on a small screen like that, not while I'm en route. It's not going to happen. I mean, I may try, if I have a moment or two to glance at it, but--It's too much, yeah. And I have a lot else going on. In high-traffic times when we're responding, I'm actually helping the driver. I'm always scanning because he may not see somebody." (FF-U-029)

\section{User Interfaces: Ineffective and inefficient}

"The way the CAD vendors do it, it just dumps whatever information is in the CAD remarks all into one rather than actually having it more 
of a filtered stuff. I don't care what the contact log information is. It should be in the background. I just want the actual remarks." (FF-U042)

\section{User Interfaces: Alerting}

"Well, you got 10 of us in a smoky room and somebody's bell starts sounding. You didn't know whose it was. And normally, the guy it was, was so focused on whatever he was doing or she was doing that they didn't think to reach back and see if it was them. So everybody's hearing this bell... And the speaker diaphragms on our SCBA that we're trying to use to communicate on our radio are right next to the regulator. So if the vibralert is sounding, that's a barrier to communications." (FF-S-040)

\section{Implementation/IT Infrastructure: Implementation/Installation issues}

"And then all of a sudden, the computers don't run on certain programs. So then you got to get rid of that program, and then you end up with a new program. So it's constantly changing." (FF-S-022)

\section{Implementation/IT Infrastructure: Cost a prohibitor}

"Well, they make [TIC] now where it can be embedded within your SCBA mask, so you don't have to carry a camera. It's like Terminator vision, right? So those kinds of things actually do exist. They're just incredibly cost prohibitive." (FF-U-012)

\section{Implementation/IT Infrastructure: No user requirements collected/considered}

"So each apparatus phone could only hold 200 numbers. You cannot add numbers, which is problematic for us because we communicate on a daily basis with the $\mathrm{FBI}$ and Secret Service and other law enforcement agencies. And yet the 200 numbers is filled up with lots of useless numbers of different firehouses that we're never going to need to call. So I think the person who implemented that program never talked to the end user of what they actually wanted, or expected, or could use." (FF-U-044)

\section{Implementation/IT Infrastructure: IT management}

"Now it's not a large enough department to continue to improve [the technology developed in-house] and deal with all the bugs, so we've had some issues on that front." (FF-S-032)

\section{Technology Outdated: Outdated}

"When a fire is paged out here they may page out the appropriate response it may or may not go out over the radio. We have somewhat of an outdated underfunded antiquated communications here in our county." (FF-R-049)

\section{Technology Outdated: Incomparable to personal technology}

"So on the squad, our systems are so dated. So Google Maps doesn't really work and they're not precise, so we rely a lot on our phones. So a lot of firefighters-- if I'm driving the squad I'll have the person behind me go, 'Can you map this out and tell me directions over the headsets?'” (FF-U-011)

\section{Connectivity: Reception}

"And whether you're using the web-based server or you're using cellular technology, there is that communication link break down. So there isn't cell reception everywhere around here. There's times when you're on a call, or you're going to a call at two in the morning, and you log onto the database and the server, where ever it is, is updating. And so you can't input any information and you're forced to write it on a piece of paper and then put that information in later." (FF-S-031) 


\section{Connectivity: Bandwidth issue}

"But every once in a while, that becomes an issue because during these events you put more resources in one area all competing for the bandwidth of one tower." (FF-R-008)

\section{Security constraints: Authentication}

"Enter a password, and a username, and everything else, and hit the right button, while you're bouncing down the street, or it's dark out. It's two in the morning. That's where that interface of, 'Okay, do I really need to logon each time I use this thing?'" (FF-S-031)

\section{Security constraints: Access control}

"When you have the IT Nazis, it's easier to just say no and lock it down, as opposed to make it useful for other purposes. We've got a $\$ 10000$ computer system in each of these apparatus, and all I can do is push a button, I'm on scene or I'm not. But if I wanted to get Google, and say, 'Okay. Well, what is this material that's in a hazmat event?' Well, now I've got to use my phone. That doesn't make sense." (FF$\mathrm{R}-008$ )

\section{Microphone/Earpiece: Cord}

"So firefighters are trying to develop ways to protect their radios. So some of them will wear them underneath their protective coat to protect the radio. The problem with that is that might interfere with the signal and the reception then. We also have the extended mic cords. So you got your radio in your breast pocket, and then the cord because that's the speaker. So that we can also hear-- we have to have the speaker close to our face so we can hear and then talk into the speaker. But those cords aren't rated for heat. One huge place where those radios can fail is the cord. If they're exposed to 160 degrees, they could fail." (FF-S-033)

\section{Microphone/Earpiece: Earpiece}

"We recently got the wire earpiece, kind of like a Secret Service agent, if you want to call that. But you've got to remember to put that on before you put a mask and helmet on, because once all that stuff's on, you can't get it back in without taking it off." (FF-U-030)

\section{Microphone/Earpiece: Wireless mics}

"The mic in the fire service has become kind of a big issue. We're pretty early adapters at [city]. We tried a Bluetooth system. And the problem with a Bluetooth system is it has to pair every time you turn it on. And it doesn't always pair. And then you're trying to smash the button to make it pair. And so we got rid of it." (FF-S-022)

\section{Mobile Data Computer (MDC): Navigation/Mapping}

"It's expected that you should know your area and know how to get there. We'd have just that function on our MDCs that we can route to a call. Maybe that is the biggest problem we have with technology, it's just horribly out of sync and, you get turn right now, you know. Five miles after your-- or, just continue ahead, and, it's just kind of odd directions." (FF-U-007)

\section{Overwhelmed: Sensory overload}

"So I call that saturation overload. And that happens a lot on incidents that are kind of beyond your scope. Obviously, a medical call is within your realm or your scope. It's easily handled. Bigger the incident, you're dealing with the human factor, the mind at the process. But if you coupled that with more degrees of difficulty with today's technology, you run into a-- it's like two trains running into each other. I have to go and get data from here, or from this computer, I have to listen to this radio, this channel has 20 different 
frequencies, 10 different-- there is a point that says keep things simple and you do have to-- because of the task at hand." (FF-U-028) 


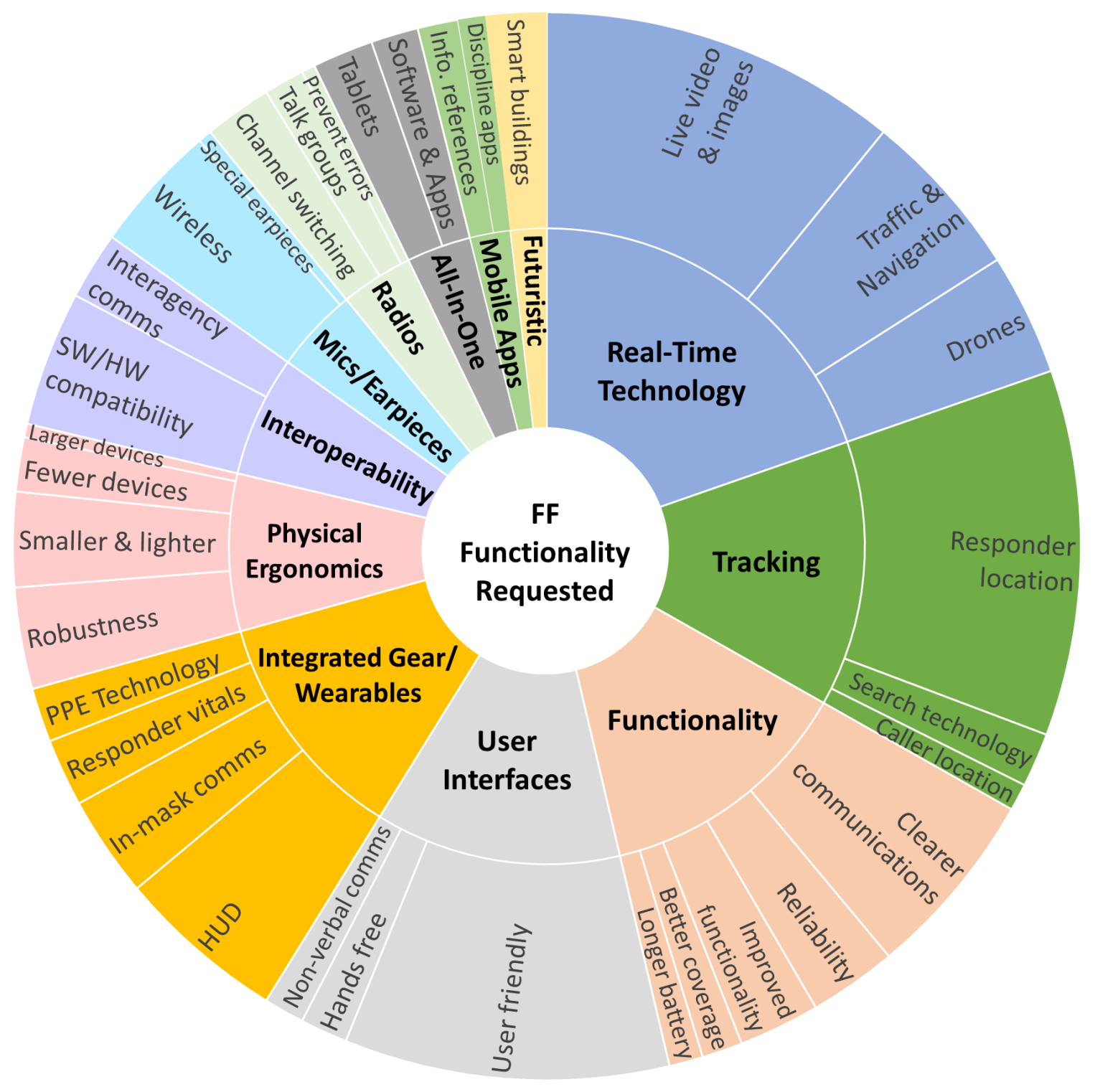

Fig. 7. FF Requested Functionality Categories and Subcategories 


\section{Real-Time Technology: Live video \& images}

"The MDTs have the ability to take pictures. So let's say I go on a hazmat, and I want to take a picture of said white substance so I could pass it back out to the hazmat unit. I mean, in theory, the way the infograph program works, I should be able to take a picture and send it in a message. It would never send the-- it would never send the picture. I could send messages, but I could never send the picture... So I don't know if it's a capacity thing, or if it's blocked, or what the issue was. But I was like, this would be a great thing. I'm the first unit in on this hazmat call, and they want more information on it, and I just go Yeah, 'Here you go.' And, in theory, it's on our secure network and all that stuff, so." (FF-U-043)

\section{Real-Time Technology: Live video \& images (aerial)}

"So earthquakes and special events, they're kind of the same thing. I want the ability to do live satellite mapping... I still have to go out in a fire engine and drive every single street and do a windshield survey of my district to know what's going on in it. So what's the answer to that? Live satellite mapping. I need to be able to tap into a satellite 15 minutes after an earthquake and go, 'That block is devastated. This one's fine. This school got 300 kids in it, but it didn't collapse. It's okay. We don't have to go there.' And so forth. So that live satellite mapping is huge. So when it comes to special events, same thing. How do I monitor my special event live with that kind of aerial view?" (FF-U-016)

\section{Real-Time Technology: Live video \& images (perimeter)}

"When we're responding to calls. I think two things. For me, I think it would be awesome to have real-time video of locations and whether it would be something with a satellite kind of thing or whatnot. And that's been talked about before where every street has cameras. And you're going to this address, and you hit this button or maybe the main can tell you, but you hit this address and it pops up, a camera pops up and gives you a good, real-time, visual shot of that street. And you could look for, "Is there smoke blowing across the street, or is there--?" So that would be awesome." (FF-U-025)

\section{Real-Time Technology: Live video \& images (other visual)}

"I would just love to see a manageable picture from [reporting party] to end user, a way to-- a picture's worth a thousand words. Let's get those pictures out there. And I know dispatchers might not want to see that or whatever... So a picture's worth a thousand words, and I think that's the other thing. Get it out there." (FF-R-019)

\section{Real-Time Technology: Live video \& images (interior)}

"So we're on a subway issue and sometimes radios don't work underground. And [chief], calling me on my personal phone, Facetimed. He's like, 'Hey look, we're going down here. Come on, come with me.' He's like, playing. He thought it was so funny. He was like, 'Here, watch the incident.' He pointed it towards with this thing sparking. So I'm upstairs in my buggy, Facetime. I can see what's going on in the tunnel... So yeah, there's technology out there and a lot of us want to use it and adopt it." (FF-U-044)

\section{Real-Time Technology: Traffic \& Navigation}

"[Something] they should have done years ago, [is] more of a GPStype direction of travel, which is huge. City's big. And if you are moving around from one area to another, say, I was a relieving officer, so I would go this firehouse and to that firehouse and then that district. So there was a lot of areas where I wasn't real familiar with, so even going from point A to point B, I couldn't tell you. So it would be nice to have that immediate, boom, hit a button. It shows you the travel route, just like the GPS that we use to go anywhere else, should pop up immediately and give you the quickest route and the more-- so those kinds of things are coming, hopefully." (FF-U-025) 


\section{Real-Time Technology: Drones}

"I thought that would have been a great thing, if we could actually fly a small drone into a fire building just to get a handle on number of victims, where they're located, fire conditions, things like that." (FFU-029)

\section{Tracking: Responder location}

"We talked a little bit about whether it's on the radio, or on my air pack, or my SCBA or something, but the ability to track me from the outside. For the chief, to be able to look at a computer screen, outside, and watch where I am in the building... A breadcrumb so that if something happens to me and I push this orange button and I say, 'I'm in trouble.' ... He can show everybody he's right here. Go get him. We just killed a firefighter in [city]. They looked for an hour for him. They couldn't find him. So those are the big things in technology I'd like to see." (FF-U-002)

\section{Tracking: Search technology}

"So I wanna see a full-time drone unit. I think it would be very beneficial to the fire department. Probably three people with a van at a station that could respond 24/7. We can save lives. It's not just to view fires. That's nice... But where we could really make a difference is out at [town] where we have a lot of cliff rescues and surf rescues and we can send the drone over, locate the actual victim. Because we spend a lot of time searching for the victim because it's very difficult to get an exact location on a cliff where you can't see the bottom... there's great benefits out there to save life with a drone, but we don't have the staff. I mean, can you imagine going to the mayor, 'I'm going to hire three more people and pay the drone unit."' (FF-U-016)

\section{Tracking: Caller location}

"So knowing where the-- so we spend half our time trying to figure out where the emergency is. So if we could use technology to better locate people, whether it's through cell phone pinging and-- I don't know if that's-- if I've watched too much TV. But we can translate cell phone GPS coordinates... And then layer that onto my map so I know exactly where to go." (FF-U-044)

\section{Functionality: Clearer communications}

"So I would like the ability with all the gear - since we're talking about communication - better communication with the people immediately around me. Specific to structure fire use. We live in a world now where once I put all that gear on, I could scream at the top of my lungs, and you would be hard-pressed to understand what I'm saying. And so, we turn to things like voice amplifiers and that technology. We're currently trying to test some Bluetooth technology on. When I'm in a big room with a group of firefighters, as a captain, trying to say, 'I want you to knock down that door. And I want you to spray that hose line. And I want you to break out that window.' I have to walk and slap you on the shoulder and do this, because I have a big muffle right here." (FF-U-002)

\section{Functionality: Reliability}

"Just better reliability. I actually don't like the technology as much or using it as much. I think we rely on it too much." (FF-U-042)

\section{Functionality: Improved functionality}

"Half the houses in this [county] have been up for sale at some point in time. So the floor plan of those houses are available. And, you know, it's all public out there. You just got to go out and get it and put it in there and the tie it in to be able to use it. That's a problem. 
We don't take that data and mine it and then regurgitate it when we need it. And 'cause we don't have the systems to do it." (FF-R-051)

\section{Functionality: Better coverage}

"I'd like to have radios that I know work all the time. Get through whatever we need to get through, be it a high rise or subway incident or anywhere." (FF-U-027)

\section{Functionality: Longer battery life}

"The question of anything technology for the fire service, is it's already there at NASA, it's just not here, would be battery technology... Battery technology is always a limitation for any rescue service because-- how great is that radio? It's terrific. How long's that battery last? 45 minutes. Okay, so it's not that terrific, right? I could get you from Mars once, and then the battery dies, right? And that's with our thermal imagers, with our radios, with our rescue tools. You name it. We are limited by the distance of a power cord or the distance of battery. Or sometimes, if you are not going to go electric, the amount of fuel that you have to power the machine that's going to give you-- that you're bringing to the scene to-- you know what I mean? So I think battery life is the new future towards, how do we fix some of those problems you're-- if the batteries lasted longer on anything you have, everything would be better." (FF-U-012)

\section{User Interfaces: User friendly}

"In a perfect world, I could have my tablet and have my whole information come in. And I could hit a button, and go to a map view. And then, manipulate my map. And then hit another button and my pre-fire would pop-up. I wouldn't have to search for a pre-fire because right now, I have to search a little bit. And all that takes time. And this is all information that-- as a first to arrive an officer, you need to process it quickly so you can quickly formulate a plan and a strategy. And if you're spending your time waiting on technology then it's not necessarily going to be helpful. It's going to... be a hindrance. So those are things I'd like to see happen." (FF-S-033)

\section{User Interfaces: Hands free}

"Ideally, the squad-level stuff would be hands-free voice activated so that I've got a chainsaw or tools in my hand, but I can say in my protected environment, 'Hey Firefighter [name], can you help me over here with this?' Not having to key anything. Not having to push anything. And then Firefighter [name] hears and acknowledges and he comes to help me, in that regard. If I need to talk to command or something like that, then, yeah, push a button or something or key up and, 'Hey, this is ladder one. We need blah, blah, blah.' or something like that." (FF-U-030)

\section{User Interfaces: Non-verbal communication}

"There's always that potential to, in theory, provide more information upon dispatch... And again, to have it available. You don't want all that clogging communication radio traffic, but at least to have that available on MDC to look at and maybe have a better idea... So it's a building that I've never been to or I'm not familiar with, so that information would be even more beneficial." (FF-U-034)

\section{Integrated Gear/Wearables: HUD}

"A heads-up display in our face piece. So I've got the thermal imager attached to my face piece, so where I look, I've got a little heads-up display right in front of me. So I can either look out through my face piece and just see what's in the environment or I can glance down at that HUD and look through the thermal imager if the smoke is too thick for me to be able to see through otherwise. A HUD for the radio would not be a bad thing either. To put a display that mirrors the 
display on my radio so I can see what my coverage is, I can see what talk group I'm on. I can see all the stuff." (FF-S-040)

\section{Integrated Gear/Wearables: In-mask microphone/earpiece}

"I wish there were a way to somewhat similar to our AGA ${ }^{3}$ masks with diving under the water where I can be under the water blowing bubbles and I can hear my tender perfectly and he or she can hear me perfectly, yet in a structure fire... the incident communicator's like, 'Engine whoever that was, could you say your last transmission?' They're having a hard time because they've got their face piece on. The hoses are loud. The saws are loud. And the microphone is out here. My lapel mic is way out here or down here or somewhere out here. It would be nice to have it integrated somewhere near my ears. And I don't know if that ends up being something wireless. It seems like they could have something that would be more wireless that you could or when I was in the military, we used to use little, like a little throat thing. So you just put it on right here and then my transmissions are completely clear and an earbud piece that goes in your ear and now I can hear really well instead of this exposed to the environment and not close to my speaking thing and my hearing thing. So I don't know. For me that's, especially at the task level, when the firefighters are trying to actually communicate critical functions during critical times to an incident commander or to somebody else that's a supervisor of a task. 'Hey, I'm trying to get this done,' or whatever. We seem to be missing that piece." (FF-U-020)

\section{Integrated Gear/Wearables: Responder Vitals}

"Whatever NASA is doing could work for us because it's the same thing. It's emergency responders in a dangerous situation with a limited amount of resources and time. That you need to know

${ }^{3}$ The Divator diving mask is known as the "AGA Mask", since the first generation of the full-face mask was developed by the AGA Corporation. everything about them. If one were to go down, how to help them quickly. Their issue is distance and help. And for us, our issue is temperature, heat in the building. But in the same respect, I got 30 minutes of air on my back, and if a floor falls through, you need to know-- you would love to know my pulse, my respiration, and all that. 'Hey, he's breathing and his heart is beating. We're good, guys. Let's go get him.' Or, 'No pulse. No respiration. This is even worse.' Right?" (FF-U-012)

\section{Integrated Gear/Wearables: PPE Technology}

"The more integrated it is into our protective equipment that it's not so ancillary or exterior that it bogs us down, the more-- because I really am asking somebody to be a triathlete. And all these extra clothes and anything that's cumbersome, wires or anything, is going to be a hazard. And so the more streamlined we can make it, lighter, faster, longer battery life, all those things, protection... that can only help us." (FF-U-001)

\section{Physical Ergonomics: Robustness}

"I think [the radio] is an awesome tool... $50 \%$ bad, $50 \%$ good. But for firemen, it needs to be built by Fisher-Price ${ }^{\circledR}$. It's got to be bacteria resistant. It's got to be waterproof. You've got to be able to throw it in the dishwasher. It's got to go through high temps, got to go through low temp. It can't have thin wires. It's got to have big buttons because I'm wearing gloves. It's got to be built for a three-year old. This is not. Because this is how we use it. We use it in the water. We use it in the cold. We use it in the hot. We use it with calls." (FF-R019) 


\section{Physical Ergonomics: Smaller and lighter}

"So I think smaller, lighter weight versions of all the equipment we already have, would be the wish of almost anybody. The number one line-of-duty injury for firefighters is usually vehicle accidents, and cancer, and some of those things. But a lot of times the injuries are back, knees, hips, so those are all repetitive stress things that happen. So that's the thing you'd like to see reduced, right?" (FF-U-012)

\section{Physical Ergonomics: Fewer devices}

"We have one thermal imaging camera. We send one in with every group of firemen that go in. So they have that technology there. But the people in the front that are on the nozzles that are doing the job- to be able to talk to them and to tell them, 'Hey, I see this,' or, 'I see that,' because you're focused on your one job. I think that would bring more value than everybody having $\$ 50000$ worth of stuff attached to them... When maybe not everybody needs that." (FF-S022)

\section{Physical Ergonomics: Larger devices}

"You need relatively simple what I call 'Fisher-Price ${ }^{\circledR}$ technology.' Big shapes, big buttons, colors, things like that so that I don't have to scroll down menus and things like that. I need it very simple because I don't have the time or the mental capability or the bandwidth to be looking at a lot of different things." (FF-S-035)

\section{Interoperability: Software/Hardware compatibility}

"If you had the pre-fire information sort of embedded in the buildings or that transmitted to the central dispatch center and then transmitted to your personal device. And so everybody was carrying around their personal device like that had access to all those things and it was compatible with all those different applications." (FF-S035)

\section{Interoperability: Interagency communication system}

"Now with our incident management team, is one thing we struggle with is when we go... on wildland fires, we work with different federal agencies, I can't talk to them. So locally, we do pretty good, but when we get outsiders coming, or we go to the outside, all bets are off." (FF-S-036)

\section{Microphones/Earpieces: Wireless}

"I think that the development of Bluetooth wireless technology for clear, better communication built into your air pack would be fabulous. And it needs to be bombproof, bulletproof, and so there can't be any loss of communication in smoke, heat, and all the other things that go along with it." (FF-U-014)

\section{Microphones/Earpieces: Specialized earpieces}

"It's a huge step for us to be able to have [earpieces]. The only step further is that if it's ever possible, some departments have some that are molded to each individual's ear. Because I've noticed, sometimes, with that, I would prefer that ear piece far more when trying to listen to that without a mic, because there's so much going on, it's hard. You have to lean over anyways. Having an ear piece in is great, but I've found several times they were popped out. And when I'm in the middle of something and I can't reach up and grab it right away, so I have to remember, "Okay, I'll pop that back in." And I think that problem is somewhat avoided with the ones that are molded to individuals, the specific individual's ear." (FF-S-035)

\section{Radios: Channel switching}

"The one thing I think we lack is just to have [our equipment] more seamlessly kind of aligned with when we go to a call. If we can hit a response button and have all the equipment on the fire engine, or 
whatever unit that you're on, automatically go to that assigned channel." (FF-U-007)

\section{Radios: Multiple talk groups}

"Like the military, public safety will often operate in kind of a squad mentality, that you may have a bigger incident with incident command and commanders and stuff that you need to talk to, but you have these little squads everywhere that also need communications amongst themselves. And so we're starting to see some people that are kind of piecemealing it together, but you have the kind of deal where it's almost like two radios within one, where you can hear the command level stuff going on, as far as updates and what's going on, but you would have the ability to, while hearing that, still have a squad-level communications." (FF-U-020)

\section{Radios: Prevent accidental transmissions}

"The only thing that I ever really thought of that I think might make an improvement is on the push-to-talk button. Having to push two on each side before you can transmit because a lot of times you know, like I said, everyone has a radio. If you're up on a roof or you're in confined space, and you're beating away at something with an ax, your push-to-talk button gets hit [crosstalk] on accident frequently, and when that happens, it ties up the radio for about three or four seconds... It's a single button. So I don't think it would be that big of a deal that'd require you to squeeze both sides." (FF-U-010)

\section{All-In-One: Tablets}

"I would love to have a tablet that I could get my calls on, that I could do my maps on, that I could do my pre-plans on, that I could have my inspection ship too. Because we still get stacks of dot-matrix-printed paper inspections. That I could do my EMS reports on. So I've got a mobile data computer mounted in the rig that I push en route and do all that. I've got a smaller one in the back, we take in for calls and enter information, and use it to transfer over via Bluetooth to the ambulance company. But I'd love to have one thing that I could just carry-- that I could put my rig and put it in a docking station, use it to go en route. Get my maps and do my inspections, do my reports, do my pre-plans, do all that stuff. And I would love to see that one day, and when you came into the station, everything just downloaded into the system and you were good." (FF-S-017)

\section{All-In-One: Software \& apps}

"I would like to have-- so we use a lot of maps, obviously. And our dispatch program has a map. And then there's a separate icon and Internet site that has our hydrant apps and GIS. And then I have to go to a third website to get the federal railroad map of the railroad system. And then I have a separate app for metro. And I'm like, 'Maybe I watch too many movies. I want it all on one.' I want one giant thing with lots of different layers that I can turn off and on to get the data I need. That's my expectation as an end user and they're not there." (FF-U-044)

\section{Mobile Apps: Information references}

"There's schematics that are available in these apps where you can pull up any type of car and automatically know where the high voltage is running, where you can cut it, where you shouldn't, where fuel lines are, things of that nature. So does the car have one battery? Does it have two? ... A lot of things that are important, and airbags. So that's technology that's there. But again, it's on an app and that's costly, but that's something I would like to see us go to eventually where you should be able to pull up on a scene and either on your computer in the rig or an iPad automatically puts in the first ten of the VIN number, it'll pop up that car. And you'll know right there that 
you have in your hand where it's safe to cut, where it's safe to stabilize, how many batteries there are, if it's electric, if it's partial hybrid, if it's even hydrogen. There are a lot of different vehicles that are out there. That'd be beneficial for us. " (FF-U-021)

\section{Mobile Apps: Discipline-specific apps}

"I'm sure there are a million apps out there. I mean, I think that's part of the problem too. There are so many options for things. Everything is super cool, and let's have that in its latest and greatest. And then you go to use it, and you're like, "Oh, maybe that wasn't so cool." So, I mean, a lot of it's trial and error, but I feel like if some of these companies could get together and have one big app that kind of addressed all of the needs that fire service has-- because there's apps for hazmat, there's apps for special rescue, there's apps for-- I mean, so putting something all together... like the fire service app and having it be broader, then I think that would be kind of cool instead of all of these individual things." (FF-S-037)

\section{Futuristic: Smart buildings}

"I mean, in a perfect world, to me, in the future, I would pull up to a building that was on fire, and the building would tell me what I had going on. So I may be able to, at some place in the building that I knew it existed, I may be able to get all my information before entering the building. For instance, how many people are in this building right now? The building would know. And the building could tell me, 'There's four occupants that are currently in the bedrooms on the third floor...' I mean, that would be-- I mean, talk about affecting our job tremendously... if we had smart buildings in the future, that would be awesome." (FF-U-029) 


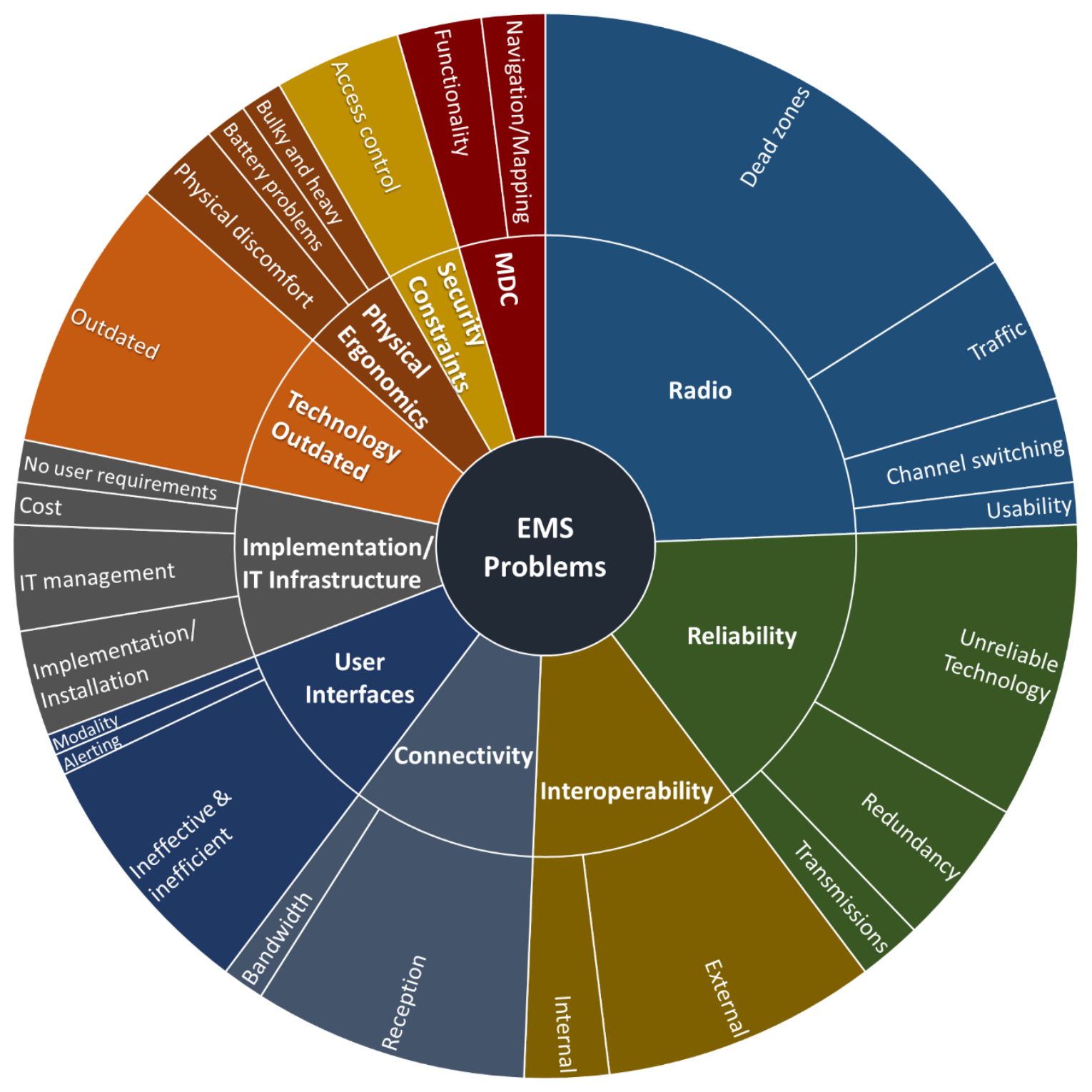

Fig. 8. EMS Technology Problems Categories and Subcategories 


\section{Radio: Dead zones}

"They can't hear us in the hospital. Sometimes, I've got to come out into the bay so they can hear us. So if I'm in the hospital in the ER, and I'm transporting patient care and, 'Ambulance 42, we need you. Can you--?' Yeah. I won't be able to hear them." (EMS-U-012)

\section{Radio: Traffic}

"Sometimes radio, if it's a major incident, a major emergency, only one person can talk at a time. So if you're trying to get urgent messages out, technology will not allow you to do that because only one person can talk, and you can only talk for limited periods of time." (EMS-S-015)

\section{Radio: Channel switching}

"Probably $80 \%$ of our guys couldn't find them; they use them so rarely." (EMS-U-003)

\section{Radio: Usability}

"I think those emergency transmission buttons on the radios need to be more effectively monitored or used and or protected so the incidental bumps don't happen." (EMS-S-006)

\section{Reliability: Unreliable technology}

"I remember the days of mobile data computers going in and we could be going on the road. I'm looking at a dispatch on a computer, and all of a sudden, the computer just completely shuts off on me. Or I'm trying to respond on a call and the computer communications is too slow." (EMS-S-014)

\section{Reliability: Redundancy}

"And then we use the Map, just the Google Maps. I use Google Maps and the Apple maps. And there are addresses that do not exist in there, in both. And we have map books for old technology. When the dispatch tells us where we're going, it gives us a cross street and a map page." (EMS-R-007)

\section{Reliability: Unreliable transmissions}

"So for the most part here you hear dispatch calling to see if you're okay. So you send somebody back to the truck to tell them you're okay. You can hear on your portable you know it's garbled but you can hear you just can't respond. So you'll tell them you know yeah we're okay then come back. The problem with that is you know service where you just have you and your partner now you're down one in the house there trying to work on somebody so often times if it's a real bad situation we just won't answer. I mean you know we just won't answer until we can get back to the truck because we're more interested in the patient's wellbeing than we are letting dispatch if they send us somebody else great we got somebody else you know." (EMS-R-018)

\section{Interoperability: External interoperability}

"When we back away, we would allow the police to do what they do... But what happens is, let's say, sometimes our communication center will tell us, 'Hey, scene is not secure, based upon what we're hearing. Wait.' Then we will stage at a certain location away from the incident, so that the police can come. Well, then the police has to call their dispatcher. Their dispatcher has to talk to our dispatcher, and then our dispatcher tells us that we can go in." (EMS-S-014)

\section{Interoperability: Internal interoperability}

"And each one has to be learned, and you have to learn all of the little intricacies of them. And lots of times, that's not a big user base because we're not that big an industry... It's very specific. You have to learn very specific things to run a certain vendor's safe software platform." (EMS-R-008) 


\section{Connectivity: Reception}

"I know we have issues with WiFi every once in a while. If I'm on the WiFi of the computer and then I drive to the hospital and now I'm inside the hospital writing my report and I'm on the hospital's WiFi and I go to leave, there is a space in between where I'm on neither network until I get away from the hospital. And I've had reports just get lost." (EMS-S-015)

\section{Connectivity: Bandwidth issue}

"The only real issue we have with cell phones is, again, certain events, New Year's Eve. Really giant crowds can overwhelm the system, and so occasionally we'll have connection problems there." (EMS-U-003)

\section{User Interfaces: Ineffective and inefficient}

"Paper reports are the easiest you can get. I mean they were quick. I had paper reports down to a you know a 10 minute deal and it could be a complete report you know now I got to write my paper report but I can't write my narrative yet so I write my paper report with all my demographics then I go on to the computer and write my narrative then I have to go to a separate computer app to pull up my times to write on my report and then after that I got to take a copy of it and put it with whatever drugs I use, submit that, then I've got to put my we used to have to put that into a computer system then after that." (EMS-R-018)

\section{User Interfaces: Alerting}

"We used to have a technology here that would, you had fog and you would beep it in when you would drive, and it would keep track of your driving, your speed, around the curve thing. I'm sure it had some kind of driver scope inside the ambulance to tell you if you're taking the turn, all that stuff. Everybody hated it and the day it got uploaded every month. And they didn't really use it punitively. But it made noise. So it clicked when you come around a turn. And if you take the turn too fast at all, it would alarm. It was so annoying. And even if you were hitting this at a normal speed, it was telling you you were taking it too fast. Let alone when you were actually going fast, then it would just alarm the whole time. So everybody hated it. We kind of mutinied. And when we merged, we got rid of it." (EMS-R-007)

\section{User Interfaces: Modality}

"I can't get information from dispatch straight to me that says, 'Hey, this is a dangerous -' without having to make it out loud and everybody hears it." (EMS-S-005)

\section{Implementation/IT Infrastructure: Implementation/Installation issues}

"But basically, because [the CAD database] maintains that large currently-used data set, that active data set of like three years. If we've transported somebody anytime in the last three years, it'll pull up at least. Now, with the new systems - we just transferred over the new system at the beginning of this year - I don't think they moved all that data over from the old system." (EMS-U-017)

\section{Implementation/IT Infrastructure: IT management}

"You have to deploy it on portable equipment, which is out of your control a lot of times. It's out on an ambulance somewhere. If somebody's having a problem, a technology problem in the ambulance, they're paramedics, they don't go to IT school, they go to paramedic school, okay?" (EMS-R-008)

\section{Implementation/IT Infrastructure: Cost a prohibitor}

"Technology is very expensive. You don't just buy it and you're good. You've got to maintain it... You've got to upgrade it." (EMS-R-008) 
Implementation/IT Infrastructure: No user requirements collected/considered

"[RE: technology requiring internet connection] I think that when they're bringing in technology I think they and maybe they look at this but it seems like they don't to me because I'm on the outside. I'm just the person that uses it. I don't know the ends and outs but it seems as though when you're in a rural setting that those things should be considered when they're choosing yes. There may be a cheaper way to go and it maybe budget friendly to our county but when we're one of the more rural counties and we have all of these areas that we can't even get radio reception, we can't get cell phone reception then you need to recognize that some of these things are not going to work for us." (EMS-R-019)

\section{Technology Outdated: Outdated}

"Technology advances can be an issue, maybe as not catching as fast as we want. Or maybe we're using a system that's one down from what's already happening because I'm sure you know as well as I do, technology is always moving, and a jurisdiction has to operate under here because they've already spent a lot of money on a particular ends, and it may not communicate with that technology because it's outdated." (EMS-S-014)

\section{Physical Ergonomics: Physical discomfort}

"We really need a hard-wired keyboard. It's not easy to type these reports on this [soft] keyboard." (EMS-U-017)

\section{Physical Ergonomics: Battery problems}

"We have a cardiac monitor which plugs in because it's battery operated. We have a suction unit that is battery operated. We have this, that, and the other thing that's all battery operated. It's all plugged in. When an ambulance is not running, it's on a shoreline plug... And if you forget to plug your ambulance in for an hour, it's dead. I mean, it's just the electric load, which is a technology issue as well... Whatever else we hang in an ambulance cannot be a power concern." (EMS-R-008)

\section{Physical Ergonomics: Bulky and heavy}

"[Stretchers have] been fairly definitively proven to reduce the number of at work back injuries. They also weigh three times as much as the other ones. You can argue that that weight is for-- the pros outweigh the cons. Our Toughbooks are old. Some of our equipment is a little bit clunky, but some of our stretchers are the big ones." (EMS-U-004)

\section{Security constraints: Access control}

"Although we have access to a sort of an enterprise level messaging system, it's locked down so tight by IT that it's essentially unusable. So nobody uses it." (EMS-U-003)

\section{Mobile Data Computer (MDC): Functionality}

"Our department has those MDCs, but it's kind of underutilized for a computer. I mean, all we do is get this generalized information that we probably could have sent in the ' 80 s. We just didn't have the ability to make it small." (EMS-S-005)

\section{Mobile Data Computer (MDC): Navigation/Mapping}

"The one thing that seems to have been lacking on our ambulance for years is a built-in GPS. So we don't have the ability to open CAD computer and sort of GPS ourselves if we're confused of where we're going." (EMS-U-011) 
EMS Requested Functionality

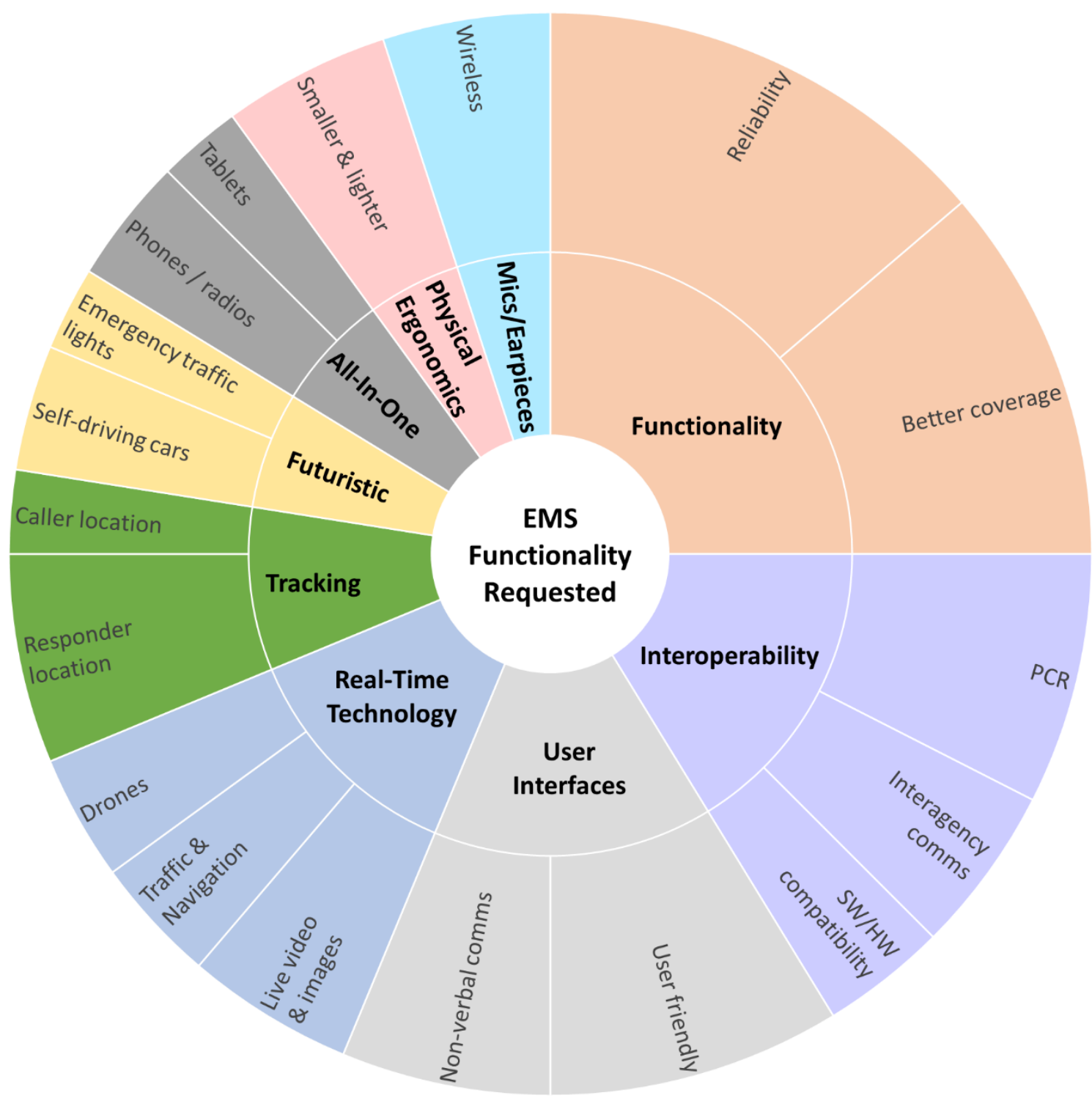

Fig. 9. EMS Requested Functionality Categories and Subcategories 


\section{Functionality: Reliability}

"The problem is the technology versus the actual performance. I mean, that's my big pick... I understand advertising people have a job too. But you better get out there and use it before you try and sell it to some people. Because you can kill people if it doesn't work right." (EMS-R-008)

\section{Functionality: Better coverage}

"I wish the radios didn't time out. I wish they worked in all locations in the sense of, if I have to talk to a physician or a doctor on the radio and I can't do it in a basement, I have to leave the patient and walk outside. Or go to my unit that has a repeater or a better radio system to try to deliver a message out." (EMS-S-015)

\section{Interoperability: Patient Care Reporting}

"Maybe something along the lines that patient tracking because that's a good tool. Doesn't get used a lot though. I think something that would be an automatic download to the Red Cross. If we had victims, multiple victims from an incident-- on our MRU, once we had their name and information, if we could tap a drop-down menu and say Red Cross or whatever, then that information would go right to their databank. And they would know where that person is. And the reason why we would notify them is if we didn't have-- if it was like a disaster situation, you know? Let's say a plane crashed. We have 100 people. If we have that information. I would like that we would be able to send it to them immediately... So they have it when we get there. They know we're coming with that person. And they know that the Red Cross has been notified." (EMS-U-009)

\section{Interoperability: Interagency communication system}

"It would be nice to talk across the country to other people. But in reality, it's a regional thing. So we need to be able to communicate within our region. And there are national talk groups that we could use if, God forbid we had some kind of big incident here. But by and large, I mean we don't-- we need to communicate with the jurisdictions that neighbor-- that surround us. I don't necessarily need to talk to my friends in Rhode Island I used to work with, on the radio from here. So it's basically making good with your neighbors and having good communications with them." (EMS-S-016)

\section{Interoperability: Software/Hardware compatibility}

"I was at a technology conference that's put on by our vendor of a lot of our software, and it was-- everybody was complaining about this one software program like, 'Why hasn't this been updated in years?' And they're like, 'We bought this company from a company that bought another company that bought another company. And the guys that wrote this code, there are still people that are using the initial version. If we change something here, we have no idea. We might shut that service down that's still using that old technology.' So backwards compatibility is a big deal, too." (EMS-R-008)

\section{User Interfaces: User friendly}

"We do have a talk around channel, which is like a chitchat channel that I can-- I'm going to be lazy and say that it's really hard to get to and you really have to double-check. It's not a quick fix and then I can deliver a message that I don't want the whole county to hear. So you have to switch to--Oscar. Yeah. O, Oscar. So it's all the way towards the end of the alphabet. If I'm always on Alpha or Bravo to go all the way to Oscar, confirm that I'm on seven's talk group. It would just be easier if a push button or something that would just give me that talk around just to be able to deliver that message a lot quicker." (EMS-S015) 


\section{User Interfaces: Non-verbal communication}

"If I'm trying to go on scene, this happens all the time where the patient can see me pull up and the fire department can see me pull up, or maybe there's a bystander trying to flag me in because it's their emergency, and so they're the ones freaking out. And I sit there in my ambulance, and I try and key up and the radio's-- Okay, so then, I try and key up again and the bystander's freaking out and waving me in. And I'm just waving to them like, 'Hi. Yeah, I'Il be there in a minute.' ... And then I try and key up, and this time, it goes through, so now I can put myself on the scene. Or if I had a CAD system, I could hit a button that said on scene. So that way, if dispatch was busy talking with someone, and they wanted to know if I made it, they could look at their screen and see, 'Oh, yeah, they've put themselves on scene.' And that way my time is accurate." (EMS-U-004)

\section{Real-Time Technology: Live video \& images}

"If you could see everywhere. The calls where they can pull it up-because in [city], there's cameras everywhere and they can pull up certain cameras and be like, 'Based on this we can see that it's this way on the highway. We can see it's at this intersection. We can see it's at this corner. We can see that it's behind this building.' There's a lot more things that they can see. " (EMS-R-007)

\section{Real-Time Technology: Drones}

"We hope to have a fully operational drone program at some point in time that would assist in search and rescue, or maybe even an aerial platform that we could observe what's going on real-time at a scene or something... So it's a vast area. And if we could keep track of our medics and the situation, the crowd movements and stuff like that, using that aerial platform, that would be something that we would be involved in, as well." (EMS-U-001)

\section{Real-Time Technology: Traffic \& Navigation}

"I mean, if the regular person running an errand, and then an Uber has to find an address quickly and can do it accurately, then you'd think that it'd be quite important for the ambulances to be able to do that. You can be detailed to an area you're not familiar with... So if the average person would do it, it seems crazy that the ambulance don't have it yet, but they don't... I would think that would be on everybody's wish list that drives a vehicle, yeah, to make it a little easier." (EMS-U-011)

\section{Tracking: Responder location}

"I can tell you that for large-scale events, from the command side of things, I would like to see or have some type of a [inaudible] saying, 'Okay, you know what? These ambulances are coming from this direction and these ambulances are coming from this direction. Where can I place them so that they don't running into each other or direct them [crosstalk]?' ... Some kind of GPS locator. I know it exists, it's just that we don't have it." (EMS-U-010)

\section{Tracking: Caller location}

"I would say, location can never be specific enough. A lot of times, in this area, we have large buildings and so someone will say, [address] but that building has three sides. And they may work in the building so they know their address, but they're actually going to exit the building on some other street side and if they forget to tell the dispatch center that, we will show up to the front entrance, which is where we were dispatched. But then we'll say, 'Can you call back to the calling party? Where are they?' And then they say, 'Oh, they're at the loading dock.' Which means we now have to drive around. It would be much better to have that information. And they do a good job and sometimes callers are not great." (EMS-S-016) 


\section{Futuristic: Self-driving vehicles}

"Self-driving ambulance is an interesting concept. And the reason why is because right now you rely on one individual in the back. And if you're treating, even if you're just treating one patient, not multiple patients, but a single patient, but a multi-system injured or ill patient that requires more than maybe one brain and more than one set of hands in order to better manage the treatment side of that patient's modalities, then you're doing it by yourself." (EMS-U-001)

\section{Futuristic: Emergency traffic light system}

"Even tie that [self-driving ambulance] in with the traffic light system or something like that, so there's absolutely no interruptions. It maybe clears out the intersection before you get there. So it clears up traffic and you just go. And then you don't have to-- driving 50 or 60 miles an hour, maybe you've set it to 40 miles an hour the whole time but you're never stopping " (EMS-U-001)

\section{All-In-One: Cell phones and/or radios}

"If you could take a smartphone and put it on a radio, it would be ideal. So I could have five to six dependable apps that I use on my radio, I can utilize it as a phone if I needed to or wanted to, as well as to a radio communication and delivering messages." (EMS-S-015)

\section{All-In-One: Tablets}

"So my wish list, by far, is an iPad for those rigs. An iPad mini would be perfect. Put it in an OtterBox case or whatever and it's going to be fine. I mean, the doctor's office that I got to go to, they have an iPad just to tell me how my visit was. That's how cheap they are. It's ridiculous that we don't have something like that that is more reliable, doesn't need a strong IT group to manage and function. As you probably know, Apples are really easy to use. We don't use it for a lot anyways and for what we use it for, I think we could do our inspections right on that thing. We could do our EMS call all on that. Because as it is, we've got the CF-19 or whatever it is. That's our MDC up front. And then we've got another $\$ 2000$ computer in the back that we use for EMS calls to do logging, to do one thing. A \$2000 computer to do one thing. Just when we could have a $\$ 300$ tablet and do the exact same. And we don't store anything on the hard drive. Everything gets sent. You don't even need a big one as far as memory goes. So that's my wish list, for sure. And we would only need one, hypothetically, mounted where the officer goes and the officer just hands it to the firefighter behind him or the engineer, actually. Our engineer is the one who does the documenting on our EMS calls because we're fortunate with staffing that it would be so easy, for sure." (EMS-S-005)

\section{Physical Ergonomics: Smaller and lighter}

"Nowadays, [the MDC] should be like an iPad. Something simpler that's easier to touch, and you could almost pick it up and take it with you so you could continue relaying information." (EMS-S-005)

\section{Microphones/Earpieces: Wireless}

"Definitely one of my wish lists would be we operate with a portable radio and everybody does - firefighters, paramedics, EMTs. It would be nice to have some form of remote. Like what you see how we utilize a cord that can get damaged in fires, if someone just shuts it in a door, or whatever, it would be nice to have some form of Bluetooth capable radio system." (EMS-S-014) 


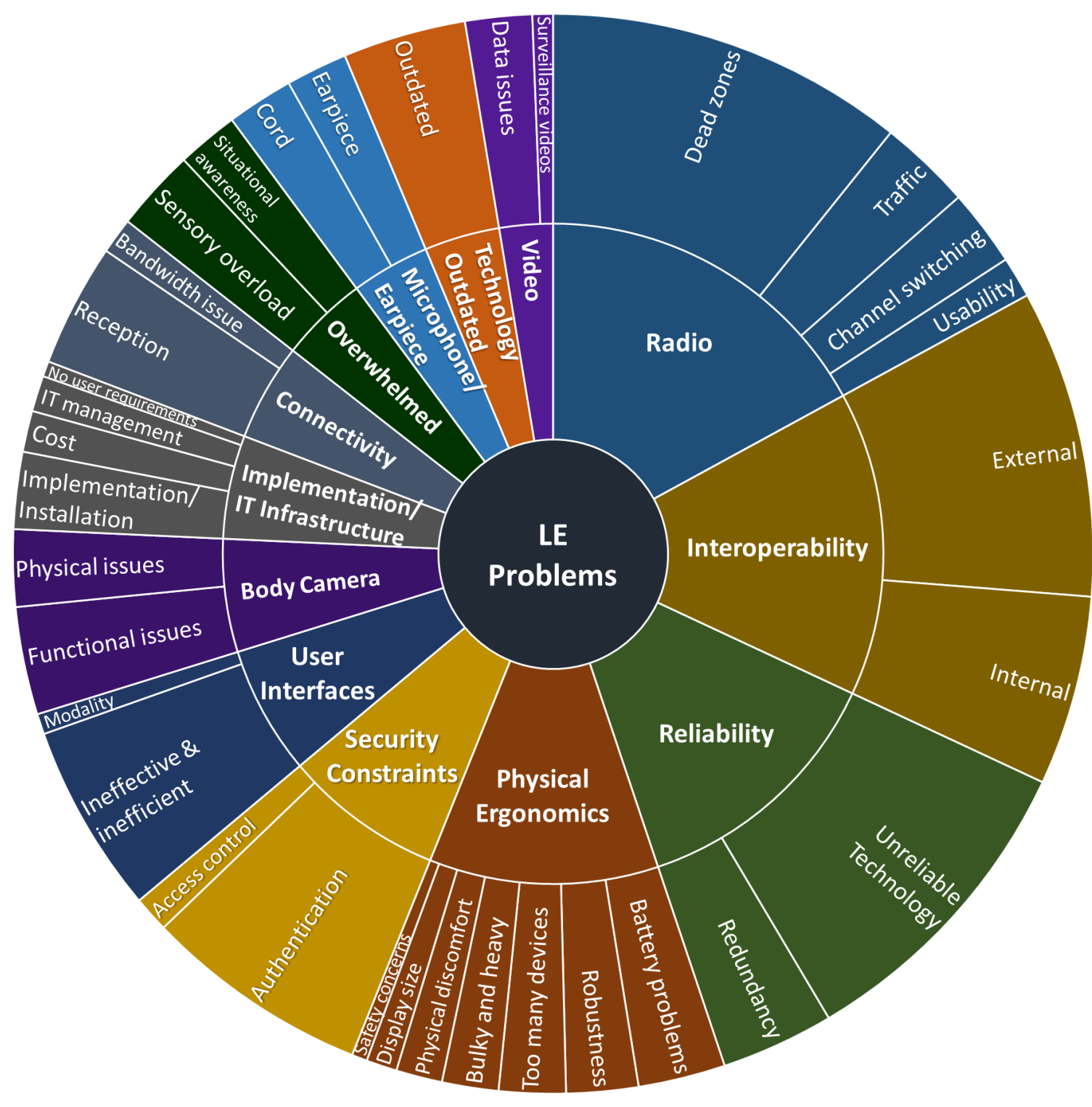

Fig. 10. LE Technology Problems Categories and Subcategories 


\section{Radio: Dead zones}

"We get into terrain issues with the mountains and no matter how much we use to try to fill in our gaps, we're not going to put a 750,000 -dollar tower to fill in one canyon. But it's important for us to talk in that canyon..." (LE-U-020)

\section{Radio: Traffic}

"The airtime is usually what causes things to crumble because if I can't communicate because everybody's trying to get on the air-- if I can't communicate to people, I can't tell them what I need them to do. And you can have incidents fail because you can't get that direction out." (LE-U-029)

\section{Radio: Channel switching}

"You chase someone down to the [subway] platform, at what point do you stop and say, 'Excuse me, I need to go to C8? Hold on a minute. Hold on.' And then go to C8." (LE-U-011)

\section{Radio: Usability}

"But getting in a fight, hitting a button-- you turn on to the different stations here. I've hit it so many times where just that little button." (LE-S-027)

\section{Interoperability: External interoperability}

"With firefighters and EMS, it's virtually impossible. And it's vice versa. It's virtually impossible for them to talk to us. It's very, very slow and very, very convoluted, because what we do is we get on the radio and we call our dispatcher. That dispatcher is one dispatcher for each district channel. And then, that dispatcher sends a message from their computer to the fire rescue dispatcher for that geographical area. And then, that person either contacts their-either answers the question or has to ask their firefighter or EMS person whatever we're asking." (LE-S-037)

\section{Interoperability: Internal interoperability}

"From a software perspective, I am tired of having a new sandbox for every single thing that I do. Our RMS doesn't really speak very well to our CAD... If I am going to take a call and I need to write a report, I'm going to run the person on the way to the call. But that never makes its way into RMS. So I'm going to type them into my CAD, even though it's on the same computer... So I would like to see an integration between all those separate systems that make it so I'm not repeating the same work over and over and over again, giving me more time to go out and do what I'm supposed to do, which is take calls." (LE-U006)

\section{Reliability: Unreliable technology}

"Sometimes you have communication technology that doesn't work. I mean it's computer, it's technology, it's electronics right? They don't always do what we want them to do. You know software has bugs." (LE-R-043)

\section{Reliability: Redundancy}

"So if two towers go down, the whole system crashes. That's why we have the backup for the cars. However, we have another backup. We have call boxes." (LE-U-010)

\section{Physical Ergonomics: Battery problems}

"[The computer in car] would drain the battery. And so then, officers got in the habit of just always leaving their cars running." (LE-U-030)

\section{Physical Ergonomics: Robustness}

"One of the issues that we see is that the equipment that's being issued is not rugged enough. I mean remember that as police officers were out there in the sun, we're out there in the freezing cold, in the 
rain, they're getting in and out of their police units so they equipment needs to be more rugged." (LE-R-053)

\section{Physical Ergonomics: Too many devices}

"The shoulder mic, I wrap my earpiece around it to try to hold it in place. Then I've got cables that go back and attach to my vest to hold onto this. And then I've got the cable that comes around to my radio and then it locks on. So it's kind of cumbersome because you only have so much space to put so much technology and we're running out of room." (LE-S-021)

\section{Physical Ergonomics: Bulky and heavy}

"So with the e-ticket writers, I think they're a bit bulky and big. So if we could have something even just a little bit smaller. Because when you're approaching a car in a traffic stop, you don't really want a lot of things in your hand or big things in your hand. You kind of want your hands to be as free as possible. We have a lot of things that we carry. So there's so much on our belts. And then we're adding body cameras. We've got a mic. And we've got everything just weighing you down." (LE-U-007)

\section{Physical Ergonomics: Physical discomfort}

"And the computer where it's at, it's not really comfortable. I mean, I would hate to have to write a report in the car. My back would be killing me because you have to turn, and lean, and type... You could take it out but if you're in the driver's seat, your steering wheel is in the way." (LE-U-024)

\section{Physical Ergonomics: Display size}

"They can go to data warehouse, and that's never going to happen. You're driving around. You can't do that. And you're moving, and the car's bumping, and the links are so tiny, you can barely get your finger on it." (LE-U-023)

\section{Physical Ergonomics: Safety concerns}

"So in the police cars just-- one thing that I've always been aware of is they have so much stuff in the front seat, so you've got the computer and you've got the screen. This car went through national highway safety transportation tests with crash dummies, right? But now we put all this crap in here and when officers have accidents, and they have accidents, nobody has said this is safe or not. I'm sure there's been a lot of injuries from-- we don't look at that stuff when we buy this equipment. We just shove it in there. We just shove it in there and say it's good to go." (LE-U-031)

\section{Security constraints: Authentication}

"Unfortunately that is one thing that, because we don't have just a single vendor for all these different applications, that is one of the things that we really, really struggle with in law enforcement, is having some sort of single sign-on, or you know, we are constantly there is not a day that, I shouldn't say a day, but there is not a week that goes by that I don't have to change some sort of password to something, and you know, that is truly - that can be a real potential issue. Now, we have to balance that with, you know, why it is that we have to make these changes, but it can very, very detrimental; you know, I spend a lot of time - administrative time, simply changing or resetting passwords that people have forgotten or, you know, misplaced or whatever it may be, so certainly that is an issue for law enforcement, not just us; I mean, I am talking law enforcement in general." (LE-R-059)

\section{Security Constraints: Access control}

"We have access to it, but there's certain aspects that we can sign into and then there's other stuff that we can't sign into. So like I said, 
sometimes the station's the best place because everything's fair game there. Everything's going to work in there." (LE-U-024)

\section{User Interfaces: Ineffective and inefficient}

"You need to be able to handle very quickly, because I can't be standing there with a ticket writer, having to enter 16 codes. I need it to be set in a manner where I can enter my specific jurisdictional code to make a traffic violation pop up, or type the first three letters. I can't sit there and type out, right turn on red, seat belt, but it has to be a quicker method of doing it. And I think that's where there are sometimes some challenges in the ability to make something work quickly and efficiently with the technology we have." (LE-U-040)

\section{User Interfaces: Modality}

"On the street, I preferred the radio as opposed to PDT just because you can hear it and you're still paying attention. If you're trying to read it off the screen, you're distracted." (LE-U-024)

\section{Body camera: Functional issues}

"But from an officer's perspective, that's scary. Because if I walk into a dark room and someone knocks me over on my head, I don't want you seeing everything in the room better than I see. I don't want the room to appear straight up and down when I'm upside down, because I'm going to make decisions based on what I'm experiencing. And if your video that you're watching in a nice cool air conditioned office later doesn't match what I experienced, you are now going to be conflicted." (LE-U-006)

\section{Body camera: Physical issues}

"And there was protesters that were basically attacking the people attending the ball. And so we had to stand in between them. And people had this in the Magnum mount, and we were losing body cameras left and right because we were pushing and shoving." (LE-U036)

\section{Implementation/IT Infrastructure: Implementation/Installation issues}

"At first the functionality of [the body camera] and getting it up and running was I think fairly difficult for us to do and some of our staff really pulled their hair out over getting it to work properly but it was really on the manufacturer's side not on our side or our IT department side. It was more the installation of the product and the lack of support from the vendor that sold us the product." (LE-R-042)

\section{Implementation/IT Infrastructure: Cost a prohibitor}

"But some type of repeater for in the building so if typically if our one of our deputies is in their office or back in the room where they write reports you'll hear dispatch calling them and they can't hear it because they're kind of towards the innards of the building and so I don't remember the name of what it was but I think we did get a bid or a quote to have it installed and it was like a hundred thousand dollars or $\$ 90000$ and we're like oh I guess we're not getting it." (LER-042)

\section{Implementation/IT Infrastructure: IT management}

"At least that's my-- they should mandate, 'Hey you want federal funds for radios, then you have a radio unit.' And you keep the-- and that way the new technology comes in, the new radios, the rebanding. I mean, I was taken off the street. Which I do what I'm told. But I was off the street for a year to do a re-banding project. So I went through 6200 radios citywide, the cars-- I was taking the radios out of the cars, unscrewing them... then putting them back in the cars and that's when I was able to, 'Hey, that mic's been broken for years, what?' And then the low-band radio, because they don't use it, they 
hide the mic underneath the seat because it's in the way I was like, 'Okay,' so that was my time to go and touch every car." (LE-U-010)

\section{Implementation/IT Infrastructure: No user requirements} collected/considered

"So the police department didn't take an active role in what they were buying. They kind of the deaf nod, yeah, yeah, yeah, and then when they got what they got, it was like, 'This is not what we want.' So the CAD in the car, really important for the more detailed issues around trying to document what they're doing. But issues with bandwidth, issues with the modems, issues with the equipment in the car, trying to upgrade things that should have been tossed a long time ago." (LE-U-011)

\section{Connectivity: Reception}

"MDTs also don't work very often; they lose connection quite frequently and if you are trying to do something and it drops the signal so it's frustrating." (LE-S-064)

\section{Connectivity: Bandwidth issue}

"And it all comes back to the same thing, bandwidth. The more that you want the officers to be able to receive on their computers, you need the bandwidth." (LE-U-012)

\section{Overwhelmed: Sensory overload}

"It's hard to drive, and listen to the radio, and look at the computer screen, and watch traffic and the bicycling. It's hard to everything. So at least with the computer, I can read kind of what's going on... Because I' $m$ trying to hear for other cars, other police cars... There's much traffic, you can usually get a couple seconds to read the computer really quick." (LE-U-013)

\section{Overwhelmed: Situational awareness}

"You're distracted no matter what. You're not paying attention to your surroundings. I mean, back when I started, we didn't have computers... But now, with all the different functions, it makes actually seeing what's going on in the neighborhood harder. And somebody's looking at this box to tell them what's going on as opposed to actually looking at the surroundings and figuring out what's going on." (LE-U-024)

\section{Microphone/Earpiece: Cord}

"Some of the things, I think, that would benefit our profession and some of it even already exists - it just needs to be improved a little bit - are shoulder mic system for our portable radios. It would be awesome to have that cordless opposed to a long cord that tends to either get caught in something or it can theoretically be used as a weapon against you, strangled with. I mean, typically, they're not, but quite frequently, we run into it getting pulled off your uniform shirt, or stretched, or gets caught on something where a Bluetooth-affixed microphone would be really nice or even a better headset system. And they make some nice stuff, but it's really expensive, and they're not going to buy that for 1100 officers." (LE-S-037)

\section{Microphone/Earpiece: Earpiece}

"Let's say you get into a fight. You're wrestling with the guy, it pops out. You can't put it back in while you're fighting somebody. You're not going to hear what's going on. Not that you wouldn't-- you're going to be fighting. You're going to be focusing, but you still can't hear anything. You don't know what's going on, if someone's coming to help you [hear] nothing." (LE-S-027) 


\section{Technology Outdated: Outdated}

"The CADs, I mean, they're outdated, man. I mean, even the new PDTs, they're super outdated." (LE-U-023)

\section{Technology Outdated: Incomparable to personal technology}

"My phone has more computing power than what's needed to run the RMS now." (LE-U-006)

\section{Video: Data issues}

"If the audio/video had its own-- literally had its own broadband network where it traveled on, and it didn't touch any other part of your network, I think it's a good thing. I think it would really help solidify the quality of video that we get, we can get even more high def quality video coming. Because sometimes we got to dial it down because of the network that it's running on. You still see what you see but it could be a whole lot more high def. The cameras have the capability. We just got to dial it down because the system can't take it." (LE-U-035)

\section{Video: Surveillance videos}

"Downtown, we have a whole bunch of cameras. Being able to pull those up would be great. But as far as I know, we don't have a way of doing that in the cars. We have a unit that does, so you can ask them. If you want to find out-- if you want to utilize this camera and find out what's going on over here, you call this unit. And they look at it, and they relay to you what's going on. But there's no way for that officer to pull up that particular camera." (LE-U-003) 


\section{LE Requested Functionality}

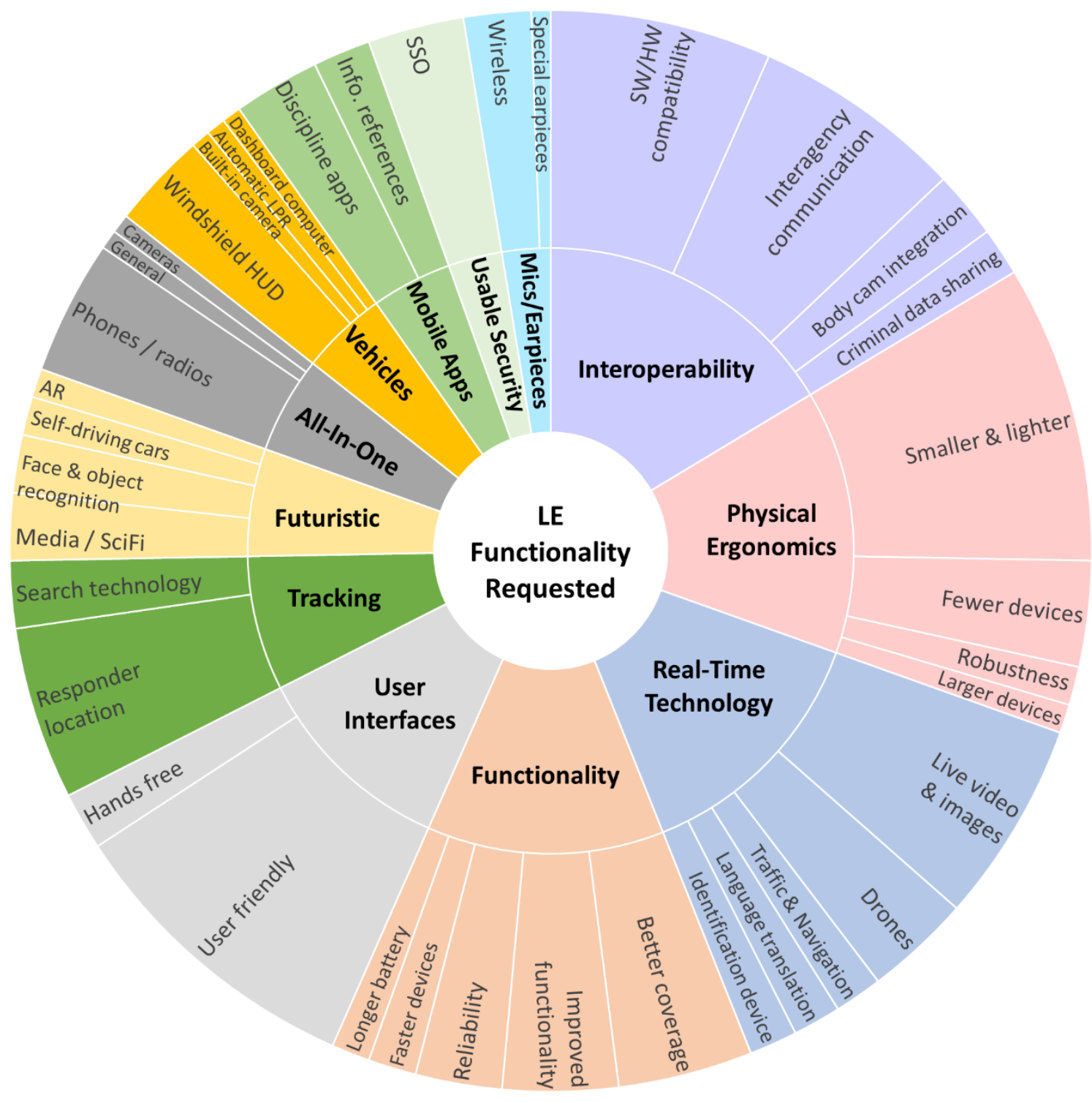

Fig. 11. LE Requested Functionality Categories and Subcategories 


\section{Interoperability: Software/Hardware compatibility}

"We pretty much have the worst computer-aided dispatch system... the ability for that particular product to integrate with other systems, we're finding, even though we were told, 'Oh yeah, it's easy.' It's not. And they're using it as a way to increase revenue by saying, "Okay. Well, if you wanted to integrate this way, it's going to cost." So, yeah. It's been a really, really disappointing process. And that's one of the things just for in technology in general with, I think, most law enforcement agencies is there are many disparate systems that need to communicate, and that's one of the real challenges is getting our CAD system who's made by one vendor to talk to our RMS, records management system, who's made by another vendor and get all that information to feed to our analytics system, which is a completely another vendor, so those kinds of things are really a challenge." (LES-015)

\section{Interoperability: Interagency communication system}

"I feel like we're so close [to neighboring departments] that we should be able to talk on the computer or something, you know? But they use a different program than we use, we use a different program than the sheriffs office use. So if it wasn't for cell phones and the crappy radio service, sometimes it would be that we couldn't get hold of somebody that's two blocks away from us... It would be nice if we all had the same kind of computer system or something so that there was always at least one way to communicate with that person. If a natural disaster happens or something and we lose radios and cell phones, how do we talk to each other? So that's kind of concerning." (LE-R-002)

\section{Interoperability: Body camera integration}

"All the body-worn-- all the video that's happening. All of that needs to get integrated. Every bit of it needs to get integrated, and we're so far from that. I mean, we're struggling with that right now with how are we going to take body-worn and know what the call was and what was the officer doing and just all of that? As simple as a number for the event getting somehow tied to that video. I mean, it seems so simple. It's not, right?" (LE-U-032)

\section{Interoperability: Interjurisdictional criminal data}

"I'd kind of like more sharing between all the databases. I know we have [state database]. If you're certified in that, you can pull up pictures of people. But I think that all of those databases should just be rolled. The states should be able to communicate. You should be able to-- the county and the city, the court systems-- you should be able to, 'Hey, you know, you're locking up this guy. You should automatically know he's got a pending court date for this,' his arrest history for the last few months, if he's a gang member. Everything kind of needs to be tied in together because everything you have to pretty much run separately through different databases and through different ways. I think it would be a lot easier for officers if all that information was just all kind of integrated into one nice package. Federal warrants and stuff-- I would think we're at the time where instead of just a description of the person, you should have his arrest photo come through with that." (LE-U-024)

\section{Physical Ergonomics: Smaller and lighter}

"In a perfect world, I would like technology that's small, that I can talk to and would get rid of all the stuff I have to carry. Some things are never-- I mean my gun, taser, that kind of stuff. That all makes sense. But some of the other stuff, if we could just kind of work it into one thing that was small and light possibly, that'd be ideal." (LE-U-007)

\section{Physical Ergonomics: Fewer devices}

"I think my biggest gripes are that e-ticketing machine and just the fact that it's not well thought-out for the application. I don't think 
there's any reason why it couldn't be done on the phone that I already carry or the computer that's already in the car. So integrating technology with stuff that we already have, that we already carry. Because when I'm on patrol, I carry 30 extra pounds of stuff, which doesn't count the two bags which are probably 30-pounds each of stuff that I keep in the car. So adding more stuff to all my stuff is more weight and redundant. So I think finding ways to use what we already carry... I think it's fairly mainstream that people have smartphones, and I think computers in the car is relatively mainstream. So adding technology or applications without adding something physical that I have to carry would be really nice." (LE-R-018)

\section{Physical Ergonomics: Robustness}

"As these new [touchscreen] technologies come into the work force, I think that some environments 24/7 operations 365 they're always being used. They're just not robust enough for some of the environments that we have here in county... so the robustness of the technology I think is something that often fails us and we're challenged to keep it functioning properly even though it's super cool sometimes it just doesn't work in that environment so it would be nice to see some of these technologies, the organic technologies and different things that are coming out of these research labs, to be designed to be robust and usable instead of fragile and cool." (LE-R042)

\section{Physical Ergonomics: Larger devices}

"If you get a chance to go in our cars and jump in there, jump in both versions. Don't just jump in the one that has the tablet. Jump in the other one that has the big monster machine, which we actually prefer, and I don't know why you would think that we would, but we do because of the fact that you can manipulate it and move it around. If it could be smaller, that'd be fantastic, but at the same time, the screen needs to be that size. You can't get a screen smaller but the keyboard and everything else-- and even the keyboard, I would say no. A standard size keyboard because we have big hands." (LE-S-021)

\section{Real-Time Technology: Live video \& images}

"Somehow maybe [victims] can give us access with the push of a button to their security cameras... Yeah. I mean, having us be able to gain access to their surveillance when we get there or if we're sent. Because what if it's a hostage situation where-- or a barricaded subject. We're not going in right away. We're going to stage out front and come up with a plan. What if we have access to that? Can they give us-- it's some sort of emergency button on their remote or on their phone that says, 'Okay. Access can be granted to--' and then I don't know. Probably, it's feasible. So it might already exist. I don't know, so." (LE-S-027)

\section{Real-Time Technology: Live video \& images (aerial)}

"So there are CAD layers that are showing the exact or very similar exact design that what the building looks like on the map. But what would be better would be having Google Maps or a satellite image that we could actually look at. That would help us in a variety of ways. We have a foot pursuit. Now, we know that there's a coal field behind here they could be hiding out, there's a tree line behind we think they could be hiding out. And all we have is a pastel color background with a square outline of a potential building that could or may not be accurate." (LE-U-005)

\section{Real-Time Technology: Live video \& images (perimeter)}

"I'd like to be able to tap into our camera systems, be it our downtown-- our cameras around town or, more specifically, our body cams or cars. So that way, you can kind of see what you're getting into, or kind of see what your partner's getting into. (LE-U-003)" (LEU-003) 


\section{Real-Time Technology: Live video \& images (other visual)}

"So we have in-car cameras. Right? And the technology is there for us to be able to stream what is going on in our car to our supervisors or anyone else, but we-- I think, mainly due to bandwidth, we do not have that feature turned on. But that would be something that would be kind of nice. If you were going to a call, to be able to look to see what your partner is currently seeing would be very helpful. So you can have an idea of maybe where I should come in from or if he's in trouble, what's going on or I look at the suspect before you even get there in case he bolts and just starts run." (LE-U-003)

\section{Real-Time Technology: Drones}

"With the technology of the drones, I know we have them but immediate live feed to the people on the team. Not just me, but the other team leaders, and to be able to alter it or highlight it, put an edit into it, show them where I want them or where they need to be or where something is located. I think to me in my aspect that would be something that we would look, that would be awesome, outstanding technology." (LE-R-052)

\section{Real-Time Technology: Traffic \& Navigation}

"I think as technology moves forward, we should move forward. Instead of staying behind the times because there are so many different things that have come out that would make our job easier, like GPS on the phone, the computer telling us where to go, how to get there. So I think as technology progresses, we should progress with it." (LE-S-038)

\section{Real-Time Technology: Language translation}

"Typically when [DWI] cases go to court, police officers aren't getting beaten because of the probable cause [inaudible] or the evidence isn't there. They're getting beat because somebody messed up procedurally through these tons of paper and forms. I would think some type of computerized system that you can hit play on, and you could eliminate the human error out of it and say no, I pressed play on the machine, the machine went through, when it got to the question, it read the question. I typed in the answer, and the entire thing is computerized where you're just literally hitting next, next, as they get to that part, would eliminate some issues on the police officers and those technicalities that a lot of DWIs or DUIs, wherever you're at, are getting thrown out on. Also it could be read in different languages, where they're complaining of some type of language barrier. It could be displayed on the screen on English where we know where they at, but it's reading to them in their native tongue. I think something like that would be great. I don't understand why that hasn't happened yet, something along those lines. But yeah, as far as advancement or something, that's the only thing over the years I've thought of would be a great tool." (LE-U-057)

\section{Real-Time Technology: Identification device}

"I think an ability to identify folks, whether it would be using the new retina scanners or the fingerprint scanners. We have fingerprint scanners. They're just not as... competent as what I would like to see. Again, if there's prints in the federal system, I think if we had a better version of that, where we could very easily identify folks, I think that would be good." (LE-S-033)

\section{Functionality: Better coverage}

"Having our tech work everywhere. It doesn't work everywhere. It doesn't work in the jail, it doesn't work in some apartment complexes, it doesn't work in the woods sometimes, as far as radios and even our cell phone. That would be nice." (LE-U-005)

\section{Functionality: Improved functionality}

"I think it would be nice if the plate reader knew if you were in motion or not. So, for example, if I'm driving, I may get a hit on a suspended 
plate. Well, I can't do anything on that car if it's parked. I can pull it over if it's moving, but I can't do anything on it. So then I have to sit there and acknowledge that, yes, this was a positive read or a misread, and it's a little cumbersome to actively be on the plate reader all day." (LE-U-024)

\section{Functionality: Reliability}

"Probably, just for [technology] to work $100 \%$. I mean, there's no such thing as $100 \%$ of the time, but just to try to maximize the percentage of times that it would work versus not work, and every aspect of it." (LE-R-001)

\section{Functionality: Faster devices}

"Faster computers in our cars, more reliable for running stuff, tags, people, that kind of stuff. Anything that cuts down on the amount of time you have to be out with somebody or dealing with somebody that may be a threat." (LE-S-037)

\section{Functionality: Longer battery life}

"So as all these new technologies come out, they're talking about Bluetooth speakers and microphones, well, something else you've got to remember to charge. If it's not charged, is it hot swappable? I think, as we look at new devices coming on potentially with the Broadband for Public Safety, that was a question. If we go to mission critical voice over LTE on a phone, do we get a hot swappable battery? Because I forgot to charge it that night or I've been on a shift longer than I thought, how is that going to be figured out?" (LE-R019)

\section{User Interfaces: User friendly}

"With everything across the board, if you don't make it simple, they're not going to do it. They're just going to move on to the-- or stay where they are, in the past." (LE-S-021)

\section{User Interfaces: Hands free}

"Have a voice activated, 'Hey, run this plate,' where you don't have to even look at it. Whatever-- like Alexa, or Google, or like-- I mean, you would think that just having the-- telling the plate and it being run would probably save-- I mean, I know of supervisors and people that have gotten into car accidents because they're [looking down]." (LE-U-024)

\section{Tracking: Responder location}

"In a foot chase, when you're chasing somebody. It would be really nice if a dispatcher could just GPS and see where you're going... Instead of you worrying about calling it all out all the time. You've got to run, you've got all this stuff, and you're like, 'I'm going left. I'm going right. I'm turning right. Southbound here and northbound here,' and sometimes you don't even know what streets you're on. You're running. Could you imagine if you didn't have to do that, and you could have your hands free and just focus on chasing after this guy? And the dispatcher would be like, 'All right, northbound, southbound.' Because whatever direction the police officer's running, then that's the definite direction that the offender's going. So the police officer's almost like a trail, a marker, a trail marker, a GPS trail marker behind the offender. And if you could see that in an aerial view, you can dispatch and coordinate cars to come from the north, come from the east and west." (LE-U-023)

\section{Tracking: Search technology}

"Last week, we had a robbery pattern where three guys were targeting Hispanic women, and they were using the same stolen vehicle, and we had to choose to get that plate run to find out if there's been a hit on it in the area. And it probably took 45 minutes before we were able to convince them to do it. And after they did, 
the car was parked two blocks away from where it was seen like two nights before. So we'd sent a car and said, 'Hey, why don't you guys just tour this area, do a grid search?' And they found it in like two minutes, and they set up and watched it for hours, but nobody came back to it. So it'd be nice for something like that if we could just do a simple GPS, toss it on the car, and, hey, it's moving." (LE-U-024)

\section{Futuristic: Media/Science-fiction influenced}

"A universal translator, like Star Trek. Put the damn thing in your ear, and it would just translate... So that would be-- if I could make anything happen, it would be that, universal translator so you could talk to everybody. It's something small, nothing big and gaudy. I don't want to get silly." (LE-R-017)

\section{Futuristic: Face and object recognition software}

"I mean we can't we can't do facial recognition, and with all these cameras, you should be able to do facial recognition. It would be nice if the cameras, like, say, we see a car that went through this camera, if the computer connects, you say, "All right, it's a white car, it's whatever shape," and look for it in all the cameras around it to see if it's passed." (LE-U-024)

\section{Futuristic: Self-driving vehicles}

"A Google car driving us somewhere 80, 90 miles an hour. Yeah, that'd be great. I think that's fantastic. With the ability to take over when we need to because sometimes we need to violate traffic laws or drive over a median or a curb. That would be great." (LE-U-005)

\section{Futuristic: Augmented reality}

"I envision a system where you are driving down the road and [unintelligible] patrol car and what you would have would automatically scan license plates and then almost kind of like a video game where you see [unintelligible] square floating above their head or something of that nature if you are in the car, how much gas you got, whatever. Also I wish like there could be some kind of heads-up virtual display like over that car, like it would scan it, you would be driving, showing like see-through letters, like driver suspended, no insurance, stolen plate, you know, vehicle not registered, warrants, you know and it would be different color coded." (LE-S-062)

\section{All-In-One: Cell phones and/or radios}

"The other thing that would be really handy that I would love to see is some way to run an ID from a radio. So all of our ID's have barcodes on them now. Some way to check that person over a radio, because right now I got to go back to my car in a rural agency - I mean sometimes we have to park at the end of the driveway because it's locked and hoof it in. So we're walking sometimes a quarter of a mile and we're not near our vehicles. You know, and that's very common- or we have injured people in the middle of the field riding a horse in back country or whatever, and we need GPS coordinates. Well crap I just left my GPS in the car. You know just having kind of a device or something that's all in one that can do a lot of different things and communicate and be able to communicate. You know, having [interoperability], that's really the key for me in my mind is being able to talk with whoever we need to talk with to get the resources that I need." (LE-R-044)

\section{All-In-One: General multifunctional devices}

"We carry a lot of crap. And I think technology is fantastic, but finding one thing that does everything, I don't see that ever happening. You have some things that do something very well. And when you try to combine that stuff together, then you have one thing that does everything kind of half-assed. So I don't ever like that. We'd had a deputy chief here for a while that he didn't like the one-trick pony. 
He didn't like our e-tickers because that's all it did. But our taser, that's all it does. And so I think if you try to combine everything, you're not going to get the best use of anything. So the more things I can put together, that actually are the same thing, I think you're better off. But trying to combine a lot of stuff that doesn't naturally go there, isn't going to work." (LE-S-016)

\section{All-In-One: Cameras}

"Advancing in technology is great but to a limit. I don't know. I think all of the solutions, if you could incorporate it into one device, it would be awesome. The digital recorders, the cameras, all of it, even if it was your body camera that turned into a regular camera too. If it's all in one device, that would be fantastic." (LE-S-021)

\section{Vehicles: Windshield HUD}

"Vehicles now, they have their odometers, pedometers on the glass on the dashboard. That would be something nice for the officers, because now your eyesight is not looking down towards the computer. Everything is visual on the screen, transparent to you, in front of you while you're driving. It's like what you see in the Sci-Fi movies. But it's not too far away, that technology, because of they can do this. But your speedometer, how fast you're going, is just a matter of time before you can integrate that information on the screen. So the officers in itself will be able to see everything on the screen. Touchscreen, everything that make it fast for time, have an earbud in there, so they can hear everything that's going on... Voice commands, 'Can you repeat the address that I'm going to?' And it'll show everything. Callback number, 'Can you call for me to make sure that the victim is there or I' $m$ at the right address?' Or, 'I need an interpreter.' Stuff like that. So everything is hands free. So I meant, that would be just incredible if they did that, if they had that for the officers in the car. Just think about it, right? I don't have to press my mic. I'm just going to voice activate and start talking, and the computer's going to dial the numbers for you. You can have it all on the screen on your windshield. Everything." (LE-U-012)

\section{Vehicles: Built-in camera}

"I really like our body-worn cameras in concept... something smaller, lighter-weight, less conspicuous would be nice. That said, I absolutely, absolutely love having video in the cars and body-worn cameras." (LE-R-018)

\section{Vehicles: Automatic license plate reader}

"There is a device that reads plates automatically and looks for stolen cars. My understanding of it is that it is very expensive so very few places have it and the ones that do usually have it [disabled]." (LE-S064)

\section{Vehicles: Dashboard computer}

"The big Toughbook [in the vehicle], you've got the big console, everything in here. Why can't we just have a flat screen or something on the dash that you can touch or something like that? Because I was in a really bad crash on duty. And I got hit on my driver's side door. And you get stuck in there. And it's like a coffin because you've got one side and you can't get out. And it's just so big and bulky and then you have all your gear and everything else. So that would be nice to have something, maybe, more built in to make our car functional." (LE-U-007)

\section{Mobile Apps: Discipline-specific apps}

"We do e-tickets for warnings and tickets - you're going to have to be focused on this damn thing. It's about the size of the original Game Boy. Except with a keyboard. And I'm like, put it on an iPhone. Put it on a Samsung. I don't care what Android or iOS, Apple platform it's 
on... But make it user-friendly. We all know how to work touch screens. We can all zip through that... put it on my phone, so it's an app. I hit my button, type in my ticket, walk up there, take their picture, hit send... it would be so much easier on the phone as opposed to an outdated and antiquated technology that's your user interface when everything else with the system is awesome." (LE-R017)

\section{Mobile Apps: Information references}

"I'd love to be able to pull up somebody's name, information, criminal history, warnings, and whatever on the phone. Pretty much anything you've seen in Minority Report or any of those, I'd love all that stuff." (LE-R-017)

\section{Usable Security: SSO}

"[New technology is] over-complicated... just make it simple... When you would get in the car, you only needed like one password to get onto the computer. Now, you need like 5 . And they have to be all different, and it has to have a hashtag. It has to have this, a number. It has to have-- so me, I put them all on my phone, because I forget. I'm only almost 40 , but I'm already forgetting things. But you have to know nine passwords to get on your technology." (LE-U-013)

\section{Microphones/Earpieces: Wireless}

"I also like to be uncorded. I would prefer some Bluetooth microphone and that type of stuff as compared to cords and everything that get stretched all over the place." (LE-S-016)

\section{Microphones/Earpieces: Specialized earpieces}

"The nice thing about this system that I use, I use a small earbud because I want to be able to hear not only this, but whoever's over here. There are specialized ones that you can get that are form-fit to your ear. They make it to where you can hear really well on the radio, but I can't hear anything on this side of my head. So I want to make sure that I can still hear so it can't completely shut off. It can't be like earmuffs are." (LE-S-021) 


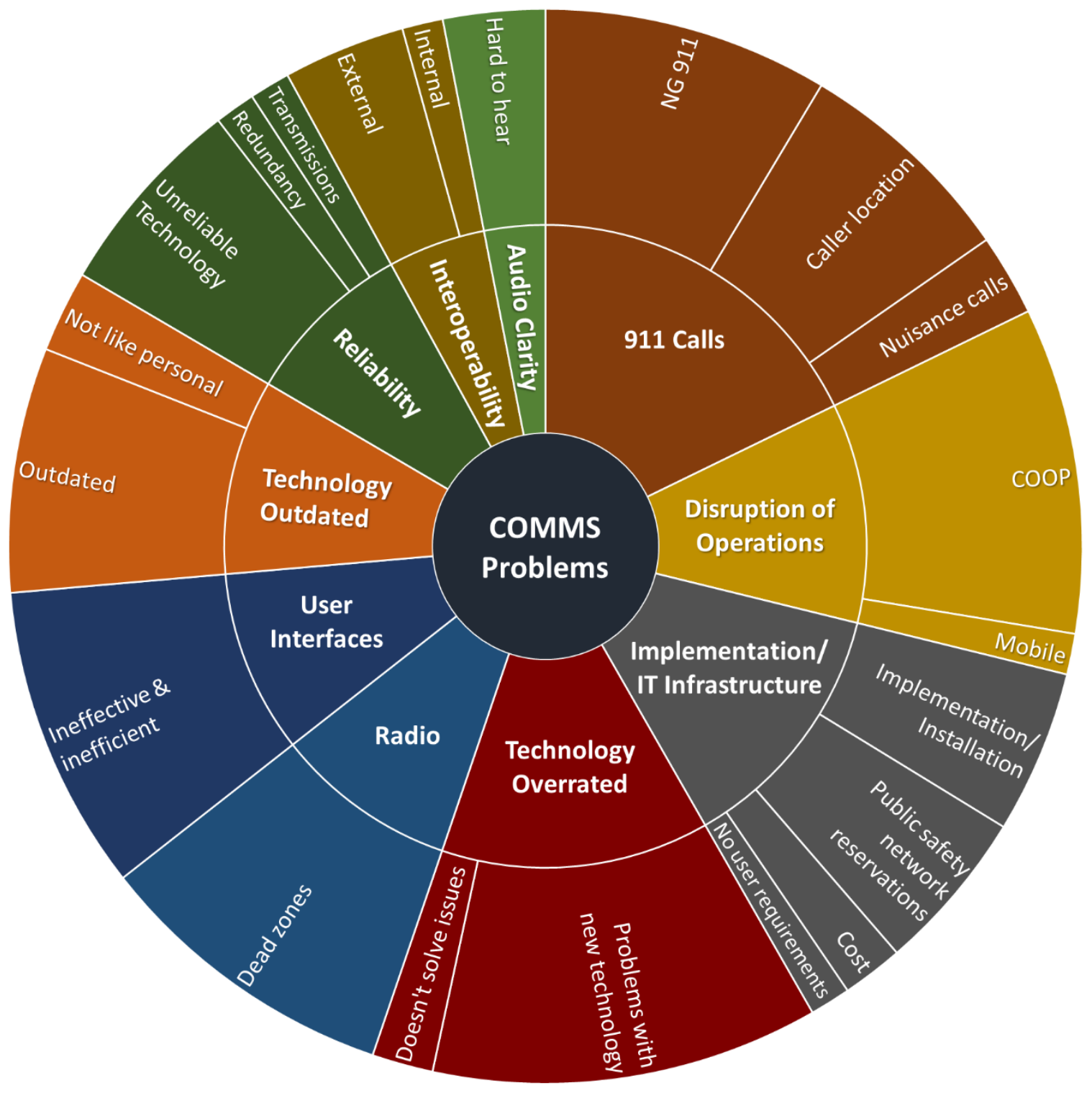

Fig. 12. COMMS Technology Problems Categories and Subcategories 


\section{Calls: NG 911}

"I'm not going to have a 30-minute conversation over text whenever I could hear your voice and... and I can really hear are you okay. I can't tell that over here. I can't tell if you're crying or--that's my fear with the Next Generation 911 is are we going to lose that important piece of our communications with technology... But I'm hoping that the texting feature and the apps that we're using on smartphones and other devices that they don't take away that human communications during an emergency because $90 \%$ of all communication is nonverbal in nature. And hearing that voice, hearing the background noise of a particular call gives us so much more information than just the words that that caller is saying." (COMMS-R-016)

\section{Calls: Caller location}

"Location information sometimes is difficult to get from a cell phone. And again, we have a lot of visitors here. And they never know where they're at... Have no clue." (COMMS-R-002)

\section{Calls: Nuisance calls}

"We get a lot of 911 hang ups mostly off the mountain. Now with the smart watches doing 911 hang ups. They move their wrist. That's a real pain. That's worse than the pocket dials." (COMMS-R-008)

\section{Disruption of Operations: Continuity of operations}

"There's also some of the sheriff's office over here and then in addition to that we also have ECC here as well and it's convenient but also in terms of public safety critical infrastructure this is not perhaps the wisest setup because everything is one place and then... across the street actually literally right across the parking lot is our backup center... there is an issue of geodiversity in the sense that all of our critical infrastructure is in one spot." (COMMS-U-006)

\section{Disruption of Operations: Mobile operations}

"If we have to leave this building and go out and get in that truck, or if I go to our [city ECC], our operational center, I'm going to be operating those cell phones. Now my CAD is set up, our CAD which we have that they don't have, so we use Citrix, I don't know if you know Citrix so anything that I need, and again this is because of the HIPAA rules and security of it, so we built a secure Citrix system, so when I go to Citrix on my laptop anywhere outside this building, I can get to everything I need to sitting in my office. Or I can dispatch calls. So we also like [town], is not tied into here, like we are. They're on Citrix, so [town] dispatches all their calls on Citrix, and it talks and it feed backs through. Because the Citrix server is sitting in [town] right here. Now if this building goes down and we lose complete power and I lose this room right now, we're on cards; we're back to the 1970s." (COMMS-R-020)

\section{Implementation/IT Infrastructure: Implementation/Installation issues}

"It's going to take two or three people to actually get on NextGen, to get on [inaudible]. It's really going to take three people to do this. It's going to take our phone vendor, it's going to take AT\&T because they own [inaudible] and it's going to take the state comtech people to do that and it's going to take me and [colleague] to be on a conference call while they are doing this because they've got the engineers and everybody to do it and they are doing it basically live, which we've switched over and so forth. But me and [colleague] is going to be on phone. So, let's look at our timeline here now. Seven hours. We are on conference call for seven hours and at the end of that seven hours, they couldn't make it work. Now when I say they -- it really doesn't matter who they are." (COMMS-R-019) 
Implementation/IT Infrastructure: Public safety network reservations

"When you start to look at the design, and you say, okay, well you know [a public safety network is] an independent system, but your core radio network is shared with the consumer. How's that going to work, right? It's going to be a challenge. So I think you'll see around here where you potentially have [a public safety network] as your primary device, then you'll have a backup cellular device with another provider, and you're right back to where you were before. It doesn't really make any sense. But Internet of Things, I think it's a good option. Pushing video over LTE, I think it's going to be a good option just because the backhaul bandwidth will be so much bigger. I am concerned about the plans that people have to use [a public safety network] system for things like... pushing [state] LETS data over that system and just all those kinds of things, make you think twice. Just based on the way the project is being run. So that's it. My two cents." (COMMS-S-001)

\section{Implementation/IT Infrastructure: Cost a prohibitor}

"The whole team has access to [free GIS software], right? Makes it work well. And it interfaces with Google Maps and those kinds of apps... Contrast that with a single-seat license for [GIS software]. If I want it on my work station, it's like $\$ 9000 \ldots$ and that's not even the server license, right? That's just the work station to connect to the server... It's probably a six-figure implementation for just a basic implementation." (COMMS-S-001)

\section{Implementation/IT Infrastructure: No user requirements} collected/considered

"Some of it has. Some of it has been every bulky and then because they didn't get the input from the user. If they had gotten the input from the user they could have fixed this upfront." (COMMS-R-016)

\section{Technology Overrated: Problems with new technology}

"We have a new CAD system that's slower than the one we had before. Well, everything about is-- it's weird. You think newer technology is going to be better... More user-friendly and it's just not- It's not the case. The phone is horrible. If someone calls you on the radio and you didn't catch what they said-- with our old system we could just go in and double click on the last radio transmission and play it back." (COMMS-S-004)

\section{Technology Overrated: Doesn't solve communication problems}

"I think [NG 911 is] going to change things for the better in most cases but I'm really leery that it's going to change how we communicate. I mean we already see it in our society now with our social media. I mean anybody can say anything they want to about anybody on the phone that you would never have said to someone to their face. And... just not... not real... real sure." (COMMS-R-016)

\section{Radio: Dead zones}

"Those are people's personal cell phones, yes. And-- but sometimes it's just easier or sometimes it's better, I'll say, to use that because we actually get them and sometimes we can't on the radio." (COMMS-R-009)

\section{User Interfaces: Ineffective and inefficient}

"We get a new system that is great on the technology side but it takes me 2 to 3 steps to what used to take me one... I used to just be able to type of command out into a line... I now have to start a command, hit tab, find which section I want to go to-- so the location might be here, but to enter a license plate it's down here, and to enter a color of a vehicle here, and it's a makeup. It's-- you end up using your mouse, and for me, having to remove my hands from a keyboard 
when I don't need to look away from-- I can look away from the keyboard and keep doing my job. It's time consuming." (COMMS-U007)

\section{Technology Outdated: Outdated}

"So in that time frame we have to deal with things we still have copper line connection to connection points so we still maintain those copper line points. We don't use IP base yet for our phone system. We have old PBX systems. We have a lot of stuff that is kind of old and in order for me to get parts I'm usually pillaging from other jurisdictions as they update to get replacement parts for mine in case something breaks which really comes into play." (COMMS-U-007)

\section{Technology Outdated: Incomparable to personal technology}

"So we have to manually enter [common places] information into our CAD system in order for us to be able to search it and then present our CAD system is not as dynamic as say Google right? If you type in Google some-- like let's say, you say-- let's say there's a place called Sizzling Steakhouse whatever at [location] right? So if you tell me I'm at Sizzling Steakhouse at [location] or if you tell me I'm at Sizzling Steakhouse I can be like okay and then type in Sizzling Steakhouse and then in Google and then it'll come up with did you mean Sizzling Steakhouse at [location] right? It will come up with a suggestion because it's like okay you're probably talking about this. Our system does not work that way... You have to enter it exactly as it is in the system." (COMMS-U-006)

\section{Reliability: Unreliable technology}

"With something like CAD, if CAD goes down we can go manual right? We can pull out boards, we've got magnets, we've got cards, we can do what we need to do. If you lose your phones... You're done. If you lose your radios you're done so in those two you really need the reliability and that means going with those that are... versus $C A D$ you know we can kind of try the waters and do different things but you want to make sure again that it's the best of the best for the operations world but you don't want technology to suffer either for it." (COMMS-U-007)

\section{Reliability: Redundancy}

"So our department just made the decision recently to give every person that's on patrol a cell phone from the agency. They're doing that for a couple reasons, one: they can't have the excuse of I didn't have the ability to make a phone call. But it's also a lifeline as well in that case, if you really need it. Our county is so big geography-wise that people can be out in places where there-- we have $95 \%$ coverage from our radio system, which is significant. I mean, you don't really find radio systems that high. But the fringe areas that our county patrol works in are the $5 \%$ that you don't really get it so you need to have an alternative way of communicating." (COMMS-S-001)

\section{Reliability: Unreliable transmissions}

"Well with our sheriffs we don't really have an issue except where maybe you know the radios don't work and we do have those kinds of coverage issues but generally not a problem when you know I'm communicating something dispatch and something out to my sheriff officers but fire is a different channel and that's not usually a problem. Only sometimes they're not always listening to their radios and we can't control that. Sometimes we don't know that so but we communicate that out, we dispatch that out and then sometimes that's out of our hands and same thing for EMS. We make that call, we dispatch them but we don't always know until somebody communicates back to us that they've gone or not so it's easy enough to communicate. I don't always know that that communication has been successful." (COMMS-R-009) 


\section{Interoperability: External interoperability}

"[RE: CAD interoperability between dispatch agencies] Linking those CAD systems up, in an appropriate manner, do I need to see everything that [city redacted] is doing right now? No, it's none of my business. But whenever something makes a difference here in us being able to respond and have that, then them sending that to us rather than them having to type all of this stuff in an email, send it in an email, that now we've got to type it into a CAD system, it's a lot of wasted effort. But having that data automatically transfer at the sender's request, not at the receiver's. I think that would probably be the number one thing I would look for." (COMMS-R-016)

\section{Interoperability: Internal interoperability}

"Just like I wait three months for my iOS update to load. You want to wait until the kinks of those kind of things are kind of worked out a little bit and you know we will have interfaces built between them but it's different when you have interfaces built between them and when you have one system that is just really integrated on its own. So there are places that the technology is going again those ideas are great in theory but the practicality of it in operations need to be tested a little bit more so that's probably where the big gap is at the moment making sure they really kind of tie together and everybody gets the best of what we can find." (COMMS-U-007)

\section{Audio Clarity: Hard to hear}

"I think right now, they're in the process of trying to upgrade our radio system and our towers because they are old. Yesterday one of the officers called me and he called four times and it sounded like he was whispering and I said, "You're totally unreadable." Well, that's an officer safety issue, when you can't communicate with your officers and they can't communicate with you it's scary because-sometimes we grab our cell phones, "Hey, are you okay? I've called you three times. I didn't hear anything." I mean, all officers and dispatchers should have equipment that works." (COMMS-R-005) 


\section{COMMS Requested Functionality}

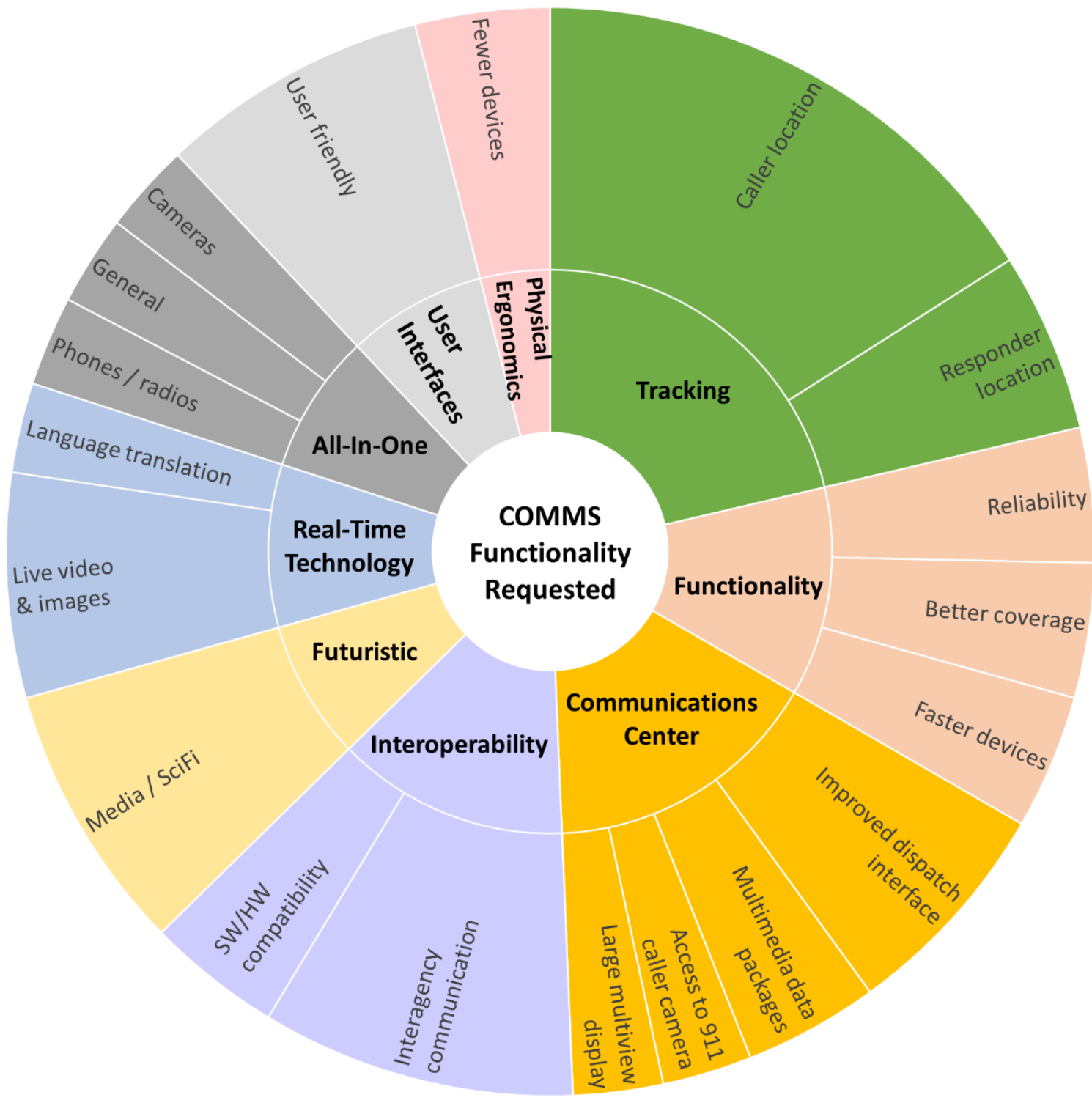

Fig. 13. COMMS Requested Functionality Categories and Subcategories 


\section{Tracking: Caller location}

"So location information is very important. I would love to be able to see you know this is a pretty big wish but one day I would love to be able to see you know accurate you know $x, y, z$ coordinates. I'm talking like $z$ coordinates would be cool especially in this environment where we have a lot [of high rises]... If we get a 911 hang up from a cell phone... and it comes back to-- you know, we don't know where you are but you're calling and you're just screaming and then I have to go trace your phone and I trace your phone. And they're going to give me-- even if they can give me an address, [if] it's an apartment complex, I don't know where you are. We can't have the officers go check every apartment. We just can't do it right? So knowing kind of an approximate would be really cool. That would be awesome. Anything where we can better direct people to where you are." (COMMS-U-006)

\section{Tracking: Responder location}

"Wouldn't that be awesome if I could have that virtual screen [from Minority Report] as a dispatcher and I see a map of the county and I can zoom into the emergency, and I can just zoom in on it and see what their problem is, look out for the closest units and just touch them and throw them at the house and just go, you, you, you, you, go. And just have it happen. And then, the system will tell them everything... I don't have to type in all these commands, that whole fat finger syndrome, or that working 18-hour shifts and there's a major storm and the 18 hours turns into 48 and you're tired, so the human factor decreases and the computer-aided part, like garbage in/garbage out, perfection in/perfection out, that will raise it." (COMMS-S-003)

\section{Functionality: Reliability}

"Some things could be a little better. Like, if we had more monitors to monitor the campus, because I mean, we have these two. Sometimes the cameras don't work, and usually it's the ones that we need at the time." (COMMS-U-018)

\section{Functionality: Better coverage}

"That would be amazing if we had--and not just out building coverage, not on the street coverage, I'm talking in the building... that type of thing." (COMMS-R-016)

\section{User Interfaces: Faster devices}

"I'd like to see a little bit better of a computer sitting underneath the desk but I mean that's something we're looking into right now because every day that we add something or we add cameras to our security system it takes up more of the computer and they're getting to the point that they're a little... Faster processor is the problem there." (COMMS-R-013)

\section{Communications Center Technology: Improved dispatch interface}

"What I want, I just applied for, is a-- it's a KVM software, and in took forever to find one that was affordable to the public sector. I had one guy come in and tell me it was $\$ 150,000$ to get KVM. There's just no way... KVM is keyboard video monitor switches. I was always told that the switches entailed connected it but you actually had to turn a switch to whichever one you want to get on. But I was able to find a company that has them that it automatically--you configure your monitors when you're installing the software but it automatically can tell by the movement of your mouse which screen it's on and what system you're operating at that point. So you're not sitting here with-because people come in and they want you to run this or our radio runs off a separate computer than our network computer. Our 
hardware, police cameras, run off a separate computer. Then the other 2 computers, 911 is its own computer. So we have some stations that has 4 keyboards and 4 mouses on them. And it is a hindrance to switch mouse and keyboard to figure out which one you need to be on. So we're looking at that right now because that in itself will help us do our job more efficiently and easier than switching stuff... That is the biggest one right now in our communication center. All of my people, you know, want it, they asked me when are we getting it." (COMMS-R-013)

\section{Communications Center Technology: Multimedia data packages}

"Some of the things talking about videos and pictures with that -- and we know that that is coming but I don't think that should be something that is law delivered anywhere. You know, I don't care whether it's New York City or Boise, Idaho, and I think any of that technology should be something that the person sitting behind that console has the option to say -- yes, I want to see this or Ms Supervisor, I need you to view this. You know, I am just talking about the whole mental viewing that -- I don't think that that should something that when we answer 911, that there is something that pops up in front of somebody's face." (COMMS-R-019)

\section{Communications Center Technology: Access to caller cell camera}

"At least allow the [caller], you know, for us to request just like if we are doing a WebEx or something like that. Can I have access to your camera? (COMMS-R-019)

\section{Communications Center Technology: Large multi-view display}

"More monitors to be able to pull up different things, especially if like, if we're in pursuit of somebody, we try to pull the cameras up to see where they're going, things like that. And it would be nice if we had more monitors in here to pull up more cameras to see where these subjects are going." (COMMS-U-018)

\section{Interoperability: Interagency communication system}

"I would want the responders to not only be able to have a radio in their hand but for all of them to be able to operate on frequencies that they can communicate with each other on. We just we see it time and time again that the left hand-- they can literally almost be standing next to each other and they don't know what the other is doing if it's not fire and law. Sorry. And so that would be I think my top priority is that funding." (COMMS-R-008)

\section{Interoperability: Software/Hardware compatibility}

"But one thing I will say is you can't do everything on a phone. I'm not going to write a report, right, on a phone. So you'll have to have different form factors. You'll have to have something that has a lot of screen real estate and that kind of stuff for certain job functions. That's not going to go away. But if I can provide an ecosystem of applications that makes a lot of the jobs simpler, that's really where I want this to go." (COMMS-S-001)

\section{Futuristic: Media/Science-fiction influenced}

"The virtual reality stuff is kind of intriguing to me... I mean, they do it on NCIS, where they have one big screen, and that's got everything they need, and they just throw it around like that. I suppose that's probably possible now... But it seems it would be nice for us to be able to have a big curve TV instead of six monitors, and still be able to manage the four different computers and the information that our dispatchers need to do their jobs. Seems like maybe virtual reality would be the way to make me do that." (COMMS-R-002) 


\section{Real-Time Technology: Live video \& images}

"I do think [911 video] has to be live because you've got firemen that are going -- people are going to be screaming from a fire. So the responding fire trucks can actually see it in their car. Well, that needs to be live so they know exactly what they are facing. Like a police officer responding to a bank robbery. He is getting live pictures from there because it has got to be live but I have seen diagrams where the data comes in to -- doesn't necessarily come into the 911." (COMMS-R-019)

\section{Real-Time Technology: Language translation}

"I would like something to where if you take the worst possible scenario, someone who doesn't speak English, who's having a panic attack about a major emergency and can't relay that. If we had that, I could see them, if there was some sort of magical technology that I could talk, it translates to their language, they could talk, it will translate to their language, so I see like a closed captioning exactly what they are saying, there's no communication breakdown, I can see what they're seeing so I could use my experience to plug in the holes of medical, traumatic, fire, whatever, and then I can tell them exactly what they need to know immediately and the communication is transparent, it's just there automatic, because of technology. Instead of having to delay and wait for all that." (COMMS-S-003)

\section{All-In-One: Cell phones and/or radios}

"I think with [a public safety network] coming I would like to see the whole radio thing probably go out of the window and the cell phones to be able to be the radios and I know that that's coming someday and those radios should be able to be protected on Band 14 [of a public safety network] system and they should be able to be affordable so that it's in everybody's hand and I think that that would be huge strides towards interoperability all together. I don't know if it will ever happen but we'll see. Kind of hard to get the LMR out of the picture." (COMMS-R-008)

\section{All-In-One: Cameras}

"I never thought that they were able to put a body camera, which obviously a body camera and a camera could go together. But like a body camera/voice recorder, almost a tablet like, 'cause you could add photos and basically talk into the mic. And it would change it into words, and you just talk out your primary narrative, and your whole job is done from your hand." (COMMS-R-012)

\section{All-In-One: General multifunctional devices}

"To me, it's bringing all your technologies and putting it into a form factor that's available. A single device, simple form factor. That's what everybody really needs. Can I do my regular job and can I do my incident stuff? Can I do it from the same platform without having to bring a ton of different stuff? Which makes it really difficult to do." (COMMS-S-001)

\section{User Interfaces: User friendly}

"Just ease of use [for] the end user. You know some of these systems come through and I've even seen it in other 911 centers where the technology is really supported and it's a great system but when the person on the end tries to use it it's useless and so just having that focus of what are you trying to accomplish? It's great if you can get it going here but if you can't use it it's not worth it. And we run into that with our CAD system it's somewhat outdated." (COMMS-R-008) 


\section{Physical Ergonomics: Fewer devices}

"People don't want to have to carry a work phone, a private phone, a NCIC capable secure device, you know what I mean? You just start adding them on and on and on... You're running out of pocket space. It's a waste of hardware... So, it starts adding on. So if we can reduce that number and... logins as well. That's the big one." (COMMS-S-001) 


\section{Summary of Results}

As public safety evolves to use advanced communication systems, research and development must be centered around first responders, how they use technology, and how technology can help them to achieve their goals. The technology first responders use to communicate must be effective, efficient, and provide user satisfaction [4]; communication technology must operate as expected without being a hinderance to their primary incident response tasks.

Communication, as stated by the nearly 200 first responders interviewed across the United States, is critical for successful incident response. When technology is used for communication, it has a grave impact on an incident: it can either improve or degrade the outcome of the event. Unfortunately, it is the latter that often occurs during incident response. This report presents the results of an analysis of the problems faced and the functionality requested by first responders in order to improve communication technology for use throughout the public safety domain. Across the fire, law enforcement, emergency medical services and communications center disciplines, three key components to effective communication technology became clear:

- Reliability

- Usability

- Interoperability

Volume 1 identified the top R\&D opportunities and user-centered design guidelines, which include reliability, usability, and interoperability [1]. First responders feel that improving these aspects of communication will have a major impact on the use by and environments of first responders across the public safety domain. In addition to these cross-cutting findings, first responders in each discipline expressed the need for real-time video and images as an incident unfolds to paint a better picture of the incident. Further examination of the data revealed the unique and most pressing problems and requested functionalities within each discipline.

The problems and functionality requests reported here cover a wide breadth of challenges faced by first responders. While some needs can be addressed by implementing existing technology, others may require more sophisticated R\&D to yield useful solutions. The PSCR usability project has provided guidance on developing usable solutions to first responders' needs [7]. In addition, the PSCR program is tackling some of the challenging areas identified in this report; many of the problems and functionality requests reported here reinforce the PSCR R\&D focus areas [6].

Throughout this report, we presented approximately 300 quotes to demonstrate key concepts and unique problems and functionality requests. This report serves as a valuable resource for the PSCR R\&D community as it provides a repository of first responders' needs, problems they experience, and what they believe would be most beneficial in terms of communication technology. The tables \& graphics included in the results section were specifically designed to provide visual references for easy comprehension of the large dataset. Having access to the research findings and methods of systematic data characterization from this project allows developers to have direct connection to the voices of first responders as they work to design, develop, and improve communication technology. 


\subsection{Future Directions}

As stated previously, this is not the final step in the PSCR usability project. Phase 1 investigated first responders, their environments, and their communication technology context of use, by conducting a series of rigorous, nationwide in-depth interviews with first responders in the fire, law enforcement, emergency medical services, and communications center disciplines. Phase 1, Volume 1 reported on initial results and findings [1]; this report, Phase 1, Volume 2, provided a deeper analysis into first responders' problems and functionality requested with their communication technology. Future volumes will present findings from other aspects of the qualitative data analysis, including further analysis of data from rural areas and communications centers.

The in-depth interviews resulted in over 20000 data extractions (quotes) from first responders. This report focused on the subset of approximately 300 quotes from those extractions, specifically the technology problems and requested functionality. The full dataset includes all of the extracted data associated with the code list in Appendix A. These extractions will be made publicly available via a web-based interface. The data will be searchable by type of discipline, geographic area (urban, suburban or rural), and participant demographics, among other attributes. The web-based tool will be available via the NIST PSCR website.

Finally, Phase 2 is the implementation of a nationwide quantitative survey of first responders and their communication technology use, providing an opportunity for statistical analysis of the data from a broader first responder population. The final report will combine the qualitive and quantitative perspectives to examine a holistic view of the public safety communication technology landscape based on Phase 1 and Phase 2 findings.

\section{Acknowledgements}

NIST would like to thank the many first responders who graciously gave their time and input for this project.

\section{References}

[1] Choong, Y, Dawkins, S., Furman, S., Greene, K.K., Spickard Prettyman, S., Theofanos, M.F. "Voices of First Responders - Identifying Public Safety Communication Problems: Findings from User-Centered Interviews. Phase 1, Volume 1." NISTIR 8216 (2018). https://doi.org/10.6028/NIST.IR.8216

[2] Choong, Y., Dawkins, S., Greene, K., and Theofanos, M. "Incident Scenarios Collection for Public Safety Communications Research: Framing the Context of Use," NISTIR 8181 (2017). https://doi.org/10.6028/NIST.IR.8181

[3] Federal Emergency Management Agency (FEMA), https://www.fema.gov/risk-mapping-assessmentand-planning-risk-map (accessed Dec. 18, 2018).

[4] ISO 9241-210:2010: Ergonomics of human-system interaction -- Part 210: Human-centred design for interactive systems, ISO, Geneva, Switzerland, 2010, http://www.iso.org/ 
[5] National Fire Protection Association (NFPA), "Firefighting occupations by women and race," https://www.nfpa.org/News-and-Research/Data-research-and-tools/ARCHIVED/Fire-statistics/Thefire-service/Administration/Firefighting-occupations-by-women-and-race (accessed Dec. 18, 2018)

[6] Public Safety Communications Research, "Research portfolios," https://www.nist.gov/ctl/pscr/research-portfolios (accessed Dec. 18, 2018).

[7] Theofanos, M., Choong, Y., Dawkins, S., Greene, K., Stanton, B., and Winpigler, R., "Usability Handbook for Public Safety Communications - Ensuring Successful Systems for First Responders," NIST Handbook 161, 2017, https://doi.org/10.6028/NIST.HB.161

[8] United States Department of Justice, "Women in Law Enforcement," in COPS - Community Policing Dispatch, 2013, https://cops.usdoj.gov/html/dispatch/07-2013/women in law enforcement.asp (accessed Dec. 18, 2018). 


\section{Appendix A: Qualitative Analysis Code Books}

\section{Code List for COMMS interviews}

Codes and Sub-codes

\section{Change}

\section{Context of Work}

Types of Calls

Multitasking

Stress/Health Wellness

Risk/Safety

Relationships

\section{Emotion}

\section{Frustration}

Information

Control

Delivery mechanism

Operational environment

Problems

Technology

People

Information

Policies/Procedures

\section{Rules/Politics}

Budget/purchasing

Priority/Influence

Policies/Procedures

Unspoken rules for behavior

Technology

Reliance on technology

Positives about/with technology

\section{Training}

User characteristics

Pride

Job commitment/satisfaction

Generation gap

Knowledge/experience/skills

Wish List

\section{Code Operationalization}

This can be about technology, about policy/procedures, rules for behavior, laws, tasks; anything that refers to if/how things have shifted or not over the course of a participant's career

Tasks related to what is done as part of the job

Different reasons people call and how calls need to be routed

Doing more than one task at the same time

Physical, cognitive, or emotional expressions of anxiety, tension, or feeling overwhelmed

Situation involving exposure to danger; harm or loss

The sense of community developed amongst individuals or groups of people, a connection, association, or involvement, including relationships present within a discipline, between disciplines, or with the public

When participant expresses a feeling, other than frustration, based on reactions to events or experiences related to calls/work

An expression of annoyance, because of inability to change or achieve something

Data, evidence, or intelligence related to an incident or to work environment/situation

Entity who has the ability/responsibility to act or pass on information

Physical (paper, evidence, objects, or other artifacts) or Face to Face

This can refer to the station, the department, the leadership, the city/state; anything that's larger than just the user (we)

Identification of issues identified by participants related to doing their jobs

Issues with technology

Issues with people

Issues with information (in getting, receiving, or producing information; situations where there was too little or too much information)

Issues with formal or informal rules and operating processes and procedures for how things should be, have been, or are being done

Formal or informal guidelines that directly or indirectly govern the work, expectations, and/or environments of first responders

Considerations related to funding and/or procurement

Related to priorities of the administration (e.g., station, local government)

Formal rules and operating processes for how things operate

Informal understandings of how things should be done (for example: radio discipline)

Devices utilized by first responders to do their jobs or as part of their daily tasks

Situations when responders don't know what to do without the technology or when it's not available (either when it breaks or is not appropriate to use)

Benefits and affirmative views of using technology

Initial and/or ongoing preparation and practice of job-relevant skills

Participant related demographics, or identification of demographic pieces related to other work colleagues

Feelings of dignity about their work, work environment, and/or work organization

Expressions of how participants love what they do or dedication to their work

Real or perceived differences due to age

Domain relevant understandings and abilities related to their work

Things (funding, information, processes, technology, devices, or equipment) that would facilitate first responders' job. 


\begin{tabular}{|c|c|}
\hline Codes and Sub-codes & Code Operationalization \\
\hline Change & $\begin{array}{l}\text { This can be about technology, about policy/procedures, rules for behavior, laws, tasks; anything that refers to if/how things have shifted or not over } \\
\text { the course of a participant's career }\end{array}$ \\
\hline Communication & $\begin{array}{l}\text { This refers to examples of when information is passed from one entity to another, or when a flow of information is needed but not necessarily } \\
\text { there; For example, "I need to talk to my partner"; this is not a specific identification of information or technology }\end{array}$ \\
\hline Context of Work & Tasks related to what is done as part of the job \\
\hline Stress/Overload & Physical, cognitive, or emotional expressions of anxiety, tension, or feeling overwhelmed \\
\hline Risk/Safety & Situation involving exposure to danger; harm or loss \\
\hline Relationships & $\begin{array}{l}\text { The sense of community developed among individuals or groups of people, a connection, association, or involvement, including relationships } \\
\text { present within a discipline, between disciplines, or with the public }\end{array}$ \\
\hline Frustration & An expression of annoyance, because of inability to change or achieve something \\
\hline Information & Data, evidence, or intelligence related to an incident or to work environment/situation \\
\hline Control & Entity who has the ability/responsibility to act or pass on information \\
\hline Delivery mechanism & Physical (paper, evidence, objects, or other artifacts) or Face to Face \\
\hline Operational environment & This can refer to the station, the department, the leadership, the city/state; anything that's larger than just the user (we) \\
\hline Problems & Identification of issues identified by participants related to doing their jobs \\
\hline Technology & Issues with technology \\
\hline People & Issues with people \\
\hline Information & Issues with information (in getting, receiving, or producing information; situations where there was too little or too much information) \\
\hline Policies/Procedures & Issues with formal or informal rules and operating processes and procedures for how things should be, have been, or are being done \\
\hline Rules/Politics & Formal or informal guidelines that directly or indirectly govern the work, expectations, and/or environments of first responders \\
\hline Budget/purchasing & Considerations related to funding and/or procurement \\
\hline Priority/Influence & Related to priorities of the administration (e.g., station, local government) \\
\hline Policies/Procedures & Formal rules and operating processes for how things operate \\
\hline Unspoken rules for behavior & Informal understandings of how things should be done (for example: radio discipline) \\
\hline Technology & Devices utilized by first responders to do their jobs or as part of their daily tasks \\
\hline Reliance on technology & $\begin{array}{l}\text { Situations when responders don't know what to do without the technology or when it's not available (either when it breaks or is not appropriate to } \\
\text { use) }\end{array}$ \\
\hline Positives about/with technology & Benefits and affirmative views of using technology \\
\hline Training & Initial and/or ongoing preparation and practice of job-relevant skills \\
\hline User characteristics & Participant related demographics, or identification of demographic pieces related to other work colleagues \\
\hline Pride & Feelings of dignity about their work, work environment, and/or work organization \\
\hline Job commitment/satisfaction & Expressions of how participants love what they do or dedication to their work \\
\hline Generation gap & Real or perceived differences due to age \\
\hline Knowledge/experience/skills & Discipline relevant understandings and abilities related to their work \\
\hline Wish List & Things (funding, information, processes, technology, devices, or equipment) that would facilitate first responders' job. \\
\hline
\end{tabular}


Appendix B: Revision History

\begin{tabular}{|l|l|}
\hline Revision Number & Comment \\
\hline 8245 & Initial version. \\
\hline 8245, Volume 2.1 & Category name updated to "Public safety network reservations." \\
\hline
\end{tabular}

